\title{
II.
}

Aus der ehirurgischen Klinik zu Göttingen.

\section{Ueber den Verlauf und Ausgang der tuberculösen Erkrankung des Ellbogengelenkes.}

\author{
Von \\ Dr. Urasaburo Kosima \\ aus Japan.
}

Auf Veranlassung und unter freundlicher Unterstitzung meines bochgeehrten Lehrers, des Herrn Geh. Medicinalraths Prof. Dr. F. König, habe ich mich damit beschäftigt, eine Zusammenstellung uber den klinischen Verlauf und den Ausgang der tuberculösen Erkrankung des Ellbogengelenkes zu machen. Das Princip der Statistik beruht darin, dass man durch eine möglichst grosse Anzahl von Fällen begründete und deswegen den Anspruch auf Richtigkeit machende endgultige Resultate erzielen kann.

Es kommt selbstrerständlich nicht nur auf die grosse Zahl der Fälle an, sondern es muss auch noch auf andere wichtige Punkte Ritcksicht genommen werden, dass das Material futir den Zweck der Statistik ,einheitlich“, sowobl in Bezug auf die Anschauungsweise, als auch auf die Bebandlungsart, sein muss. Gerade aber dieser letzten Forderung entspricht das mir bei meiner Arbeit zur Verftgung stehende Material, welches innerhalb eines Zeitraumes von 15 Jahren in der unter Herrn Prof. König's Leitung stehenden chirurgischen Klinik zu Göttingen in Behandlung kam. Um meiner Arbeit die eben auseinandergesetzten Vorzigge zu wahren, habe ich für dieselbe kein einziges Material aus anderen älteren statistischen Zusammenstellungen entlehnt und ebenso auf diese selbst fur die Vergleichung mit meinem Material keine Rücksicht genommen.

Ich habe mich bemüht, möglichst zuverlässige Angaben uber die Endresultate dadurch zu gewinnen, dass ich die Patienten zur Reise nach Göttingen zu veranlassen versuchte. Das ist mir naturlich nur in wenigen Fällen gelungen; meistens musste ich mich mit einer von Deutsche Zeitschrift $f$. Chirurgie. $\mathrm{XXXV}$. Bd. 
den Kranken selbst oder von den Aerzten gegebenen schriftlichen Mittheilung begnugen. Leider waren diese Mittheilungen nicht in allen Fällen ausreichend, sondern es blieben noch verhältnissmässig viele Fälle entweder gar nicht beantwortet, oder es sind meine Fragen, welche von mir an die Kranken gerichtet worden sind, uberhaupt gar nicht angekommen, da unter den Adressaten manche geringen Standes sind, bei denen ihr derzeitiger Aufenthalt, besonders in grossen Städten, gar nicht bekannt ist. Aber es ist im Grossen und Ganzen mein Material vollständig zu verwerthen, da es gerade für den Laien nicht ganz schwierig ist, über den Zustand und die Gebrauchsfähigkeit eines im Ellbogen erkrankten Armes einigermaassen zuverlässige Angaben zu machen. Um mit möglichst grossen Zahlen rechnen zu können, habe ich selbst diejenigen Patienten, über die ich keine Angabe über Schlussresultate bekommen konnte, mit in die Rechnung hineingezogen, um sonstige Befunde, soweit es ging, mit verwerthen za können.

Meine Arbeit zerfällt in 2 Abtheilungen, eine allgemeine und eine specielle. In der letzteren babe ich speciell eine Trennung nach jedem Decennium gemacht, in welchem die Altersstände der Kranken sich befinden, damit ich die Verschiedenheit über die Häufigkeit der Krankheitsprocesse, sowie der Schlussresultate der Operation u. s. w. vor Augen flibren konnte. Die mir zu Gebote stehenden Zahlen sind gross genug, dass die so gewonnenen Resultate wenigstens in den wesentlichen Punkten Anspruch auf Guiltigkeit machen können. Ich möchte mir zunächst erlauben, kurz gefasste geordnete Krankengeschichten vorzufüren, welche ich meiner Zusammenstellung zu Grunde gelegt habe, damit man sich in den Punkten, die ich nicht alle erledigen konnte, etwas zu orientiren vermöge.

\section{Conservativ behandelte Falle.}

1. M. Langer, 14 Jahre alt. Eintritt am 3. April 1876, Austritt am 9. Juni 1876. Alter bei Beginn der Krankheit 2 Jahre. Dauer bis zum Austritt 12 Jahre l., 2 Monate r. - A etiologie. Kyphose. Albuminurie. Fussrticken- und Drliseneiterung. - An amnese. Seit 12 Jahren leidet Patient am linken Ellbogen, ebenso an Drüseneiterung und Eiterung im Gesicht mit Nekrose des Oberkiefers. Gypsverband ohne Erfolg. Incision, Eiterentleerung. Seit 1 Jahre traten Rückenschmerzen ein und Schmerzen auf dem linken Fussricken, auf dem sich ein Abscess bildete. Seit 2 Monaten Schwellung des rechten Ellbogengelenkes. - S t a t u s praesens beim Eintritt. Schwellung des linken Ellbogengelenkes mit geringer Schwellung des rechten. Kyphose der Rückenwirbelsäule, Schwellung des Fussrickens, Albuminurie mit Eiweisscylinder. - Behand- 
lung. Magnesitverband. - Patient wurde mit Magnesitverband entlassen. - Schlussresultat. Pat. ist im Juni 1876 in seiner Heimath gestorben.

2. Emil Gesewand, 20 Jahre alt. Eintritt am 11. October 1879, Austritt am 5. Nov. 1879. Alter bei Beginn der Krankheit 191/2 Jahre. Daner bis zum Austritt 1/2 Jahr. - Aetiologie. Fractur am Ellbogengelenk. - Anamnese. Vor 6 Jahren bekam Patient Knochenbruch im Ellbogengelenk. Seit Mai 1879 hatte er Schmerzen und Schwellung an demselben Gelenk. - Status praesens beim Eintritt. Das Gelenk ist geschwollen. Es befindet sich ein Abscess im Condylus externus. - Behandlung und path.-anat. Befund. Auskratzung der Granulation im Condylus externus. Kein Sequester. Das Gelenk, welches sonst nicht krank zu sein scheint, eröffnet. - Dauernd guter Verlauf. Gypsverband. Mit drainirter Wunde entlassen. - Schlussresultat. Patient lebt noch, ist gesund und kräftig. Der Arm ist völlig geheilt und gebrauchsfähig, aber im Gelenk wenig beweglich.

3. Adolf Bierwirth, 4 Jahre alt. Eintritt am 3. Februar 1880, Austritt am 8. Februar 1880. Alter bei Beginn der Krankheit $3 \frac{1 / 2}{2}$ Jahre. Dauer bis zum Austritt $1 / 2$ Jahr. - A etiologie. Trauma. - Anamnese. Vor 6 Monaten liess ein Mädchen den Knaben fallen. Seitdem Schwellung des rechten Ellbogengelenkes. Einreibung mit Salbe und Gypsverband ohne Erfolg angewandt. - Status praesens beim Eintritt. Das rechte Ellbogengelenk stark geschwollen und flectirt. Die Schwellung befindet sich nicht nur im Gelenk, sondern auch um dasselbe. Fluctuation zwischen Ulna und Condylus externus. - Behandlung und path.-anat. Befund. Punction der Granulation am Condylus externus. Kein Sequester. Gelenk eröffnet. Entleerung des diunnen Eiters. Gypsverband. Mit Gypsverband gebessert entlassen. - Schlussresultat. Patient starb angeblich $1 / 4$ Jahr nach der Entlassung an Lungenkrankheit. Der Arm eiterte noch bis zum Tode.

4. S. Busch, 7 Jahre alt. Eintritt am 7. Februar 1880, Austritt am 21. Februar 1880. Alter bei Beginn der Krankheit 5 Jahre. Dauer bis zum Austritt 2 Jahre. - A namnese. Patient ist auswärts an Ellbogentuberculose operirt. - Status praesens beim Eintritt. Schlottergelenk, Fisteln, Abscess auf der Ruckseite. - Behandlung und path.-anat. B e f u d. Incision. Auskratzung der Fisteln. Am Knochen nichts Krankhaftes zu finden. - Reactionsloser Verlauf. Zur poliklinischen Behandlung entlassen.

5. Emilie Kroesing, 3 Jahre alt, Eintritt am 31. Mai 1881, Austritt am 30. Juni 1881. Alter bei Beginn der Krankheit 3 Jahre. Dauer bis zum Austritt 4 Wochen. - A tiologie. Oberschenkel- und Fingertuberculose. - Anamnese. Seit längerer Zeit spindelförmige Schwellung des linken Zeigefingers. Seit 4 Wochen trat eine Schwellung des linken Ellbogengelenkes ein. - Status praesens beim Eintritt. Wohlgenährtes Mädchen. Spindelförmige Schwellung des Mittelfingers mit einer auf den Knochen führenden Fistel. Starke Schwellung am linken Ellbogen. Abscess auf der Aussenseite desselben. - Behandlung und path.-anat. B ef und. Operation. Incision am 1. Juni 1881 am inneren und äusseren Rande. Auskratzung tuberculöser Herde im Olekranon. 
- Aseptischer Verlauf. Abscessbildung am Oberschenkel in Verlauf. Incision. Drainage. Mit fast geheilter Wunde entlassen.

6. Karl Heidmann, 63 Jahre alt. Eintritt am 24. April 1883, Austritt am 24. Mai 1883. Alter bei Beginn der Krankheit 621/4 Jahre. Daner bis zum Austritt 3/4 Jahre. - A eti ol o gi e. Rechtsseitiger Lungenspitzenkatarrh. - Anamnese. Der Vater des Kranken starb an Schwindsucht. Patient hustet wenig. Seit 2 Jahren verschlimmert sich der Husten. Seit 3/4 Jahren Schmerzhaftigkeit und Schwellung und Steifigkeit des Ellbogen"gelenkes. - Stat us praesens beim Eintritt. Ziemlich magerer, schwächlicher Mann. Das rechte Ellbogengelenk in stumpfwinkliger Contractionsstellung. Schwellung der Kapsel. Fluctuirender Herd an einer einzelnen Stelle. Rechtsseitiger Lungenspitzenkatarrh. - Bebandl ung und path.an at. B ef und. 26. April 1883. Typische Resectio cubiti. Dunner, eiteriger Inhalt. Weicher, synovialer Fungus. - Fieberloser Verlauf. 3 Tage nach der Operation verdächtig auf Jodoformintoxication. Unruhe. Verkehrte Antworten. Beschleunigter Puls. Ruickgang der beschriebenen Erscheinungen. Mit fast geheilter Wunde entlassen.

7. Martha Hocke, 4 Jahre alt. Eintritt am 5. Mai 1883, Austritt am 2. Juni 1883. - A etiologie. Tuberculose des rechten Fingers. Anamnese. Aus gesunder Familie. Patientin ist schon längere Zeit in poliklinischer Behandlung wegen Tuberculose der Hand. - Stat. praes. beim Eintritt. Abscess im Condylus internus humeri sinistrae. Keine erhebliche Schwellung in der Ellbogengegend. - Behandlung und path.an at. B e fund. 8. Mai 1883. Incision des Abscesses. Tuberculöser Eiter. Man kommt direct in das Ellbogengelenk auf eine Grube in der Fossa supratrochlearis post. humeri. Gelenk sonst gesund. Kein Sequester. Verlauf mit wechselndem Fieber. Später günstiger Verlauf. Mit wenig secernirender Wunde wurde Patientin entlassen. - Schlussresultat. Der Arm ist kräftig und gebrauchsfähig geheilt. Bewegungen nach allen Richtungen hin möglich. Patientin ist, mit Ausnahme von Kopfausschlag, gesund.

8. Siegfried Busch, 7 Jahre alt. Eintritt am 12. Februar 1884, Aus. tritt am 21. Februar 1884. - An amnese. Vor 2 Jahren Resectio cubiti wegen Tuberculose auswärts vorgenommen. Wieder Schwellung des operirten Armes. - Status praesens beim Eintritt. Es ist eine an der ganzen Ulna nahe bis ins Gelenk führende Narbe vorhanden. Schlottergelenk, Fistel am Ellbogengelenk. Abscess auf der Ruckseite. - Behandlung und path.-anat. Befund, 14. Februar 1884. Incision, Auslöffelung der Fistel. Am Knochen nichts zu finden. - Verlauf. Keine Reaction. Zur poliklinischen Behandlung entlassen.

9. Louise Peinemann, 5 Jahre alt. Eintritt am 13. Februar 1885, Austritt am 30. Februar 1885. Alter bei Beginn der Krankheit $4 \frac{1}{2}$ Jahre. Dauer bis zum Austritt 1/2 Jahr. - A etiolog i e. Tuberculose der Hand. - Anamnese. Seit letztem Herbste hat Patientin eine Schwellung des linken Ellbogens, des dritten linken Fingers und des kleinen Fingers. Die letzte Affection entstand zuerst. - Status praesens beim Eintritt. Schwelhung und Schmerzhaftigkeit des linken Ellbogengelenkes mit Abscess auf der ulnaren und dorsalen Seite. Bewegungen im Gelenk frei. 
Spina vent. des 2. und 5. linken Fingers an den zwei Phalangen. - Behandlung und path.-anat. Befund. 23. Februar 1885. Operation. Incision des Abscesses. Es findet sich eine subcutane Höhle, mit tuberculöser pyogener Membran geftillt. Nirgends findet sich eine Fistel, weder im Gelenk noch in der Ulna. Gleichzeitig Operation an der Spina ventosa. - Nach gutem Verlauf mit Verband entlassen. - Schlussresultat. Patientin starb im März 1890 an Schwäche. Sie wurde wiederholt am Oberschenkel, Fuss und Hand an Tuberculose operirt. Nähere Angaben uber das Ellbogengelenk fehlen.

10. Johanna M ull, 6 Jahre alt. Eintritt am 8. Juni 1885, Austritt am 18. Juni 1885. Alter bei Beginn der Krankheit $51 / 2$ Jahre. Dauer bis zum Austritt $1 / 2$ Jahr. - A namnese. Seit letztem Herbst eine allmählich zunehmende Schwellung des linken Ellbogengelenkes. Vor Weihnachten Aufbruch, seitdem eiternde Fisteln. - Status praesens beim Eintritt. Linkes Ellbogengelenk geschwollen und schmerzhaft. An der Vorderseite und Rückenseite ungenügend entleerter Eiterabscess. Ausserdem 5-6 Fisteln mit Hantunterminirung. Die Beweglichkeit erhalten, aber schmerzhaft. Am Vorderarm ein tuberculöser Abscess. Behandlung und path.-anat. Befund. 12. Juni 1885. Operation. Spaltung und Auslöffelung der Fistel. Der Löffel dringt von der Seite in die Ulna und in das Gelenk ein. Ein Herd in der Ulna. - Verlauf mit $40^{\circ}$ Fieber. Mit gut heilender Wunde nach einem Fieberanfall entlassen.

11. Hermann Krattmull, 5 Jahre alt. Eintritt am 6. Juli 1885, Austritt am 30. Juli 1885. Alter bei Beginn der Krankheit 5 Jahre. Dauer bis zum Austritt 3 Monate. - A etiologie. Trauma. - Anamnese. Aus gesunder Familie stammend. Fall im März auf dem Glatteise. Mehrere Wochen später Schwellung und Schmerzhaftigkeit des rechten Ellbogengelenkes, die allmählich zunahm. - Status praesens beim Eintritt. Anscheinend gesunder Junge. Gleichmässige Schwellung des rechten Ellbogengelenkes. Vom Oberarm nach aussen eine Fistel mit unterminirten Rändern, direct ins Gelenk führend, - Behandlung und path.-anat. Befund. 9. Juli 1885. Locale Resectio cubiti ohne Resection des Humerus. Diffuse Synovialtuberculose. Als Ausgangspunkt erwies sich ein tuberculöser Herd im Olekranon. - Fieberloser Verlauf. Mit so gut wie geheilter Wunde in kleinem Verband entlassen. - Schlussresultat. Der Arm ist mit Beweglichkeit geheilt. Die Flexions- und Extensionsbewegungen in einem Winkel von $30 \mathrm{Grad}$ möglich. Rotationsbewegungen im Vorderarm etwas beschränkt. Der Patient ist sonst gesund.

12. Friederike Deneke, 7 Jahre alt. Eintritt am 15. Februar 1886, Austritt am 1. März 1886. Alter bei Beginn der Krankheit 7 Jahre. Dauer bis zum Austritt $1 / 2$ Jahr. - Aetiologie. Lupöse Handaffection. A namnese. Patientin stammt aus gesunder Familie. Seit 1 Jahre Ausschlag. Seit Herbst 1885 allmählich zunehmendes Ellbogenleiden. Status praesens beim Eintritt. Mässig kräftiges Kind mit mehrfachen lupösen Hautaffectionen am Knie und Arm. In der Wadengegend tuberculöse Fisteln im subcutanen Gewebe. Linkes Ellbogengelenk stark spindelförmig geschwollen. Es steht in stumpfwinkliger Flexionscontraction. 
Unterhalb des Ellbogens befindet sich ein Abscess. - Behandlung und path. -a nat. Befund. 19. Febr. 1886. Resectio cubiti ohne Humerusresection. Ein grosser tubereulöser Keilsequester, dessen Basis in der Cavitas sigmoidalis maj. Synovialis erkrankt. Auslöffelung des Abscesses. - Aseptischer Verlauf. Mit fast geheilter Wunde wurde Patientin enlassen. Schlussresultat. Vor 2 Jahren starb Patientin an Tuberculose der Wirbelsäule und an anderweitiger Knochenkrankheit. Der Arm eiterte bis zuletzt.

13. Oscar Boening, 6 Jahre alt. Eintritt am 18. November 1886, Austritt am 13. December 1886. Alter bei Beginn der Krankheit 51/2 Jahre. Dauer bis zum Austritt 1/2 Jahr. - A etiolog ie. Tuberculose am Finger. - Anamnese. Seit Anfang Sommer Ellbogenleiden und Erkrankung des Fingers. Incision am Ellbogen. Exstirpation des Sequester im Finger, vor einigen Monaten hier in der Poliklinik vorgenommen. Seitdem eiternde Fistel. - Status praesens beim Eintritt. Eine Fistel am Condylus externus sinister. Das Gelenk wenig geschwollen. Die Bewegungen kaum beschränkt. Die Sonde dringt direct in den kranken Knochen. - Behandlung und path.-anat. Befund. 19. Novbr. 1886. Operation. Erweiterung der Fisteln. Man kommt auf einen grossen gelösten Sequester, der fast eine ganze Hälfte der Epiphyse betrifft. Keine Perforation nach dem Gelenk. Herd rings durch glatte Wand geschlossen. - Verlauf fieberlos. Mit noch nicht geheilter Wunde auf Wunsch der Mutter entlassen.

14. Carl Mantel, 31/2 Jahre alt. Eintritt am 16. März 1887, Austritt am 20. April 1887. Alter bei Beginn der Krankheit $1 \frac{1 / 2}{2} \mathrm{Jahr}$. Dauer bis zum Austritt 21/2 Jahre. - A etiologie. Hereditäre Belastung. - Anam nes e. Der Vater starb an Schwindsucht. Seit $2 \frac{1}{2}$ Jahren allmähliche Schwellung des rechten Ellbogengelenkes. Aufbruch desselben, Eiterentleerung. - Status praesens beim Eintritt. Gesund aussehender Knabe. Der Ellbogen steht in Flexion eines rechten Winkels. Bei Bewegung im Gelenk starke Hemmung, und bei Druck Schmerz. Nur $4 \mathrm{Cm}$. oberhalb des Condylus externus eine geröthete, mit Schorf bedeckte fluctuirende Stelle. - Behandlung und patholog.-anat. Befund. 17. März 1887. Incision des Abscesses, der nicht mit dem Gelenk communicirt. Käsiger Eiter im Gelenk. In der medialen Hälfte der Cavitas sigmoid. major in der Höhe der Basis des Oberarmes eine kirschgrosse Granulation. Ferner ein kirschgrosser Herd mit kleinem Sequester in der Fossa supratrochl. post. Diffuse Synovitis. - Verlauf aseptisch. Mit Verband entlassen. - Schlussresultat. Patient lebt noch. Er ist mit seiner Mutter nach Amerika gereist. Nähere Angaben fehlen.

15. August St a u d e, 46 Jahre alt. Eintritt am 27. Juni 1887, Austritt am 6. August 1887. Alter bei Beginn der Krankheit 45 Jahre. Dauer bis zum Austritt 1 Jahr. - Aetiologie. Vorausgegangene Rippentuberculose. - Anamnese. Im Winter 1887 wurde an ihm eine Operation wegen Rippentuberculose vorgenommen. Seit einem Jahre Schmerzen beim Arbeiten im linken Ellbogen und Verdickung des rechten Zeigefingers. - Status praesens beim Eintritt. Das linke Ellbogengelenk spin- 
delförmig geschwollen. Auf der Aussenseite zwei secernirende Fisteln, auf der Rtickenseite des Vorderarmes Fluctuation. Der Arm kann nicht vollkommen gedreht werden. - Behandlung und path.-anat. Befund. 28. Juni 1887. Operation. Erweichung der Fistel, Auslöffelung der Abscesshöhle. Am Knochen ist nichts zu finden. - Verlauf aseptisch. Mit Verband entlassen. - Schlussresultat. Der Ellbogen, der sich nach der Operation als geheilt erwies, eitert bis jetzt noch. Das Gelenk ist zu strecken und zu beugen. Pro- und Supination möglich. Weder Verkürzung, noch Abmagerung. Der Arm ist kräftig und gebrauchsfähig.

16. Ludwig Heng st, $21 / 2$ Jahre alt. Eintritt am 13. Januar 1890. Alter bei Beginn der Krankheit 2 Jahre. Dauer bis zum Austritt 1/2 Jahr. A namnese. Patient klagt seit etwa $1 / 2$ Jahr tiber Sehmerzen am linken Ellbogen. - Status praesens beim Eintritt. Der linke Ellbogen steht flectirt und ist geschwollen. Bewegungen beschränkt. Auf der Innenseite des Oberarmes dicht über dem Condylus internus eine eigrosse Geschwulst. In der Achselhöhle liegen mehrere geschwollene Drüsen. Behandlung und path.-anat. Befund. Operation. Incision der Geschwulst, in der sich zum Theil Eiter, zum Theil kirschgrosse Drïsen befinden. - Verlauf aseptisch. Injection von Jodoformglycerin. Nach dreimaliger Injection keine Besserung des Gelenkes. Der Knabe litt an Diphtheritis, und infolgedessen trat der Tod ein.

17. Helene Maier, 18 Jahre alt. Eintritt am 10. Mai 1890, Austritt am 25. Juli 1890. Alter bei Beginn der Krankbeit $17 \frac{1}{2} 2$ Jahre. Dauer bis zum Austritt 5 Monate. - A nam nese. Patientin stammt aus gesunder Familie. Seit Januar allmählich zunehmende Schwellung und Schmerzen im linken Ellbogengelenk. Incision vom Arzt, wonach heftige Eiterentleerung stattfand. - Status praesens beim Eintritt. Sonst gesundes Mädchen mit einem im Ellbogen flectirendem Arm. Das Gelenk und der Arm geschwollen und weich. In der Gegend des Condylus externus ein 20 Pfennig grosses Geschwür von tuberculösem Aussehen, von dem man im einen tuberculösen Abscess im Vorderarm gelangt. Die Beweglichkeit beschränkt und schmerzhaft. - Behandlung und path.-anat. Bef und. 17. Mai 1890. Locale Abmeisselung des erkrankten Theiles. Incision des Abscesses. Im Condylus externus findet sich eine etwa kirschgrosse Infiltration. Die übrigen Knochen sind gesund. - Verlauf mit geringem Fieber. Wunde bis auf eine kleine Stelle geheilt. Arm krumm gemacht und in Verband gelegt. So entlassen.

18. Anna Harting, 34 Jahre alt. Eintritt am 3. November 1890, Austritt am 22. November 1890. Alter bei Beginn der Krankheit $331 / 4$ Jahre. Dauer bis zum Austritt 3/4 Jahre. - A etiologie. Schwere Lungentuberculose. - Anamnese. Anamnestisch ist nicht viel hervorzuheben. Seit einiger Zeit leidet sie an Husten. Der linke Ellbogen ist seit Weihnachten steif geworden. - Status praesens beim Eintritt. Sehr elend aussehende Frau mit schwerer Lungenveränderung. Urin eiweissfrei. Der linke Ellbogen rechtwinklig flectirt und geschwollen. Bewegungen beschränkt. - Behandlung und path. anat.-Befund. Injection von Jodoformglycerin wegen des schlechten Allgemeinbefindens. 
- Verlauf mit hohem Fieber. Husten und Auswurf. Ohne Besserung auf Wunsch entlassen. - Schlussresultat. Patientin starb im Februar 1891 an Schwindsucht. Nähere Angaben fehlen.

19. Christoph Fersemann, 47 Jahre alt. Eintritt am 20. September 1890, Austritt am 23. November 1890. Alter bei Beginn der Krankheit 46 Jahre. Dauer bis zum Eintritt 1 Jahr. - A e ti o lo g i e. Lungen- und Nierenleiden. Lupus im Gesicht. - A n a m nes e. Patient leidet seit seinem 12. Jahre an Lupus im Gesicht. Im Jahre 1878 wurde er hier am Kniegelenk wegen Tuberculose resecirt, und nachher wurde wegen Recidirs eine Amputation humeri vorgenommen. Seit diesem Frühling eine allmählich zunehmende Schwellung am linken Ellbogen. - Status praesens beim Eintritt. Eine mässige Schwellung des linken Ellbogengelenkes, besonders in der Gegend des Radiusköpfchens. Bewegungen im Gelenk ausflihrbar, aber schmerzhaft. Veränderung der Lungen. Eiweiss im Urin. $-\mathrm{Be}$ handlung und path. - anat. Befund. 22. September 1890. Opera. tion, Punction und darauf Injection von Jodoformglycerin. Nach 3-4 Wochen Injection derselben Flussigkeit. Injection von Tuberculin. Trotzdem trat keine Aenderung ein. - Verlauf und nähere Angaben unbekannt.

20. Friederike Schuch ard, 34 Jahre alt. Eintritt am 23. August 1881, Austritt am 14. September 1881. Alter bei Beginn der Krankheit $33^{1 / 2}$ Jahre. Dauer bis zum Eintritt $1 / 2$ Jahr. - A etiologie. Lungenphthise. Anamnese. Seit mehreren Jahren leidet Patientin an Schmerzen und Schwellung des rechten Ellbogens. - Status praesens beim Eintritt. Das rechte Ellbogengelenk stark geschwollen, besonders zu beiden Seiten des Olekranon und an der Hinterseite desselben. An einer Lunge vorgeschrittene Phthise, und an der vorderen Seite beginnende Infiltration. - Behandlung und path.-anat. Befund. 23. August 1881. Operation. Incision an der medialen Seite des Olekranons. Dann Auslöffelung der ausgedehnten Synovialgranulation. - Verlauf aseptisch. Mit beinahe geheilter Wunde wurde Patientin entlassen. - Schlussresultat. Patientin starb im November 1881 an allgemeiner Tuberculose, besonders am Lungentuberculose. Nähere Angaben fehlen.

21. Lina M üller, 19 Jahre alt. Eintritt am 31. Juli 1881, Austritt am 24. August 1881. Alter bei Beginn der Krankheit $173 / 4$ Jahre. Dauer bis zum Austritt 11/4 Jahr. - A etiologie. Tuberculose des Handgelenkes und der Finger. - Anamnese. Seit etwa $5 / 4$ Jahren geringe Schmerz. haftigkeit, allmählich zunehmende Schwellung des rechten Ellbogengelenkes, gleichzeitig Schwellung des rechten Handgelenkes und des linken Mittelhandknochens. Die Mutter ist auf Tuberculose verdächtig. - Statu s praesens beim Eintritt. Eine eigrosse fluctuirende Geschwulst auf der Innenseite dicht uiber dem Ellbogengelenk. Schmerzhaftigkeit bei Druck. Die Bewegungen im Gelenk etwas beschränkt. Schwellung des rechten Handgelenkes und des linken Mittelhandknochens. - Behandlung und patb.-anat. Befund. Operation. Incision des Abscesses, welcher eine etwas trübe Flüssigkeit enthält. Ein Herd im Condylus internus humeri mit erbsengrossem Sequester. Auskratzung der Granulation. - Aseptischer Verlauf. Heilung ohne Bewegungsstörungen im Ellbogen. Damit entlassen. 


\section{Resecirte, resp. amputirte Falle.}

1. Rieke $\mathrm{K}$ le in hans, 16 Jahre alt. Eintritt am 24. Juli 1876, Austritt am 14. December 1876. Alter bei Beginn der Krankheit 16 Jahre. Dauer bis zum Eintritt 8 Monate. - Anamnese. Patientin soll sich vor 3 Wochen das Ellbogengelenk mit einer Maschine verletzt haben, wonach eine eiternde Wunde zuritekblieb. Dagegen geben die Verwandten an, dass schon seit $3 / 4$ Jahren das Gelenk geschwollen ist. Auf der rechten Wange befindet sich seit 3 Jahren ein Ulcus mit unterminirten Rändern und tuberculöser Granulation. - Status praesens beim Eintritt. Weiche elastische Schwellung im Olekranon. Von der Wunde am Condylus externus dringt man direct in das Gelenk. Die Bewegungen sind sehr beschränkt. - Behandlung und path. - anat. Befund. Typische Resectio. Ein Herd im Olekranon, der ins Gelenk perforirt. Ihm gegenuber ist auch ein erbsengrosser, von Knorpel entblösster Herd im Humerus. Ein zweiter Herd findet sich weiter unten in der Ulna. Synovialis diffus erkrankt. - Verlauf mit Fieber. Abscessbildung. Incision. Mit ankylotisch schmerzlosem Arm, der bis auf eine kleine Stelle geheilt war, entlassen. - Schlussresultat. Der Arm ist ankylotisch völlig heil, aber wenig gebrauchsfähig. Er steht im rechten Winkel und pronirter Stellung. Pro- und Supination unmöglich. Weder erhebliche Verkïrzung, noch Abmagerung. Patientin hat Lupus am Gesicht und Hals. Der Finger des operirten Armes beweglich.

2. Friederike Nolte, 42 Jahre alt. Eintritt am 5. Juli 1876, Austritt am 21. August 1876. Alter bei Beginn der Krankheit 41 Jahre. Dauer bis zum Eintritt 1 Jahr. - A etiologie. Leichte Verletzung. - Ana m nese. Seit einem Jahre nach leichter Verletzung eine Schwellung, Scbmerzen und Bewegungsbeschränkung des linken Ellbogengelenkes. Patientin stammt aus gesunder Familie. - Status praesens beim Eintritt. Beschränkte Bewegungen. Starke Schwellung des Ellbogens, besonders in der Gegend des Condylus internus humeri und in der Uebergangs. stelle vom Radiusköpfchen auf die Ulna; Druck erregt Schmerzen. Innere Organe sind anscheinend gesund. - Behandlung und path.-anat. Befund. Magnesitverband olıne Erfolg. Dann Resectio cubiti nach Langenbeck. Eiter im Gelenk. Knochenherd im lateralen Theile des Humerus. - Fieberloser Verlauf. Mit Verband entlassen. - Schluss resultat. Der Arm ist noch nicht ganz geheilt. An zwei Stellen bestehen Fisteln. Der Arm steht in einem Winkel von $13^{\circ}$ und ist ganz wenig beweglich. Pro- und Supination möglich. Die Hand steht pronirt und im Handgelenk gebeugt. Sie ist daher wenig arbeitsfähig.

3. Emil Männer, 9 Jahre alt. Eintritt am 16. Januar 1877, Austritt am 8. April 1877. - Aeti ologi e. Trauma. - Anamnese. Patient soll den Arm gegen den 'Tisch gestossen haben. Näheres dartiber ist unbekannt. - Status praesens beim Eintritt. Das Ellbogengelenk ist geschwollen, rechtwinklig flectirt, unbeweglich und empfindlich. Die Schwellung besonders neben dem Olekranon dentlich. - Behandlung und path.-anat. Befund. Gypsverband erfolglos. 13. Januar 1877 Resection nach Langenbeck. Das Gelenk ist mit fungöser Masse gefuilt. Der Knorpel ist liberall intact. - Aseptischer Verlauf. Geheilt mit Verband entlassen. 
4. Otto Hirsch, 17 Jahre alt. Eintritt am 1. Februar 1878, Austritt am 11. Februar 1878. Alter bei Beginn der Krankheit 13 Jahre. Dauer bis zum Eintritt 4 Jahre. - A e ti ol o g i e. Hereditäre Belastung. - Anamnese. Aus tuberculöser Familie stammend. Seit 4 Jahren Schwellung des linken Ellbogengelenkes. Dann fiel der Patient auf den linken Ellbogen, wodurch starke Schwellung hervorgerufen wurde. Abscessbildung, Incision, Auskratzung in der Poliklinik. - Status praesens beim Eintritt. Ein schwacher Junge. Er hatte ein Recidiv der Ellbogentuberculose. Das Gelenk ist geschwollen und tuberculös, dabei auch fistulös. - Behandlung und path. - anat. Befund. Resectio cubiti wie gewöhnlich. Ein Knochenherd im Condylus internus humeri. Aseptischer Verlauf. Zur poliklinischen Behandlung entlassen. - Schl u ssresultat. Der Ellbogen ist völlig heil. Der Arm ist, wenn auch nicht im vollen Umfange, gebrauchsfähig und kräftig. Flexion und Extension zur Hälfte möglich. Pro- und Supination möglich. Verkürzung und $\mathrm{Ab}$ magerung wenig. Patient ist gesund.

5. Bernhard Wa g n er, 19 Jahre alt. Eintritt am 9. Mai 1878, Austritt am 15. Juli 1878. Alter bei Beginn der Krankheit 16 Jahre. Dauer bis zum Eintritt 3 Jahre. - An am nese. Seit 3 Jahren Schwellung des rechten Ellbogengelenkes, Incision. Patient hatte vorher Schmerzen in der Schulter und in der Hand, wonach Fistelbildung entstand. - Status praesens beim Eintritt. Das Ellbogengelenk wenig geschwollen. Bewegungen im Gelenk beschränkt. - Behandlung und path. -anat. $\mathrm{B}$ ef und. 4. Mai 1878 Resectio cubiti. Knochenherd sowohl im Humerus, als auch in der Fossa trochlearis der Ulna. In letzterer ein Sequester. Synovialtuberculose. - Aseptischer Verlauf. Mit ankylotisch geheiltem Arm entlassen. - Schlussresultat. Der Arm ist völlig heil und gebrauchsfähig. Das Gelenk ist wenig beweglich. Der operirte Arm ist etwas kurzer als der gesunde. Der Patient ist sonst gesund.

6. August $\mathrm{Kaufmann}, 61$ Jahre alt. Eintritt am 28. Juni 1878, Austritt am 15. August 1878. Dauer bis zum Eintritt 1 Jahr. - A namne se. Seit 1 Jahre Schwellung und Schmerzen im rechten Ellbogengelenk. Seit 1 Vierteljahre Eiterung. Keine Aetiologie. - Status praesens beim Eintritt. Schwellung des rechten Ellbogens. Fisteln. Die Bewegungen nach allen Seiten hin ziemlich gut möglich. Patient ist gesund. - Behandlung und path.-anat. Befund. Resectio cubiti nach Langenbeck. Diffuse Synovialtuberculose. Die Knochen sind relativ intact. - Aseptischer Verlanf. Mit bis anf kleine Stelle geheilter Wunde und Gypsverband entlassen. - Schlussresultat. Patient ist 1880 an Magenleiden gestorben. Nähere Angaben fehlen.

7. Michael Schieber, 52 Jahre alt. Eintritt am 8. Januar 1879, Austritt am 2. Februar 1879. Alter bei Beginn der Krankheit 50 Jahre. Dauer bis zum Eintritt 2 Jahre. - A etiolog i e. Hereditäre Belastung. - Anamnese. Seit 2 Jahren langsame Schwellung mit Schmerzen im linken Ellbogengelenk. - Status praesens beim Eintritt. Kräftiger Mann. Schwellung des Gelenks. Senkungsabscess am Radius hinunter, Fluctuation. Innere Organe gesund. - Behandlung und path. -anat. Befund. 13. Januar 1879 Resectio cubiti. Ziemlich intacte Knochen. 
Kleiner Knochenherd, aber starke Synovialtuberculose. - Verlanf nicht ganz aseptisch. Es trat Fieber ein. Patient wurde aber bald entlassen.

8. Johann Busch, 23 Jahre alt. Eintritt am 20. Februar 1879, Austritt am 3. April 1879. Alter bei Beginn der Krankheit 13 Jahre. Dauer bis zum Eintritt 10 Jahre. - A namnese. Seit 10 Jahren Schwellung und Schmerzen am linken Ellbogengelenk. Incision, Exstirpation kleiner Knochenstiickchen. Patient stammt aus tuberculöser Familie. Status praesens beim Eintritt. Patient ist anämisch. Der Arm steht in stumpfem Winkel, ein Ellbogengelenk ist geschwollen und mit Fisteln durchsetzt, die weiter nach unten gehen. Man kommt überall auf nekrotische Knochen. Patient ist sonst gesund. - Behandlung und path.a nat. B ef und. 26. Februar 1879 Resectio cubiti. Knochen sehr gestört. Sequester entfernt. Alle Fisteln wurden ausgekratzt. Primäre Knochentubereulose. - Verlauf mit Fieber. Nach kurzer Zeit Auskratzung der Fisteln. Mit Verband entlassen. - Schlussresultat. Das Gelenk ist ganz schlottrig. 4 Jahre nach der Operation geheilt. Der Arm ist wenig gebrauchsfähig. Geringe Atrophie und bedeutende Verkurzung $(15 \mathrm{Cm}$.).

9. S. A hlb orn, 32 Jahre alt. Eintritt am 24. Februar 1879, Austritt am 15. März 1879. Alter bei Beginn der Krankheit 32 Jahre. Dauer bis zum Eintritt 3 Monate. - Anamnese. Seit 8 Monaten Lähmung, Schwellung und Schmerzen. Ebenso Fistel im Ellbogengelenk. Patient stammt aus gesunder Familie. - Status praesen s beim Eintritt. Starke Schwellung des Gelenkes und des ganzen Oberarmes. Grosser Abscess auf derselben Seite unterhalb des Gelenkes, Fistel an der Innenseite mit eitrigem Secret. - Behandlung und path.-anat. Befund. 4. März 1879 Eröffnung des Abscesses. Resectio cubiti nach Langenbeck. Die Knochen sind total von Granulation zerfressen. Kein Knochenherd, jedoch sclerosirt. - Verlauf nicht ganz aseptisch. Abscessbildung. Incision. Mit noch nicht geheilter Wunde entlassen. - Schlussresultat. Patient ist 1880 an Lungenschwindsucht gestorben. Nähere Angaben fehlen.

10. R. Sch neider, 27 Jahre alt. Eintritt am 13. März 1879, Austritt am 30. März 1879. Alter bei Beginn der Krankheit 22 Jahre. Dauer bis zum Eintritt 5 Jahre. - An a mnese. Seit 5 Jahren langsam zunehmende Schwellung und SchmerzLaftigkeit des rechten Ellbogengelenkes, mit dem Patient bis vor Kurzem arbeiten konnte. Ausser congenitaler Luxation der Hufte gesund. - Status praesens beim Eintritt. Allgemein guter Zustand. Stark fluctuirende Schwellung des ganzen Gelenkes, welches stark destruirt und nach allen Seiten hin wackelt. - Behandlung und path.-anat. Befund. Resectio cubiti am 17. März 1879. Knochenenden ziemlich intact, wenn auch der Knorpel ziemlich gelöst ist. In der Rotula ein Knochenherd. Olekranon und Radiusköpfehen ziemlich intact. - Septischer Verlauf mit Temperatursteigerung, dann fortdauernd niedrigere Temperatur. Mit wackeligem Gelenk entlassen. Schlussresultat. Patient ist 1880 an Lungenleiden gestorben. Der Arm war nicht geheilt und eiterte bis zu Ende.

11. Karl Sch off, 17 Jahre alt. Eintritt am 6. Mai 1879. Alter bei Beginn der Krankheit 16 Jahre. Dauer bis zum Eintritt 6 Monate. Aetiologie. Lymphdrüsenschwellung am Kinn. - Anamnese. Seit 
6 Monaten Schwellung und Schmerzen des linken Ellbogengelenkes ohne Veranlassung. Zu gleicher Zeit Drtisenschwellung am Kinn, die in der Poliklinik exstirpirt wurden. Gypsverband ohne Erfolg. Fistelbildung. S ta tu s praesen s beim Eintritt. Das Ellbogengelenk steht spitzwinklig gebeugt und ist stark geschwollen. Mehrfache Fisteln, die ins Gelenk führen. - Behandlung und path.-anat. Befund. Resectio cubiti nach typischer Methode. Humerns relativ intact. Die Knorpel theilweise abgelöst. Processus coronoidalis ganz verschwunden durch Herderkrankung. Radius ist intact. Ansgedehnte tuberculöse Granulation. - Verlauf mit Eiterung. - Schlussresultat. Der Ellbogen ist seit 11 Jahren völlig geheilt. Der Arm ist kräftig und gebrauchsfähig. Flexions- und Extensionsbewegungen fast normal möglich, aber nicht ganze Streckung. Pro- und Supination gut möglich. Der kranke Arm ist kürzer als der gesunde. Patient ist sonst gesund.

12. J. Schmidt, 60 Jahre alt. Eintritt am 12. Mai 1879, Austritt am 11. Juni 1879. Alter bei Beginn der Krankheit 64 $1 / 2$ Jahr. Dauer bis zum Eintritt 6 Monate. - Anamnese. Seit 6 Monaten Schmerz und Schwellung des rechten Ellbogengelenkes, welche allmählich zunahm. Vor 4 Wochen entwickelte sich eine Fistel. - Status praesens beim Eintritt. Schlecht ernährte Fratu. Das rechte Ellbogengelenk ist stark geschwollen. Fistel an der Rückseite. Bewegungen schmerzhaft. - B e handlung und path.-anat. Befund. Amputatio humeri am 16. Mai 1879. Knorpel erhalten. Auf dem Durchschnitt 2 bohnengrosse communicirende Herde. Ausserdem ein kleiner subchondraler Herd im Humerus und einer im Olekranon. - Verlauf mit Eiterung und Temperatursteigerung. Patientin wurde mit Verband entlassen.

13. S. Schuster, 40 Jahre alt. Eintritt am 30. Juni 1879, Austritt am 14. Juli 1879. - An am nese. Allmählich zunehmende Schwellung und Schmerzen im Ellbogengelenk. Kein Husten. - Status praesens beim Eintritt. Ziemlich zarte Frau. Rechtes Ellbogengelenk stark geschwollen, Bewegungen noch möglich, jedoch schmerzhaft. An der Aussen. seite des Vorderarmes ein haselnussgrosser Abscess. - Behandlung und path. - a nat. B ef und. Resectio cubiti mit Abmeisselung einer Schicht vom Olekranon am 16. Mai 1879. Gelenk mit tuberculöser Granulation besetzt. Knorpel zerstört. - Abscessbildung im Verlauf. Incision. Zur Poliklinik entlassen. - Schlussresultat. Der Ellbogen ist nicht ganz heil. An einigen Stellen lupöse Borkenbildung. Das Gelenk ist etwas schlottrig. Der Arm ist gebrauchsfähig. Bewegung activ normal. Streckung bis zu einem Grade von $160^{\circ}$. Pro- und Supination beschränkt. Verkutrzung beträgt $8 \mathrm{Cm}$. Patientin hat Ellbogengelenkstuberculose der anderen Seite.

14. Auguste Ehlers, 27 Jahre alt. Eintritt am 6. Juli 1879, Austritt am 6. August 1879. Alter bei Beginn der Krankheit 24 Jabre. Dauer bis zum Eintritt 3 Jahre. - Anamnese. Patientin ist gesund. Seit 3 Jahren allmähliche Schwellung und Schmerzhaftigkeit des rechten Ellbogens. Seit gestern arbeitsunfähig. - Status praesens beim Eintritt. Das Ellbogengelenk ist stark geschwollen, besonders auf der lateralen Seite des Olekranon. Bei Druck und Bewegung schmerzhaft. Der Arm 
steht in reclitem Winkel. - Behandlung und path.-anat. Befund. Resectio cubiti nach $\mathrm{J}_{\mathrm{a}}$ nge nbeck am 7. Juli 1879. Im Gelenk finden sich mehrere Reiskörper von glatter Gestalt und etwas Flissigkeit. Knorpel noch erhalten, jedoch abgehoben. Tuberculöse Granulation. An dem Knochen kein Herd zu finden. - Aseptischer Verlauf. Später Abscessbildung und Incision. Mit Gypsverband entlassen. - Schlussresultat. Nach 1 Jahre stellte Patientin sich vor. Der Arm ist vollständig ausgeheilt. Streckung bis zum stumpfen Winkel, Beugung bis zu einem rechten Winkel, Pro- und Supination passiv, aber nicht activ möglich.

I5. Elise $\mathrm{Has}$ a heim, 42 Jahre alt. Eintritt am 12. Februar 1880 , Austritt am 12. März 1880. Alter bei Beginn der Krankheit 40 Jahre. Dauer bis zum Eintritt 2 $\frac{1}{2}$ Jahre. - An amnese. Seit 2 $1 / 2$ Jahren trat ohne äussere Veranlassung, langsame Schwellung und Schmerz des rechten Ellbogengelenkes ein. - Status praesens beim Eintritt. Das rechte Ellbogengelenk stark geschwollen. Mehrere Abscesse, welche den Druckbruch entlang führen und demselben nahe sind. Der Arm ist empfindlich. Fieber. - Behandlung und path.-anat. Befund. Resectio cubiti. Viel käsiger Eiter im Gelenk. Das Olekranon theilweise zerstört. Stark ausgedehnte Synovialtuberculose. An der äusseren Fläche des Olekranon eine Höhle. Knorpel zum Theil erhalten, am Humerus intact. - Anfangs aseptischer Verlauf. Später Abscessbildung. Mit noch geschwollenem Arm entlassen, weil man es wünschte. - Schlussresultat. Der Ellbogen ist seit mehreren Jahren völlig heil. Der Arm ist kräftig und gebrauchsfähig. Bewegungen beschränkt möglich. Der erkrankte Arm ist etwas kürzer als der gesunde. Patientin befindet sich gut.

16. Johann Berg, 26 Jahre alt. Eintritt am 12. Mai 1880, Austritt am 27. Juli 1880. Alter bei Beginn der Krankheit 25\% Jahr. Dauer bis zum Eintritt 8 Monate. - A etiologie. Trauma. Hereditäre Belastung. - Anamnese. Patient hat vor $3 / 4$ Jahren den linken Arm verletzt, wonach Schwellung, Schmerzhaftigkeit und Bewegungsstörung eintrat. Patient stammt aus tuberculöser Familie. - Status praesens beim Eintritt. Gesundes Aussehen. Das rechte Ellbogengelenk stark geschwollen, rechtwinklig flectirt und pronirt. Bei Bewegung und Druck entsteht Schmerz. - Behandlung und path. - an at. Bef und. Resectio cubiti am 25. Mai 1880 . Knochen sind ziemlich intact. Radius und Una sogar mit Knorpel bedeckt. - Aseptischer Verlanf. Mit geheilter Wunde entlassen.

17. Carl Lange, 40 Jahre alt. Eintritt am 12. Juli 1880. Alter bei Beginn der Krankheit $39^{3 / 4}$ Jahre. Dauer bis zum Eintritt 3 Monate. A tiologie. Abscess auf dem Fussrïcken. - Anamnese. Seit 1 Jahre Abscess auf dem Fussrücken. Seit Mai 1880 Schwellung und Schmerzhaftigkeit des rechten Ellbogengelenkes. Die Schwellung nahm sehr rasch zu. Gypsverband ohne Erfolg. - Status praesens beim Eintritt. Das Gelenk ist stark geschwollen. Die Fluctuation an 2 Stellen vom Gelenk entfernt. Lungenspitzenkatarrh. - Behandlung and path.-anat. Bef und. Resectio cubiti. Knochen ganz gesund. Dagegen besteht ein colossaler Synovialfungus mit Abscess an der Innenseite des Gelenkes. Aseptischer Verlauf. Später Abscessbildung an der Innenseite. Incision. 
18. Fritz Roven, 10 Jahre alt. Eintritt am 11. Januar 1881, Austritt am 3. April 1881. Alter bei Beginn der Krankheit 91/2 Jahre. Dauer bis zum Eintritt 6 Monate. - Anamnese. Seit Juli 1880 Schmerzen im linken Ellbogen von selbst. 4 Wochen nachher fiel Patient auf den Arm, seitdem Schwellung. Gypsverband ohne Erfolg. Perforation des Gelenkes. Eiterentleerung. Tuberculöse Familie. - Status praesens beim Eintritt. Das linke Ellbogengelenk stark geschwollen und flectirt. An der Innenseite des Olekranon dicht oberhalb des Epicondylus eine ins Gelenk führende Fistel. - Behandlung und path.-anat. Befund. 13. Januar 1881. Resectio cubiti. Ausgedehnte Erkrankung der Synovialis, Knorpel noch erhalten, aber locker. Gerade in der Mitte des Humerus ein kleiner Knochenherd, der ins Gelenk perforirt. - Anfangs aseptischer Verlauf. Später Abscessbildung und Eiterung. Incision. Mit Verband entlassen. Nach 5 Monaten war der Arm bis auf eine kleine Stelle heil. - Schlussresultat. Der Ellbogen ist ohne Fistel, mit ziemlich guter Beweglichkeit geheilt, aber vollständige Beugung und Streckung unmöglich. Der operirte Arm ist schwächer als der gesunde. Patient ist sonst gesund.

19. Anna Oppermann, 38 Jahre alt. Eintritt am 6. April 1891, Austritt am 16. Mai 1891. Alter bei Beginn der Krankheit $371 / 2$ Jahre. Dauer bis zum Eintritt 6 Monate. - Anamnese. Gesunde Frau. Sie bemerkte im Verlauf des Winters 1880 Schmerzhaftigkeit und geringe Schwellung des rechten Ellbogengelenkes, deren Zunahme von letzter Gravidität. Vor 4 Wochen Incision des Abscesses, seitdem Fisteln. Status praesens beim Eintritt. Starke spindelförmige Schwellung. Grosser tuberculöser Abscess hinten am Ellbogen. Man dringt von der Fistel direct in das Gelenk. Urin eiweissfrei. - Behandlung und path.-anat. Befund. 8. April 1891. Resectio cubiti. Ausgedehnte Weichtheil- und Synovialistuberculose. Knochenherde im Humerus und Olecranum Ulnae. Faserstoffartige Zottenbildung. - Verlauf ausser leichter Jodoformintoxication gtinstig. Die Wunde bis auf kleine Stelle geheilt. Nach 2 Wochen vollständig geheilt. Das Gelenk ist wacklig. - Schlussresultat. Patientin ist etwa 21/2 Jahre nach der Operation angeblich an Keblkopfschwindsucht gestorben. Der Arm war schlotterig und nur mit Schiene wenig gebrauchsfähig.

20. Karl $\mathrm{K}$ ti $\mathrm{ch}$ h off, 20 Jahre alt. Eintritt am 28. Juni 1881, Austritt am 15. November 1881. Alter bei Beginn der Krankheit 191/2 Jahr. Dauer bis zum Eintritt 6 Monate. - Aetiologie. Lungenleiden und Fingertuberculose. - An amnese. Der Vater starb an Phthisis pulm. Seit 6 Monaten Schwellung und Schmerz am rechten Ellbogengelenk. Incision ohne Erfolg. - Status praesens beim Eintritt. Schwellung des Ellbogengelenkes oberhalb des Ellbogens. Fluctuation an der Innenseite desselben. Bewegungen sind frei. - Behandlung und path.-anat. Bef und. 8. Juli 1881. Resectio cubiti. Knochen und Knorpel sind ganz gesund. Das Gelenk ist mit tuberculöser Granulation ausgefullt. Verlauf aseptisch. Nach Auskratzung der Fisteln mit Verband entlassen. - Schlussresultat. Patient ist im Jahre 1885 an Lungenkrankheit gestorben. Er wurde auswärts wegen Tuberculose operirt. 
21. Franz Pult, 28 Jahre alt. Eintritt am 13. August 1881, Austritt am 6. October 1881. Alter bei Beginn der Krankheit 271/2 Jahr. Dauer bis zum Eintritt 6 Monate. - A etiologi ie. Hereditäre Belastung. - Anamnese. Vater starb an Schwindsucht. Vor 20 Jahren ein Schlag gegen den rechten Ellbogen und seitdem Schmerzhaftigkeit, Schwellung, Incision. Seit Februar des Jahres versehlimmert. - Status praesens beim Eintritt. Ellbogengelenk steht in Flexion. Kann nur mit Schmerzen bewegt werden. Starke elastische Schwellung des ganzen Gelenkes. In das Gelenk führende Fisteln, aus denen sich putrid riechender Eiter entleert. Patient gesund, aber anämisch. Urin eiweissfrei. - Behandlung und path.-anat. Befund. Sehr ausgedehnte Synovial- und Weichtheiltuberculose. Gelenkenden sind gänzlich ihrer Knorpel beraubt und schon unregelmässig zerfressen. - Aseptischer Verlauf. Mit einer bis auf eine kleine Stelle geheilten Wunde entlassen. - Schl ussresultat. Der Ellbogen ist völlig heil. Der Arm ist gebrauchsfähig. Flexions- und Extensionsbewegungen sind gut ausftuhrbar. Pro- und Supination ebenfalls. Der Arm ist kräftig, aber 3 Zoll kürzer als der gesunde. Patient ist sonst gesund.

22. Doris $\mathrm{Schulz}, 59$ Jahre alt. Eintritt am 30. October 1881, Austritt am 1. Januar 1882. Alter bei Beginn der Krankheit 55 Jahre. Dauer bis zum Eintritt 4 Jahre. - A n a mnese. Sonst gesunde Patientin bemerkte seit 4 Jahren allmählich zunehmende Schwellung am rechten Ellbogen. Aufbruch. Arbeitsunfähig. - Status praesens beim Eintritt. Rechtes Ellbogengelenk besonders hinten stark geschwollen, Bewegungen sehr beeinträchtigend. Auf das Olekranon führende Fisteln. - Behandlung und path.-anat. Befund. 2. November. Resectio cubiti. Ein Herd im Olekranon, der ins Gelenk führt. Knorpel dort sehr leicht ablöslich. Knochen sehr malacisch weich. - Aseptischer Verlauf. Wunde bis auf mehrere kleine Fisteln geheilt. Ellbogen ziemlich fest und mässig beweglich. Damit entlassen.

23. Marie Blanke, 67 Jahre alt. Eintritt am 16. December 1881, Austritt am 9. Januar 1882. Alter bei Beginn der Krankheit $661 / 2$ Jahr. Dauer bis zum Eintritt 1/2 Jahr. - A e tio lo gi e. Lungenspitzenkatarrh. - Anamnese. Die Kranke war ausser Lungenentzündung stets gesund gewesen. Seit Ostern des Jahres Schwellung und Schmerzhaftigkeit des linken Ellbogengelenkes. Vor 5-6 Wochen Incision des Abscesses; hinter dem Condylus internus humeri besteht seitdem Fistelbildung. Status praesens beim Eintritt. Beschränkte Beweglichkeit des Ellbogengelenkes und Schwellung desselben, besonders auf der Innenseite und auf der Ulna herunter. Wenig secernirende Fisteln, - Behandl ung und path.-anat. Bef und. 19. December 1881. Resectio cubiti mit Abmeisselung der Muskelansätze von den Epicondylen. Sehr starke Synovialtuberculose. Ein grosser, meistentheils gelöster tuberculöser Sequester im Condylus internus humeri, der an 2 Stellen ins Gelenk perforirt ist. Gelenkknorpel relativ gut erhalten. Ein Abscess geht mit dem Radius tief nach unten. - Aseptischer Verlauf. Bei der Patientin trat 6 Tage nach der Operation Unruhe, beschleunigter Puls, Irrereden, Fieber und Erbrechen ein. Spärlicher jodoformhaltiger Urin. Tod nach 
kurzer Agonie. Sectionsbefund war Jodoformintoxication und alter Lungenspitzenkatarrh. - Schlussresultat. Patientin starb in der Klinik an Jodoformintoxication.

24. Wilhelm D ormann, 37 Jahre alt. Eintritt am 25. Januar 1882, Austritt am 20. Februar 1882. Alter bei Beginn der Krankheit 34 Jahre. Dauer bis zum Eintritt 3 Jahre. - A etiologi e. Lungenspitzenkatarrh. - Anamnese. Im März 1879 entstand ein mit stechendem Schmerze verbundenes Gelenkleiden serung und Verschlimmerung. Vor 14 Jahren hatte Patient Lungenentzulndung. Vater starb an Lungenschwindsucht. - Status praesens beim Eintritt. Spindelförmige Schwellung des rechten Ellbogengelenkes. Rechtwinklige Stellung desselben. Leichte Unebenheit am Radiusköpfchen und Olekranon. Lungen sind verdächtig. - Behandlung und path.-anat. Befund. 30. Januar 1881. Resectio cubiti mit Abmeisselung der Epicondylen und der Olekranonspitze. Tuberculöse Granulation besonders zwischen Olekranon und Epicondylus internus und am Radiusköpfchen. Eine erbsengrosse Grube im Olekranon. - Aseptischer Verlauf. Mit Verband entlassen. - Schlussresultat. Der Arm ist völlig heil und bis zu einem gewissen Grade gebrauchsfähig. Bewegungen im Gelenk bis zu einem Winkel von 2-3 Grad möglich. Weder Verkutrung noch Abmagerung des operierten Armes. Patient ist sonst gesund.

25. Emilie Jung behrend, 22 Jahre alt. Eintritt am 17. Jan. 1881, Austritt am 26. Februar 1881. Alter bei Beginn der Krankheit 12 Jahre. Dauer bis zum Eintritt 10 Jahre. - Aetiologie. Drüsenleiden. An amnese. Die mit scrophulösem Habitus, Hornhaut- und Drïsennarben versehene Patientin leidet seit 10 Jahren an Fungus cubiti dextra. Gypsverbände ohne Erfolg. - Status praesens beim Eintritt. Das Ellbogengelenk ist theilweise ankylotisch. Beugen und Strecken ist nicht möglich. Aber Pro- und Supination ist frei. Arm steht in rechtwinkliger Flexion. Eine Anzahl von Narben am Ober- und Vorderarm deuten frühere Fisteln an. Fistel am Epicondylus internus. - Behandlung und path.-anat. Befund. Resectio cubiti. Ein grosser Defect am Epicondylus internus humeri, der ins Gelenk durchbricht und mit tuberculöser Granulation und einem beweglich gelösten Sequester behaftet ist. - Verlauf mit Eiter. Auswaschen mit starker Carbollösung. Leichte Temperatursteigerung. Mit granulirender Wunde zur poliklinischen Behandlung entlassen. - Schlussresultat. Das Ellbogengelenk ist ganz geheilt. Fast normal arbeitsfähig. Streckung und Beugung bis zu einem Winkel von $40 \mathrm{Grad}$. Wenig Pronation und Supination ausfuihrbar. Keine Abmagerung noch Verkürzung bemerkbar. Patientin ist sonst gesund.

26. Heinrich $\mathrm{K} \ddot{\text { öther }} 21$ Jahre alt. Eintritt am 28. März 1882, Austritt am 28. April 1882. Alter bei Beginn der Krankheit 17 Jahre. Dauer bis zum Eintritt 4 Jahre. - A etiologi e. Hereditäre Belastung. - Anamnese. Seit 4 Jahren Schmerz und allmähliche Schwellung des rechten Ellbogengelenkes. Arbeitsunfahig. Der Vater starb an Schwindsucht. - Status praesens beim Eintritt. Weiche Schwellung des rechten Ellbogengelenkes. Bewegungen schmerzhaft. - Behandlung und path.-anat. Befund. 31. März 1882. Resectio cubiti. Gelenk 
wenig tuberculöse Granulation enthaltend. Die Gelenkfläche der UIna stark zerstört. In der Fossa intercondyloidea ein über erbsengrosser tuberculöser Herd. - Aseptischer Wundverlauf. Mit Verband entlassen. - Schlussresultat. Der Arm ist vollständig geheilt. Der Arm ist kräftig und gebrauchsfähig. Gelenk ist ganz steif. Patient ist sonst gesund.

27. Margarethe Althaus, 33 Jahre alt. Eintritt am 5. Mai 1882, Austritt am 27. Mai 1882. Alter bei Beginn der Krankheit 32 Jahre, Daner bis zum Eintritt 1 Jahr. - A e tiologie. Trauma. - Anamnese. Aus gesunder Familie stammende Patientin leidet seit 1 Jahre. Nach einem Falle trat Schwellung des rechten Ellbogengelenks ein. Incision des einen mit dem Gelenk nicht communicirenden Abscesses. Heilung. Erst im Frühjahr eine Abscessbildung in derselben Stelle. Ausbruch derselben. - Status praesens bis zum Eintritt. Hochgradiges Oedem der Extremität. Spindelförmige Schwellung des Gelenkes. An der Innenseite des Olekranons eine dünne, Eiter secernirende Fistel. Am Vorderarme mehrere Geschwüre mit unterminirten Rändern. - Behandlung und path,-anat. Befund. 6. Mai 1882. Resectio cubiti. An der Aussenseite des Olekranons findet sich ein käsiger Knochenherd. Starke Schwellung der Synovialis, welche mehr einen acuten Charakter trägt. - Gunstiger Verlauf. Mit geringer Beweglichkeit entlassen.

28. Laurentia D untze, 59 Jahre alt. Eintritt am 6. Juni 1882, Austritt am 7. Juli 1882. Alter bei Beginn der Krankheit 58 Jahre. Dauer bis zum Eintritt 1 Jahr. - A etiologie. Lungenspitzenkatarrh. Anamnese. Aus gesunder Familie stammend, hustet Patientin seit mehreren Wochen viel. Seit Herbst 1881 allmählich zunehmende Schwellung und geringe Schmerzhaftigkeit des linken Ellbogengelenkes. - Status praesens bis zum Eintritt. Weiche Schwellung der ganzen linken Ellbogengegend, besonders ausgesprochen auf der Innenseite. Druck verursacht Schmerz. Mässige Flexion. Lungenspitzenkatarrh nach Eich horst. Urin eiweissfrei. Bewegungen des Armes sehr beschränkt. - Behandl ung und path.-anat. Befund. 9. Juni 1882. Resectio cubiti mit Abmeisselung der Epicondylenspitzen. Sehr ausgedehnte Synovialtuberculose. Ein tuberculöser Herd, mit mittelgrossem Sequester im Condylus internus humeri. Von da erstreckt sich eine mit Eiter gefullte Höhle durch den ganzen Condylus externus nach oben. - Fieberloser aseptischer Verlauf. Mit geheilter Wunde entlassen. - Schlussresultat. Die Kranke ist am 14. Juni 1891 gestorben an doppelseitiger Lungenerkrankung. Der Arm war gelenkig und vollständig gebrauchsfähig. Die Bewegungen des Gelenkes waren etwas beschränkt. Der operirte Arm war etwas kürzer als der gesunde.

29. Heinrich Klettwich, 52 Jahre alt. Eintritt am 6. Juni 1882, Austritt am 26: August 1882. Alter bei Beginn der Krankheit 51 Jahre. Dauer bis zum Eintritt 1 Jabr. - A etiologie. Lungenspitzenkatarrh. - Anamnese. Seit Herbst 1881 ziehender Schmerz und allmählich zunehmende Schwellung der Ellbogengegend. Der Patient will schon wiederholt an Blasenkatarrh gelitten haben. - Status praesens bis zum Eintritt. Rechtes Ellbogengelenk geschwollen. Bewegungen frei Deutsche Zeltschrift f. Chirurgio. XXXV. Bd. 
und Schmerzen nicht dabei vorhanden. Dicht über beiden Condylen zwei grosse Abscesse. Die rechte Lungenspitze verdächtig. Albuminurie geringen Grades. - Behandlung und path. -anat. Befund. 8. Juni 1882. Resectio cubiti mit Abmeisselung eines kleinen Stückes beider Condylen. Nach Eröffnung des Gelenkes zeigte sich nur die Synovialis erkrankt. Im Olekranon secundäre oberflächliche Erosion. Kein Knochenherd. - Verlauf mit Fieber. Incision des gebildeten Abscesses. Mit bis auf eine oberflächliche kleine Stelle geheilter Wunde und ziemlich guter Beweglichkeit entlassen. - Schlussresultat. Der Ellbogen seit Frilhjahr 1884 völlig heil. Der Arm ist gebrauchsfähig. Das Gelenk ist rechtwinklig völlig steif. Weder Strecken noch Beugen noch Rotationsbewegungen möglich. Patient ist sonst gesund. Keine Verkürzung noch Abmagerung.

30. Christian Blum, 50 Jahre alt. Eintritt am 8. Juli 1882, Austritt am 16. October 1882. Alter bei Beginn der Krankheit 50 Jahre. Dauer bis zum Eintritt 4 Wochen. - Anamnese. Seit 1880 Schwellung ohne Veranlassung im rechten Ellbogengelenk. Steifigkeit desselben. Seit 4 Wochen bedeutendere Schwellung, Abscessbildung, Incision. Status praesens bis zum Eintritt. Das rechte Ellbogengelenk steht flectirt. Bedeutende Schwellung. Abscess in der Ellbogenbeuge. Starker Bronchialkatarrh. Urin eiweissfrei. - B ehandlung und path.-anat. B e f und. 13. Juli 1882. Resectio cubiti. Ausgedehnter Synovialfungus. Knorpeltuberzug meist geschwunden. In dem Knochen kein Herd. Verlauf aseptisch. Bis auf kleine Stelle gebeilt entlassen. 16. October Amputatio humeri wegen hinzugetretener Albuminurie und zu langsamer Heilung. Geheilt entlassen. - Schlussresultat. Patient ist gestorben. Nähere Angaben fehlen.

31. Wilhelmine M tiller, 36 Jahre alt. Eintritt am 24. August 1882, Austritt am 25. October 1882. - Anamnese. Aus gesunder Familie stammend, hustet Patientin. Im Anschluss an das normal verlaufende Wochenbett trat eine Entztindung des rechten Ellbogengelenkes ein, welche trotz aller angewandten Mittel immer schlimmer wird. - Status praesens beim Eintritt. Spindelförmige, weiche, überall deutlich fluctuirende Schwellung des Ellbogengelenkes. Abscess liber dem Condylus internus. Das Gelenk steht in leichter Flexion. Active und passive Bewegungen möglich, aber schmerzhaft. - Behand lung und path.-anat. B ef und. 24. August 1882. Resectio cubiti. Ausgedehnte Synovialtuberculose. Der Knorpel ist uberall von den Gelenkenden abgehoben. In den Knochen findet sich kein Herd. - Im Verlauf ein Erysipel. Zurückgang desselben nach mehreren Tagen. Mit fast ganz geheilter Wunde entlassen.

32. Walter Poessel, 4 Jahre alt. Eintritt am 1. December 1882, Austritt am 25. Februar 1883. Alter bei Beginn der Krankheit 1/2 Jahr. Dauer bis zum Austritt 31/2 Jahr. - A etiologie. Kyphose. Tuberculose der Hand. - A namnese. Aus gesunder Familie stammend. Im Alter von $1 / 2$ Jahr bildeten sich kleine Geschwüre auf der Dorsalseite der linken Hand und auf dem Fussricken. Kurze Zeit darauf Schmerzhaftigkeit des linken Ellbogengelenkes. Gypsverbände ohne Erfolg. Vor sechs Wochen Aufbruch. - Status praesens beim Eintritt. Blasser, gut 
genährter Junge. Der linke Arm befindet sich in fast rechtwinkliger Contractionsstellung im Ellbogengelenk. Spindelförmige Schwellung desselben. Eine Fistel am Condylus externus humeri. Kyphose. Abscess in der linken Iliacalgegend, sowie tuberculöse Geschwüre anf dem Handriicken. Urin eiweissfrei. - Behandlung und path.-anat. Befund. 14. December 1882. Resectio cubiti. Es findet sich ein etwa wallnussgrosser Knochenherd im Condylus externus humeri. Die gewöhnliche tubercalöse Granulation der ganzen Synovialis. - Verlauf mit Temperatursteigerung. Scharlach. Abscessincision. Mit fast geheiltem Gelenk entlassen.

33. Karl Strate, 63 Jahre alt. Eintritt am 9. Januar 1883, Aus. tritt am 25. März 1883. Alter bei Beginn der Krankheit 62 Jahre. Dauer bis zum Eintritt 1 Jahr. - A namnese. Aus gesunder Familie. Vor 4 Jahren eine linksseitige Pleuritis durchgemacht. Seit 1 Jahre Schmerz und Schwellung des linken Ellbogengelenkes ohne Veranlassung. Nach einiger Zeit Aufbruch. - Status praesens beim Eintritt. Jetzt besteht multiple Abscessbildung weiter nach oben und unten. Dazu Fisteln von tuberculösem Aussehen. - Behandlung und path.-anat. Befund. 16. Januar 1883. Resectio cubiti. Grosser Sequester in der Ulna circa $4 \mathrm{Cm}$. vom oberen Ende entfernt. Kleiner am Gelenk von Radius und Ulna. Humerus ziemlich gesund. - Aseptischer Verlauf. Nach 10 Tagen Eiterung. Incision mit geringer Eiterentleerung und Fisteln. Trotzdem mit Verband entlassen. - Schlussresultat. Patient ist im October 1883 an Meningitis tuberculosa gestorben. Weiteres ist nicht $z u$ ermitteln.

34. Friederike Ehmer, 31 Jahre alt. Eintritt am 3. October 1883, Austritt am 16. Dec. 1883. Alter bei Beginn der Krankheit 301/2 Jahre. Dauer bis zum Austritt $1 / 2$ Jahr. - A etiologie. Tuberculose des Fingers. - Anamnese. 31. Januar 1883. Operation an Tuberculose der Grundphalanx des linken Daumens. Geheilt entlassen. Nach einigen Monaten Schwellung und Schmerzhaftigkeit des Ellbogengelenkes. Status praesens beim Eintritt. Die Schwellung des Ellbogengelenks. Fisteln auf der Aussenseite. Dämpfung der Lungenspitze. - Behandlung und path.-anat. Bef und. 15. October 1883. Locale Resectio cubiti. Oberflächliche Tuberculose im Olekranon. Absägung desselben. Diffuse Synovialtuberculose. - Aseptischer Verlauf. Nachher bekam Patientin Tuberculose des Kniegelenkes, welche zur Amputation desselben fuihrte. Mit fast geheilter Wunde entlassen. Am 2. Januar 1884 wieder vorgestellt mit dem Abscess in demselben Gelenk. Incision. Auskratzung. Mit kleiner Wunde entlassen. - Schlussresultat. Patientin ist im Winter 1885 an allgemeiner Tuberculose gestorben. Es fehlt nähere Angabe.

35. Martha Homann, 35 Jahre alt. Eintritt am 16. Februar 1883, Austritt am 20. März 1883. Alter bei Beginn der Krankheit 35 Jahre. Daner bis zum Eintritt 2 Monate. - A e ti o lo gi e. Lungenspitzenkatarrh. - Anamnese. Ans gesunder Familie stammend, hustet Patientin seit $1 / 2$ Jahr. Im 20. Lebensjahre Typhus durchgemacht. Seit 2 Jahren Schmerzen im linken Ellbogengelenk. Dabei arbeitete sie bis vor 14 Tagen 
ununterbrochen. - Stat u s p r a sen s beim Eintritt. Linksseitiger Lungenspitzenkatarrh. Urin eiweissfrei. Sehr elend aussehende Frau. Ein Abscess am Condylus externus humeri sinistra. Die Schwellung der hinteren Gelenkgegend. Der Arm steht in leichter Flexion. Bewegung wenig beschränkt. - Behandlung und pathol.-anatom. Befund. 19. Februar 1883. Incision des Abscesses. Resectio cubiti mit stellenweiser Abmeisselung der Tricepsinsertion. Gelenkknorpel ziemlich normal. Diffuse Synovialtuberculose mit viel Eiter im Gelenk. Vom äusseren Condylus in den Schaft hineinreichende diffuse tuberculöse Infiltration des Gelenkes. - Reactionsloser Verlauf. Mit fast vollständig geheilter Wunde entlassen. - Schlussresultat. Patientin ist im Jahre 1884 an Lungenleiden gestorben. Der Arm eiterte bis zum Tode fortwährend.

36. Friederike Grobe, 41 Jahre alt. Eintritt am 21. Mai 1883, Austritt am 2. Juni 1883. Alter bei Beginn der Krankheit 40 Jahre. Dauer bis zum Eintritt $1 \mathrm{Jahr}$ - - A etiologie. Beiderseitiger Lungenspitzenkatarrh. - Anamnese. Der Vater starb angeblich an Lungenschwindsucht. Seit Beginn des Jahres 1883 hartnäckiger Husten. Seit einem Jahre langsam zunehmende Schwellung und Schmerzhaftigkeit am linken Ellbogen ohne Ursache. - Status praesens beim Eintritt. Elend aussehende Frau, mit beiderseitigem Lungenspitzenkatarrh behaftet. Urin eiweissfrei. Rechtwinklige Stellung. Schmerzhaftigkeit bei Bewegungen. Schwellung des Ellbogengelenkes. Fisteln. - Behandlung und path. - anat. B efund. 22. Mai 1883. Resectio cubiti. Kein Knochenherd. Reichliche Knochenneubildungen vom Humerus. Starke Synovialtuberculose. Reichlicher Eiter. - Vollständig reactionsloser Verlauf. Mit Verband nach 3 Wochen entlassen.

37. Elisabeth W ade, 16 Jahre alt. Eintritt am 24. Mai 1883, Austritt am 29. Juni 1883. Alter bei Beginn der Krankleit 151/2 Jahr. Dauer bis zum Eintritt 6 Monate. - A eti ologie. Lungenspitzenkatarrh. - Anamnese. Der Vater starb an einem Lungenleiden. Patientin hatte Lungenentzundung, Unterleibsentztindung, Bleichsucht. Schon während dieser Zeit Anfänge von Schmerzhaftigkeit im linken Ellbogen. Seit 6 Monaten allmähliche Schwellung des linken Ellbogens. Eiterbildung mit Durchbruch des Eiters. - Status praesens beim Eintritt. Linker Ellbogen rechtwinklig flectirt. Bewegungsversuche sehr schmerzhaft. 'Tuberculöse Fistel innerhalb vom Olekranon. Weiter unten auf der Ulna. Das Ellbogengelenk selbst erscheint wenig geschwollen. Verdächtige Lungenspitzen. - B ehandlung und path.-anat. Befund. 30. Mai Resectio cubiti mit Abmeisselung der Knochenschale vom Olekranon. Ausgedehnte Tuberculose des Gelenkes. Ein wahrscheinlich primärer Herd an der Innenseite der Ulna. Seitlich am Olekranon kein Sequester. Reactionsloser Verlauf. Mit bis auf kleine Stelle geheilter Wunde entlassen. - Schlussresultat. Der Ellbogen ist im stumpfen Winkel fast ankylotisch völlig geheilt. Der Vorderarm steht in halb pronirter Stellung fest. Bewegungen bis zu 1-2 Grad möglich. Der Arm ist arbeitsfälig, aber schwach. Sonst ist Patientin gesund.

38. Veronica Kliebis ch, 11 Jahre alt. Eintritt am 9. Juni 1883, Austritt am 12. Juli 1883. Alter bei Beginn der Krankheit $103 / 4$ Jahre. 
Daner bis zum Eintritt $1 / 4$ Jahr. - Anamnese. Aus gesunder Familie. Seit $1 / 4$ Jahre allmähliche Schwellung und Schmerzhaftigkeit des linken Ellbogengelenkes. Vor einigen Wochen Incision, Eiterentleerung. Status praesens beim Eintritt. Das rechte Ellbogengelenk ist rechtwinklig flectirt und steht in pronirter Stellung. Spindelförmige Schwellung. Fluctuirende Abtreibung am Condylus internus. Fisteln am Condylus externus humeri. - Behandlung und path. -anat. Befund. 11. Juni 1883. Resectio cubiti mit Abmeisselung der Knochenschale vom Olekranon und Humerus. Sehr ansgedehnte Synovialtuberculose. Sehr tiefgehender Herd am Jateralen Epicondylus humeri. - Verlauf mit mässiger Eiterung und Temperatursteigerung. Abscessbildung. Incision. Zur poliklinischen Behandlung entlassen. - Schlussresultat. Patientin ist gestorben, und es fehlen nähere Angaben über das Gelenk.

39. Katharina Schlüter, 58 Jahre alt. Eintritt am 11. Juni 1883, Austritt am 30. Juni 1883. Alter bei Beginn der Krankheit $57^{1} / 2$ Jahr. Dauer bis zum Eintritt $3 / 4$ Jahr. - Anamnese. Seit $3 / 4$ Jahren langsame Zunahme der Schwellung. Eiterung des linken Ellbogengelenkes. Gebrauchsunfähig. Incision. Patientin soll an Husten gelitten haben. Status praesens beim Eintritt. Linkes Ellbogengelenk rechtwinklig flectirt. Sehr stark geschwollen, besonders am unteren Ende des Humerus. Zahlreiche Fisteln an der ganzen Umgebung des Gelenkes von tuberculösem Aussehen. - Behandlung und path. - anat. Befund. 13. Juni 1883. Amputatio humeri im mittleren Drittel. Nach einem Versuche zur Resectio sofort Amputatio humeri wegen der Aussichtslosigkeit. Ausgedehnte Weichtheiltuberculose. Ein zum Theil gelöster grosser Sequester in der Ulna. Derselbe reicht weiter herunter. Ein wahrscheinlich secundärer Granulationsherd im Gelenke des Humerus. - Fieberloser Verlauf. Mit fast geheilter Wunde entlassen.

40. Anna Neumeier, 18 Jahre alt. Eintritt am 4. August 1883, Austritt am 7. Sept. 1883. Alter bei Beginn der Krankheit $17 \frac{1}{2}$ Jahr. Dauer bis zum Eintritt $1 / 2$ Jahr. - A nam nese. Aus gesunder Familie stammend. Seit $1 / 2$ Jahre Schmerzhaftigkeit und Schwellung in der linken Ellbogengegend. Eiterung und Aufbruch. Fistelbildung an der lateralen Seite. Operation in Halle ohne Erfolg. - Status praesens beim Eintritt. Blasses Mädchen mit einer kleinen, anseheinend tuberculösen Hautaffection mitten auf der Stirn. Eine wenig secernirende Fistel am Epicondylus externus humeri. Rechtwinklige Stellung des Gelenkes. Unvollständige Extension und Rotation. Lunge gesund und Urin eiweissfrei. - Behandlung und path.-anat. Bef und. 6. August 1883. Resectio cubiti mit einer Schale rom Olekranon und Epicondylen. Am und im Gelenk ziemlich erhebliche Verwachsung. Knorpelschwund. Einige Granulation, besonders im oberen Radiusgelenke. Knochen gesund. Verlauf mit geringer Temperatursteigerung. Wunde bei Entlassung fast geheilt.

41. Babette K ircher, 15 Jahre alt. Eintritt am 15. October 1883, Austritt am 16. April 1884. Alter bei Beginn der Krankheit 7 Jahre. Dauer bis zum Eintritt 8 Jahre. - Aetiologie. Tuberculose der Haut. - Anamese. Aus gesunder Familie stammend. Seit 8 Jahren 
Schwellung und Fistelbildung am rechten Ellbogengelenk. Rechter Arm sehr in der Entwicklung zurickgeblieben. - Status praesens beim Eintritt. Das rechte Ellbogengelenk ist ziemlich unbeweglich und in rechtwinkliger Stellung. Tuberculöser Ulcus. Fistel auf dem Olekranon und auf der Innenseite. - Behandlung und path.-anat. Befund. 16. October. Resectio cubiti. Ein grosser Granulationsherd an der lateralen Seite des Olekranon und des Humerus. Kein grosser Sequester. - Verlauf mit Abscessbildung. Incision. Mit wenig secernirender Wunde entlassen. - Schlussresultat. Patientin starb an allgemeiner Tuberculose im Jahre 1885. Nähere Angaben fehlen.

42. Henriette $\mathrm{W}$ a $\mathrm{h} \mathrm{mer}, 6$ Jahre alt. Eintritt am 26. November 1883, Austritt am 6. Januar 1884. Alter bei Beginn der Krankheit 5 Jahre. Dauer bis zum Eintritt 1 Jahr. - Anamnese. Seit 1 Jahr langdauernde Erkrankung des rechten Ellbogengelenkes. - Status praesens beim Eintritt. Das rechte Ellbogengelenk unbeweglich. Taberculöse Fistel vor dem Epicondylus med. Grosser Abscess neben dem Epicondylus externus. Viele tuberculöse Narben an verschiedenen Stellen des Körpers. - Behandlung und path-anat. Befund. 28. Nov. Resectio cubiti mit Abmeisselung des Epicondylus internus und der äusseren Schale vom Olekranon. Diffuse Synovialtuberculose. Die Knochen sind ganz gesund. - Reactionsloser Verlauf. Zur poliklinischen Behandlung entlassen. 25. Januar 1884 wieder vorgestellt mit tuberculösem Abscess. Incision. Auslöffelung. Mit kleiner Wunde entlassen. - Schlussresultat. Vor 6-7 Jahren im Diakonissenhause zu Cassel gestorben. Nähere Angaben fehlen.

43. Eduard Jung behrend, 27 Jahre alt. Eintritt am 21. Januar 1884, Austritt am 12. Februar 1884. Alter bei Beginn der Krankheit 25 Jahre. Daner bis zum Eintritt 2 Jahre. - Aetiologie. Lungenspitzenkatarrh. - A namnese. Keine hereditäre Belastung. Seit 2 Jahren Schwellung des linken Ellbogens, besonders in der Gegend des Condylus internus humeri. Vor einigen Monaten Incision, wobei sich Eiter entleerte. Es blieb eiternde Fistel zurück. Der Arm ist arbeitsunfähig. - Status praesens beim Eintritt. Die Gegend des Condylus internus humeri ist geschwollen, druckempfindlich. Etwas nach unten zu eine in den Condylus internus führende Fistel. Lungenspitzenkatarrh. - Be liandlung und path.-anat. Befund. 22. Januar 1884. Resectio cubiti. Hydrops, diffuse Synovitis tuberculosa. Ein kleiner primärer Granulationsherd im Condylus internus humeri, der ins Gelenk durehgebrochen ist. Sonst ist das Gelenk wenig erkrankt. - Aseptischer Verlauf. Mit Verband entlassen. - Schlussresultat. Das Ellbogengelenk ist fast in rechtwinkliger Stellung $(190 \mathrm{Grad})$ heil. Bewegung in einem Winkel von $10 \mathrm{Grad}$ möglich. Der Arm ist gebrauchsfähig. Keine Pro- und Supination möglich. Der Vorderarm stelıt zwischen Pro- und supination. Weder Atrophie noch Abnahme der Länge. Patient ist sonst gesund.

44. Wilhelm Schülte, 14 Jahre alt. Eintritt am 24. April 1884, Austritt am 19. Juni 1884. Alter bei Beginn der Krankheit 14 Jahre. Daner bis zum Eintritt 6 Wochen. - A etiologi e. Hereditäre Belastung. 
- Anamnese. Vater starb an Schwindsucht. Seit 6 Wochen Ellbogenleiden. - Status praesens beim Eintritt. Die ganze Oberextremität im Wachsthum stark zurtickgeblieben. Der Ellbogen stumpfwinklig flectirt, pronirt, fast olne alle Beweglichkeit. Die Schwellung beschränkt sich auf die Umgebung des Condylus externus humeri und den oberen Theil der Ulna. Radius sehr druckempfindlich. - Behandlung und path.-anat. Bef und. 1. October 1884. Resectio cubiti. Eiter und tuberculöse Granulation im total zerstörten Gelenk. Die Gelenkoberfläche der 3 Knochen von Granulation zerfressen. - Reactionsloser Verlauf. Beweglichkeit von 145 Grad und Rotation frei. - Schlussresultat. Patient ist 4 Jahre nach der Operation an Lungenleiden gestorben. Der Arm war geheilt und theilweise gebrauchsfähig. Der Kranke konnte ihn in beschränktem Maasse gebrauchen und beugen.

45. Albert Maering, 24 Jahre alt. Eintritt am 25. April 1884, Austritt am 11. Juni 1884. Alter bei Beginn der Krankheit 23 Jahre. Dauer bis zum Eintritt 1 Jahr. - A etiologie. Lungenspitzenkatarrh. - Anamnese. Wiederholter Bluthusten. Seit einem Jahre Schwellung des rechten Ellbogengelenkes, die zur Eiterung führte. Incision. Status praesens beim Eintritt. Starke Schwellung des rechten Ellbogengelenkes. Abscess anf der lateralen Seite der Ulna mit kleiner Fistel. Der Arm steht in stumpfwinkliger Contractionsflexion und ist sehr schmerzhaft bei Bewegung. Urin eiweissfrei. Exquisite Phthisis. - Be handlung und path.-anat. Befund. 26. April 1884. Resectio cubiti mit Abmeisselung der schmalen Schale vom Olekranon. Ausgedehnte Synovialtuberculose. Ein erbsengrosser Knochenherd im lateralen Condylus humeri. - Aseptischer Verlauf. Mit geheilter Wunde und beweglichem Gelenk entlassen. - Schlussresultat. Der Ellbogen ist völlig gelenkig und heil. Der Arm ist gebrauchsfähig, aber zuweilen schmerz. liaft. Bewegungen beschränkt. Patient ist sonst gesund, fuihlt sich aber noch schwach.

46. Karl Taubert, $\delta$ Jahre alt. Eintritt am 2. Mai 1884, Austritt am 9. Juni 1884. Alter bei Beginn der Krankheit $7 \frac{1}{2}$ Jahre. Dauer bis zum Eintritt 6 Monate. - A etiologie. Lupus des Vorderarmes. Fall auf den Ellbogen. - Anamnese. Seit $1 / 2$ Jahre infolge eines Falles auf den linken Ellbogen Schwellung desselben. Sie ging von selbst anf, und es blieben eiternde Fisteln. - Status praesens beim Eintritt. Linkes Ellbogengelenk geschwollen und elastisch. Bewegungen beschränkt und schmerzhaft. Fisteln an der hinteren und äusseren Seite. Vergrösserte Halsdrüsen. - Behandl ung und path.-anat. Befund. 5. Mai 1884. Resectio cubiti. Verdickte Synovialis. Gelenk sonst gesund. Kein Knochenherd. Dagegen sind pararticuläre Gewebe mit Granulationshöhlen versehen, die mit dem Gelenk communiciren. - Aseptischer Verlauf. Mit Gypsverband an dem so gut wie geheilten Arm entlassen. - Schlu ss resultat. Das Ellbogengelenk ist im rechten Winkel ankylotisch heil. Der Vorderarm steht zwischen Pro- und Supination. Der Kranke hat am Vorderarm eine markstuickgrosse lupöse Hautulceration.

47. Heinrich Otte, 56 Jahre alt. Eintritt am 17. Juni 1884, Austritt am 18. Juli 1884. Alter bei Beginn der Krankheit 55 Jahre. Daner 
bis zum Eintritt 1 Jahr. - An a mnese. Aus gesunder Familie stammender Patient leidet seit fast 1 Jahre an langsam zunehmender Schwellung des rechten Ellbogens. Ausser langdauerndem Husten nie krank. Vor 6 Wochen Incision durch den Arzt. - Status praesens beim Eintritt. Der rechte Arm steht in rechtwinkliger Flexionscontraction, stark pronirt. Bewegungen beschränkt. Schwellung des Gelenkes. 2 Fisteln. - Behandlung und path. - anat. Bef und. 18. Juni 1884. Resectio cubiti nach Langenbeck. Ausgedehnte Synovialtuberculose. Ein haselnussgrosser, mit käsigem Eiter und pyogenem Membran versehener Herd im Condylus lat. humeri, der in die Fossa supratrochl. intern. ins Gelenk führt. - Aseptischer Wundverlauf. Mit oberflächlicher Granulation entlassen. - Schlussresultat. Der Ellbogen steht in einem Winkel von $120^{\circ}$. Winkelbewegungen bis zu $15^{0}$ möglich. Der Arm ist wenig gebrauchsfähig. Keine Pro- und Supination möglich. Die Finger der operirten Hand nicht streckbar. Patient ist sonst gesund.

48. Marie Kulike, 3 Jahre alt. Eintritt am 30. Juni 1884, Austritt am 24. Juli 1884. Alter bei Beginn der Krankheit $21 / 2$ Jahre. Dauer bis zum Eintritt $1 / 2$ Jahr. - A e ti ologi e. Scrophulöse Augenentzündung. - Anamnese. Aus gesunder Familie. Scrophulöse Augenentzündung. Seit etwa 1/2 Jabre Ellbogenleiden. Seit 8 Wochen Fisteln. - Status pr a es e n s beim Eintritt. Spindelförmige Schwellung. Eine Eiter entleerende Fistel uber dem Olekranon, 2 andere weiter am Vorderarm, aussen und innen. Druck verursacht Schmerz im Gelenke. - Behandlung und path.-anat. Befund. Resectio cubiti. Die käsige Granulation reicht etwa $3 \mathrm{Cm}$. in der Ulna abwärts. Radiuskopf von festem Bindegewebe überwachsen. Synovialis mit käsiger Granulation erfullt. - Aseptischer Verlauf. Mit Zinksalbe eingerieben entlassen. Am 12. December 1884 wieder aufgenommen wegen eines Abscesses am lateralen Condylus humeri. Incision, Auslöffelung. Arm ziemlich gut beweglich. Geheilt entlassen.

49. Adolphine $\mathrm{K} 0 \mathrm{ch}, 36$ Jahre alt. Eintritt am 22. September 1884, Austritt am 19. October 1884. Alter bei Beginn der Krankheit 351/4 Jahre. Dauer bis zum Eintritt $3 / 4$ Jahr. - A etiologie. Phthisis pulmon. Anamnese. Seit 9 Monaten schmerzhafte Anschwellung des linken Ellbogengelenkes, die allmählich zunahm. Sie soll Rippenfellentzundung gehabt haben. Ausserdem Lungenleiden. Gypsverband am Arm ohne Erfolg. - Status praesens beim Eintritt. Linksseitiger Lungenspitzenkatarrh. Urin eiweissfrei. Schwellung des linken Ellbogengelenkes. Behandlung und path.-anat. Befund. 24. September 1884. Resectio cubiti. Ein käsiger Abscess in der Gegend des Condylus internus. Ein haselnussgrosser Granulationsherd im lateralen Condylus. Diffuse Erkrankung der Synovialis. Ulna und Radius gesund. - Aseptischer Verlauf. Mit Verband entlassen. - Schlussresultat. Der Ellbogen ist mit ziemlich guter Beweglichkeit geheilt. Beugung bis zum spitzen Winkel, Streckung bis zum spitzen Winkel möglich. Pro- und Supination etwas beschränkt. Der Arm ist gebrauchsfähig. Es bessert sich von Jahr zu Jahr. Patientin ist jetzt lungenleidend.

50. Minna Witte, 32 Jahre alt. Eintritt am 10. October 1884, Austritt am 26. October 1884. Alter bei Beginn der Krankheit $31^{2 / 3}$ Jahre. 
Dauer bis zum Eintritt $1 / 3$ Jahr. - A etiologie. Doppelseitige Lungenphthise. Tuberculöse Abscesse des Halses. - An a mnese. Seit 4 Monaten Schmerzen und geringe Schwellung des rechten Ellbogens, Beides allmählich zunehmend. Patientin leidet schon lange Zeit an Husten mit Auswurf. - Status praesens beim Eintritt. Rechtes Ellbogengelenk sehr schmerzhaft und stark geschwollen. Grosser Abscess in der Umgebung. Tuberculöser Abscess am Halse, ferner Retropharyngealabscess, der noch nicht geheilt ist. - Behand lung und path. - an at. Be fund. 13. Oct. Incision des Abscesses. Sofort folgende Amputatio humeri. Diffuse Synovialerkrankung. Grosser Herd im unteren Theil des Humerus, der ins Gelenk und in die Fossa intercondyloidea perforirt. - Reactionsloser Verlauf. Mit Verband und wenig secernirender Wunde entlassen. Schlussresultat. Patientin ist im Jahre 1884 an Lungenleiden gestorben. Der Arm war ganz geheilt. Nähere Angaben fehlen.

51. Auguste Schröder, 18 Jahre alt. Eintritt am 16. December 1884, Austritt am 18. Januar 1885. Alter bei Beginn der Krankheit 10 Jahre. Dauer bis zum Eintritt 8 Jahre. - Aetiologie. Hereditäre Belastung. - An a m nese. Seit 8 Jahren langsam zunehmende Schwellung und Schmerzhaftigkeit des Ellbogengelenkes, welches mit Gypsverband ohne Erfolg behandelt wurde. Die Mutter starb an Lungenschwindsucht. - Status praesens beim Eintritt. Kräftiges Mädchen. Lunge frei. Urin eiweissfrei. Das rechte Ellbogengelenk steht in rechtwinkliger Flexion und ist sehr empfindlich bei Bewegungen. Es fühlt sich fluctuirend an und ist stark geschwollen. - Behandlung und path. - anat. Befund. 19. December 1884. Resectio cubiti wie gewöhnlich. Synovialis diffus erkrankt. Im Olekranon findet sich ein tuberculöser Sequester, der nach seiner Längsaxe liegt. Die Knochenfläche des Humerus theilweise zerfressen. - Verlanf mit einiger Temperatursteigerung. Zur poliklinischen Behandlung entlassen. 20. Februar 1885 vorgestellt mit fast geheiltem, ziemlich gut beweglichem Gelenk. Pro- und Supination nicht ausftihrbar. Der Arm steht in Supinationsstellung.

52. Adolf Struek, 19 Jahre alt. Eintritt am 19. Januar 1885, Austritt am 26. Februar 1885. Alter bei Beginn der Krankheit 18 Jahre. Dauer bis zum Eintritt 1 Jahr. - A e ti ologi e. Verletzung. - A namnese. Vor 1 Jahre bekam Patient einen schweren Schlag gegen den linken Ellbogen. Darauf folgte allmähliche Schwellung und Schmerzhaftigkeit. Ein Abscess an der Aussenseite, der incidirt wurde. - Status praesens beim Eintritt. Kräftig gebauter blasser Mann. Lungen gesund. Urin eiweissfrei. Das linke Ellbogengelenk wenig geschwollen und sehr schmerzhaft bei Bewegungen. Der Arm steht in stumpfem Winkel. Fistel am Condylus internus humeri mit eitriger Secretion. - Behandlung und path. - a a t. Befund. 26. Januar 1885. Resectio cubiti. Ein tuberculöser Granulationsherd an der Hinterseite des Condylus ext., der tief in die Diaphyse reicht. A usserdem einige kirschgrosse, käsig. eitrige Sequester am Humerus, die nach vorn durchbrochen sind. Synovialis diffus erkrankt. Die Knorpelfächen der Knochen von Granulation zerfressen. - Verlauf mit Erysipel. Günstiger Verlauf. Mit bis auf eine kleine granulirende Stelle geheilter Wunde und gewisser Beweglichkeit entlassen. - Sc hluss. 
resultat. Der Ellbogen ist seit $1 / 2$ Jahre völlig heil. Der Arm ist kräftig und gebrauchsfähig. Die Flexionsbewegungen bis zum rechten Winkel möglich. Extensionsbewegung bis zum stumpfen Winkel möglich. Pro- und Supination beschränkt, aber ziemlich gut möglich. Patient ist sonst gesund.

53. Liua M üller, 23 Jahre alt. Eintritt am 2. April 1885, Austritt am 13. Mai 1885. Alter bei Beginn der Krankheit 19 Jahre. Dauer bis zum Eintritt 4 Jabre. - A e ti o lo g i e. Tuberculose des Handgelenkes. Anamnese. Im Sommer 1881 Operation eines localisirten tuberculösen Herdes im Condylus internus humeri dext. Nach 2 Jahren schmerzloser Erguss im Gelenke. Im vorigen Jahre ein Fungus carpi, der zur Resectio manus fuhrte. Seit 5-6 Wochen schmerzhafte Anschwellung des rechten Ellbogengelenkes. - Status praesens beim Eintritt. Das Ellbogengelenk ist geschwollen, theils elastisch, theils fluctuirend. Jeder Bewegungsversuch schmerzhaft. - Behandlung und path.-anat. Befund. 21. April 1885. Resectio cubiti nach Langenbeck. Synovialis diffus erkrankt. Gelenkknorpel theilweise gelockert, theils auch verschwunden. Kein Knochenherd. - Verlauf mit kleiner Temperatursteigerung. Arm bis auf kleine Stelle geheilt. Mit Verband in die Stadt entlassen. Schlussresultat. Der Ellbogen ist seit Juni 1885 völlig heil und gebrauchsfähig. Streckung und Beugung möglich, ebenso Rotationsbewegungen. Weder Verktirzung noch Abmagerung bemerkbar. Patientin ist nicht lungenleidend, hat aber eine Nasenerkrankung.

54. Carl $0 \mathrm{hming}, 10$ Jahre alt. Eintritt am 6. Juni 1885. Alter bei Beginn der Krankheit 3 Jahre. Dauer bis zum Eintritt 7 Jahre. A etiologie. Lungenphthise. - Anamnese. Seit 7 Jahren ist das rechte Ellbogengelenk krank. Schwellung. Incision, Gypsverband. Status praesens beim Eintritt. Rechter Ellbogen steht in stumpfem Winkel. Flexionscontraction. Spindelförmige Schwellung am Gelenk, Fisteln auf der Innen- und Aussenseite. Alle Bewegungen gehindert. Behandlung und path.-anat. Befund. Resectio cubiti mit Abmeisselung der Knochenschale am Humerus. Es findet sich ein erbsengrosser Knochenherd an dem unteren Ende der Cavitas sigmoidea major am Uebergang in die Ulna. Ausgedehnte Synovialtuberculose. - Verlauf mit hohem Fieber und Eiterung der Wunde, Abscessbildung. Incision. Wiederholte Auskratzung in Narkose. Im Verlauf Hämoptoe. Mit verkleinerter Wunde entlassen. - Schl ussresultat. Patient ist im Sommer 1889 an allgemeiner Tuberculose gestorben. Es bestanden noch bis zum Tode immer eiternde Fisteln.

55. Lorenz Schweppe, 8 Jahre alt. Eintritt am 19. Juni 1885, Austritt am 26. Juli 1885. Alter bei Beginn der Krankheit $63 / 4$ Jahre. Dauer bis zum Eintritt 11/4 Jahr. -- A e tio o o gi e. Lupus am Gesicht. Anamnese. Patient hat seit $11 / 4$ Jahren eine allmählich zunehmende Schwellung, Schmerzhaftigkeit des rechten Ellbogens. Bewegunger werden immer beeinträchtigt. Seit Ostern Aufbruch der Schwellung, Eiterentleerung. - Status praesens beim Eintritt. Rechtes Ellbogengelenk geschwollen und schmerzhaft. An der Volarseite, sowie an der Dorsalseite ein ungenügend entleerter Abscess. Ausserdem 5-6 Fisteln mit 
Handunterminirung. Beweglichkeit erhalten, aber schmerzhaft. Am Vorderarm ein tuberculöser Abscess. Gelenk schlottrig. - B ehand lung und path. - anat. Befund. 23. Juni 1885. Resectio cubiti nach Langenbe ck. Gelenkknorpel theilweise zerstört und abgehoben. Eine Herderkrankung weder im Humerus, noch in dem Vorderarmknochen zu finden. Diffuse Synovitis. - Aseptischer Verlauf. Mit kleinen Fisteln entlassen. Schlussresultat. Der Arm ist seit 4 Jahren gebrauchsfähig und heil. Das Gelenk ist völlig steif. Der Arm ist etwas kurzer, aber nicht magerer. Patient ist kräftig und gesund, hat aber starken Lupus im Gesicht.

56. Johanna Ahlborn, 24 Jahre alt. Eintritt am 12. October 1885, Austritt am 1. November 1885. Alter bei Beginn der Krankheit 22 Jahre. Dauer bis zum Eintritt 2 Jahre. - Anamnese. Seit 2 Jahren allmählich zunehmende Schwellung des linken Ellbogengelenkes. Im vorigen Herbst eine Operation an demselben Gelenk, nach der Heilung eintrat. Vor einigen Wochen wieder Schmerzen bei Bewegung. - Status praesens beim Eintritt. Rechtes Ellbogengelenk mässig geschwollen. Zu beiden Seiten des Olekranons fluctuirende Geftihle. Am Dorsum der Ulna eine Narbe. - Behandlung und path.-anat. Befund. 13. Oct. 1885. Resectio cubiti. Ein noch nicht vollständig gelöster Sequester. Diffuse Synovialtuberculose mit Fibrinauflagerung. - Aseptischer Verlauf, mit Verband in die Stadt entlassen. - Schlussresultat. Rechtwinklige Stellung des Gelenkes. 5 Jahre nach der Operation war der Arm gebrauchsfähig. Seit Sommer Schmerzen und Schwellung auf dem Condylus externus. Fluctuation in derselben Stelle. Pro- und Supination wenig fuiblbar. Sonst gesunde Frau.

57. Fr. S ỉ s smann, 43 Jahre alt. Eintritt am 5. November 1885, A ustritt am 28. November 1885. Alter bei Beginn der Krankheit $42^{1 / 2} \mathrm{Jahr}$. Dauer bis zum Eintritt 1/2 Jalır. - Anamnese. Seit 1/2 Jahre langsam entstandene Schwellung des linken Ellbogengelenkes. - Status praesens beim Eintritt. Schwellung des linken Ellbogengelenkes und eine besonders pronirende elastische Schwellung von Halbkugelform am Radiusgelenk. - B ehandlung und path. - anat. B ef und. 5. November 1885. Eröffnung der Schwellung am Radiuskopf; mit Reiskörpern gefüllte Synovialtuberculose; dann Resectio cubiti mit Abmeisselung der schmalen Schalen von beiden Epicondylen des Humerus. Synovitis tuberculosa mit Fibringerinnung. - Verlauf mit Eiterung an der Wunde und Temperaturerhöhung. Mit Verband zur poliklinischen Behandlung entlassen. Schlussresultat. Im April 1888 zu Hause an Darmtuberculose mit Perforation gestorben.

58. Dorette S e m m ler, 58 Jahre alt. Eintritt am 3. Mai 1886, Austritt am 28. Mai 1886. Alter bei Beginn der Krankheit 54/2 Jahr. Dauer bis zum Eintritt $3 \frac{1}{2}$ Jahr. - A e tiologie. Lungenspitzenkatarrh. A na m n ese. Seit $3^{1 / 2}$ Jahren eine Anschwellung und Steifigkeit des rechten Ellbogengelenkes, welche allmählich und von selbst zu Stande kam. Beiderseitige Schwerhörigkeit. - Status praesens beirn Eintritt. Diffuse Schwellung des in rechtem Winkel gebeugten Ellbogengelenkes. Bewegungen beschränkt, auf Druck uberall schmerzhaft. Linksseitiger Lungenspitzenkatarrh. Urin eiweissfrei. - Behandlung und path.-anat. 
Bef und. 4. Mai 1886. Resectio cubiti. Ausgangspunkt der Krankheit ist ein grosser Herd im Olekranon (Caverne mit Sequester). Die Gelenkenden der Vorderarmknochen vom Knorpel gelöst. - Verlauf mit einige Tage dauernder 'Temperaturerhöhung. Mit gut aussehender Wunde entlassen. Schlussresultat. Der Arm ist mit geringer Beweglichkeit geheilt. Patientin ist sonst gesund. Es fehlt nähere Angabe.

59. Sophie Henke, 53 Jahre alt. Eintritt am 20. Mai 1886, Austritt am 24. Juni 1886. Alter bei Beginn der Krankheit 52 Jahre. Dauer bis zum Eintritt $1 \mathrm{Jahr}$ - - A e ti o lo g i e. Lungentuberculose. - A n a m nese. Patientin hat lange Zeit Husten und blutigen Auswurf. Vor 1 Jahre Anschwellung und Steifigkeit des linken Ellbogengelenkes, die allmählich zunahm. Erst vor 3 Monaten Aufbruch der Geschwulst. Seitdem eiternde Fistel. - Status praesens beim Eintritt. Linksseitige Phthisis pulm. Urin normal. Gleichmässige Schwellung des linken Ellbogengelenkes. Auf der Aussenseite dicht am Olekranon eine Fistel, mit dem Gelenk communicirend. Die Bewegungen beschränkt. - Behandlung und path. -anat. Befund. 24. Mai 1886. Resectio cubiti mit Längsschnitt. Es handelt sich um einen festsitzenden tuberculösen Sequester im Olekranon. Die Kapsel diffus erkrankt, zwar unter dem Bilde sich organisirenden Fibrins mit lockerem Reiskörper und wenig fertigem tuberculösen Fungus. Aseptischer Verlanf. Mit fast geheilter Wunde im Verband entlassen.

60. Christian Loges, 48 Jahre alt. Eintritt am 27. Mai 1886, Austritt am 25. Juni 1886. Alter bei Beginn der Krankheit 32 Jahre. Dauer bis zum Eintritt 16 Jahre. - Aetiologie. Verletzung. Pleuritis. A namnese. Vor 16 Jahren, nachdem ein Stein auf den rechten Ellbogen gefallen war, Aufbruch einer nicht mehr Eiter secernirenden Stelle, seit Februar wesentliche Verschlimmerung. - Status praesens beim Eintritt. Recidiv alter rechtsseitiger Pleuritis. Urin eiweissfrei. Rechter Ellbogen fast rechtwinklig flectirt und in pronirter Stellung, weiche gleichmässige Schwellung des Gelenkes, mehrere Fisteln mit wenig Secret. Alle Bewegungen beschränkt und schmerzhaft. - Behandlung und path.a n a t. B ef und. Resectio cubiti. Kleiner Herd im Olekranon. Wenig feste Synovialtuberculose. - Aseptischer Verlauf. Mit Verband entlassen. Schlussresultat. Der Ellbogen ist seit Mai 1887 völlig heil. Das Gelenk ganz schlottrig und wenig arbeitsfähig. Die Bewegungen im Gelenk in beschränkter Weise möglich. Der operirte Arm ist kürzer und magerer als der gesunde. Patient ist gesund.

61. Karl Ha en ke, 45 Jahre alt. Eintritt am 1. Juni 1886, Austritt am 16. Juli 1886. Alter bei Beginn der Krankheit 41 Jahre. Dauer bis zum Eintritt 4 Jahre. - A na mnese. Seit 9 Jahren stechende Schmerzen. Seit 4 Jahren langsam zunehmende Schwellung des rechten Ellbogengelenkes mit Arbeitsfähigkeit und grosser Schmerzhaftigkeit. In letzter Zeit einmal Bluthusten; sonst gesund. - Status praesens bein Eintritt. Rechtes Ellbogengelenk zeigt eine mässige Schwellung, besonders zwischen Ulna und Radius anf der Vorderseite. Arm in stumpfem Winkel pronirt gehalten. Bewegung sehr schmerzhaft. - Behandlung und path. - anat. Befund. 2. Juni 1886. Resectio cubiti. Das Gelenk ist sehr zerstört. Primärer Herd im Olekranon, der sich auch noch nach dem 
Verlauf und Ausgang der tuberculösen Erkrankung des Ellbogengelenkes. 93

Ulnaschaft bin in einem schmalen Gang erstreckt. Synovialis diffus erkrankt. - Verlauf mit subcutanem Abscess. Wunde geheilt. Schlottergelenk. Mit Schiene entlassen. Am 13. Januar 1887 vorgestellt mit Schlottergelenk.

62. Helene $\mathrm{W}$ aelz, 10 Jahre alt. Eintritt am 5. Mai 1886, Austritt am 5. Juni 1886. Alter bei Beginn der Krankheit 10 Jahre. Aetiologie. Tuberculose der Hand. - Anamnese. Von seinem 7. Lebensjahre an soll das Kind scrophulös gewesen sein. Seit Fastnacht ist das rechte Ellbogengelenk geschwollen. Seit 3 Wochen Aufbruch desselben. - Status praesens beim Eintritt. Nicht sehr kräftig gebautes Kind mit dem in rechtem Winkel flectirten und geschwollenen Ellbogengelenk. Die Gelenkkapsel an beiden Seiten des Olekranons verdickt zu fühlen. An der Innenseite über dem Condylus internus eine Fistel. An der Aussenseite mit fungöser Granulation bedeckte Geschwürfläche. Auf dem Handrucken 2 oberflächliche Subcutanabscesse. - Behandlung und patb.-anat. B efund. Resectio cubiti. Ausgedehnte Synovialtuberculose. An ausgesägtem Knochen zeigt sich keine Erkrankung. - Verlauf aseptisch. Die Wunde war fast geheilt. Mit kleiner Oeffnung im Verband entlassen. - S chlussresultat. Am 23. November 1891 stellte sie sich vor mit dem rechtwinklig und pronirt geheilten Ellbogengelenk. Die Bewegungen ganz unmöglich. Ferner einige Fisteln auf der Aussenseite des Gelenkes. Tuberculöse Geschwülste an den beiden Handrücken. Bewegungen in den Fingern sehr beschränkt.

63. Anna Bode, 29 Jahre alt. Eintritt am 21. Juni 1886, Austritt am 16. Juli 1886. Alter bei Beginn der Krankheit $27 \frac{1}{2}$ Jahr. Dauer bis zum Eintritt $1 \frac{1}{2}$ Jahr. - A etiologi e. Doppelseitiger Lungenspitzenkatarrh. Kniegelenktuberculose. - Anamnese. Seit $1 \frac{1}{2}$ Jahren linksseitiges, von selbst entstandenes Ellbogenleiden, welches auswärts wiederholt operirt wurde. Seit Ostern Knieleiden im Anschluss an das Trauma. - Status praesens beim Eintritt. Kachektisch aussehend. Doppelseitiger Lungenspitzenkatarrh. Linkes Ellbogengelenk steht gestreckt. Ulna und Radius proniren am Ellbogen nach hinten, wie bei Luxation. Gleichzeitig Schwellung am Kniegelenk mit geringem Erguss. - B ehandlung und path.-anat. Be fund. 24. Juni 1886. Resectio cubiti. Das Gelenk ist von käsiger Granulation zerfressen. Weiche käsige Masse im Gelenke. Die Spitze des Olekranons käsig infiltrirt. - Verlauf aseptisch. Mit wackeligem Gelenk in einer Schutzschiene entlassen. - Schluss re sultat. Patientin starb am 3. September 1887 an allgemeiner Tuberculose. Der Arm war nur wenig gebrauchsfähig.

64. Wilhelm Jaeckel, 15 Jahre alt. Eintritt am 26. Juni 1886, Austritt am 22. Juli 1886. Alter bei Beginn der Krankheit 10 Jahre, Dauer bis zum Eintritt 5 Jahre. - Anamnese. Aus gesunder Familie stammend. Leidet seit 5-6 Jabren an Schwellung und Bewegungsstörung am rechten Ellbogen. Incision im Hospital Marburg. - Status prae. sens beim Eintritt. Schlecht ernährter Junge. Lungen und Nieren gesund. Rechtes Ellbogengelenk geschwollen. Stumpfwinklig gebeugt. Mehrere eiternde Fisteln. Bewegungsbeschränkung. - B e handlung und path.an at. Bef und. 30. Juni 1886. Resectio cubiti. Eiter in dem sehr stark 
zerstörten Gelenk. Herd in der Gelenkfläche des Olekranons. Ausgedehnte Synovialtnberculose. - Verlauf mit leichter Temperatursteigerung. Mit fast geheilter Wunde entlassen. - Schlussresultat. Der Arm ist seit 5 Jahren völlig heil. Der Arm mager, schwach, aber gebrauchsfähig. Gelenk völlig heil, aber steif. Patient ist sonst gesund.

65. Friedrich Steinmann, 31 Jahre alt. Eintritt am 27. Mai 1886, Austritt am 27. Juni 1886. Alter bei Beginn der Krankheit 27 Jahre. Dauer bis zum Eintritt 4 Jahre. - A etiologie. Tuberculose der Hand. Nach einem Stosse Ellbogenleiden. - An amnese. Im Mai 1880 hier wegen Handtuberculose behandelt. Seit 4 Jahren nach einem Stoss auf den rechten Ellbogen eine langsam zunehmende Sehwellung. - Status praesens beim Eintritt. Gleichmässige spindelförmige Schwellung des rechten Ellbogengelenkes. Bewegungen, wie Flexion und Extension, Pround Supination beschränkt. - Behandlung und path.-anat. Befund. 6. Mai 1886. Resectio cubiti. Ausgedehnte Synovialtuberculose mit vielen Reiskörpern, die wesentlich um das Radiusköpfchen liegen. Ein flacher Knochenherd mit kleinem Sequester findet sich nach Absägung des Olekranons im Gelenkende der Ulna. - Verlauf mit hohem Fieber und Eiterung an der Wunde. Abscessbildung am Oberarm. Incision. Fieber liess nach. Mit Verband entlassen. - Schlussresultat. Arm geheilt. Flexion bis zu einem Winkel von $80^{\circ}$, Extension bis $145^{\circ}$ möglich. Pround Supination völlig ausfübrbar. Kein Schlottergelenk. Patient kann einen Stuhl aufheben, ihn aber nicht wagerecht halten. Patient ist sonst gesund.

66. Sophie Kahls, 32 Jahre alt. Eintritt am 2. Juli 188G, Austritt am 29. Juli 1886. Alter bei Beginn der Krankheit 28 Jahre. Dauer bis zum Eintritt 4 Jahre. - A etiologie. Stoss auf den Ellbogen. A n a m n se. Vor 4 Jahren eine Operation in hiesiger Klinik wegen eines Ellbogenleidens. Damals wurde ein nussgrosser Sequester aus dem Condylus externus humeri entfernt. Das Leiden soll damals nach einem Stosse sich entwickelt haben. Heilung. Im Lanfe dieses Jahres wieder Verschlimmerung. - Status praesens beim Eintritt. Jetzt kommt Patientin mit einem typischen Gelenkfungus, nicht fistulös. Diffuse Kapselschwellung, druckempfindlich, deutliches Krachen bei Bewegungen, die nur noch minimal möglich sind. Urin eiweissfrei. Lungen anscheinend frei. - Behandlung und path.-anat. Befund. 3. Juli 1886. Resectio cubiti. Das Gelenk ist stark zerstört, Knorpel ganz verschwunden. Der äussere Condylus käsig infiltrirt und theilweise sequestirt. Tiefer Granulationsdefect in der Ulna. Ueberall im Gelenk weiche Granulationsmasse. Verlauf aseptisch. Mit fast geheilter Wunde im Verband entlassen.

67. Johanna Burgdorf, 55 Jahre alt. Eintritt am 31. Juli 1886, Austritt am 18. August 1886. Alter bei Beginn der Krankheit 53 Jahre. Dauer bis zum Eintritt 2 Jahre. - A tiolog i e. Lungenspitzenkatarrh und Tuberculose der Hand. - Anamnese. Patientin hat seit 4 Jahren eine Erkrankung des linken Armes. Zuerst hatte sie eine Erkrankung mit Eiterung der Hand. Nach 2 Jahren eine Schwellung des linken Ellbogengelenkes. Seit 1 Jahre Fistelbildung an demselben Gelenk. Status praesens beim Eintritt. Es handelt sich um einen fistulösen linksseitigen Ellbogenfungus mit mehreren anderen Erkrankungen an 
Schulter, Hand und Finger. Linke Lunge an der Spitze infiltrirt, ferner leichte Albuminurie. - Behandlung und path.-anat. Befund. 3. August 1886 aus dem oben beschriebenen Grunde Amputatio humeri in der Mitte. Humerus sehr malacisch. Weichtheile entartet, speciell Muskeln. Gelenk stark durch weichen diffusen Fungus zerstört. - Verlauf aseptisch. Mit geheilter Wunde entlassen.

68. Wilhelm Schrick, 14 Jahre alt. Eintritt am 20. Juli 1886, Austritt am 21. August 1886. Alter bei Beginn der Krankheit 13 Jahre, Dauer bis zum Eintritt 1 Jahr. - A etiologie. Vorausgehende Tuberculose der Hand. - Anamnese. Aus gesunder Familie. Vor 3 Jahren langsam entstehende Erkrankung der Hand infolge eines Falles auf dieselbe. Incision, Knochenherausnahme. Seit 1 Jahre ein Ellbogenleiden. Status praesens beim Eintritt. Mittelkräftiger Knabe von gesundem Aussehen. Der rechte Arm wird im Ellbogen flectirt gehalten. Bewegung sehr beschränkt. Verdickte Kapsel. Eine Fistel $8 \mathrm{Cm}$. oberhalb des Gelenkes mit unterminirten Rändern. Lunge und Urin normal. Tuberculose der Handknochen. - Behand lung und path. - anat. B efund. 26. Juli. Resectio cubiti. Es handelt sich um einen halbkirschgrossen Herd im medialen Condylus. Die übrigen Knochen gesund. Synovialis erkrankt. Er bildet ein derbes Gewebe. - Verlauf aseptisch. Mit Verband nach 3 Wochen entlassen. - Schlussresultat. Patient ist im October 1891 an allgemeiner Tuberculose gestorben. Der Arm war steif geheilt und zu leichter Arbeit gebrauchsfähig.

69. Georgina Dormann, 31 Jahre alt. Eintritt am 12. October 1886, Austritt am 2. December 1886. Alter bei Beginn der Krankheit 24 Jahre. Dauer bis zum Eintritt 7 Jahre. - A e ti o lo gi e. Vorausgegangene Coxitis. - Anamnese. Angeblich seit 7 Jahren Schwellung und Steifigkeit des rechten Ellbogengelenkes, die sich nach einem Fall anf das Ellbogengelenk entwickelt haben. Gypsverband in der Poliklinik ohne Erfolg. Als Kind hat Patientin Coxitis gehabt. - Status praesens beim Eintritt. Das rechte Ellbogengelenk in toto geschwollen, weich, elastisch, nur minimal beweglich und sehr empfinfilich. Weder Abscess noch Fisteln. - Behand lung und path.-anat. Bef und. 13. October 1886. Resectio cubiti. Diffuse Synovitis. Knorpel zum grossen Theil zerstört. Im Humerus ein primärer Herd, ausserdem ist der Condylus externus humeri käsig infiltrirt. - Fieberloser Verlauf. Wunde geheilt. Mit wackligem Gelenk entlassen. - Schlussresultat. Der Arm seit Januar 1886 völlig heil und ganz gebrauchsfähig. Gelenk ist beweglich, aber nicht streckbar. Drehbewegungen in beschränkter Weise möglich. Abmagerung und Verkürzung ganz wenig. Sonst ist Patientin gesund.

70. Sophie Heuer, 10 Jahre alt. Eintritt am 7. September 1886, Austritt am 8. November 1886. Alter bei Beginn der Krankheit 7 Jahre. Dauer bis zum Eintritt 3 Jahre. - A etiologie. Nachfolgende Coxitis. - Anamnese. Vor 3 Jahren eine Anschwellung und Abscess in dem rechten Ellbogengelenke. Nach Incision kam der Abscess zur Heilung. Kurz darauf trat ein Leiden am Hüftgelenke ein. Seit Ostern Fisteln am Ellbogen. - Status praesen s beim Eintritt. Zartes, mageres Kind. Keine Lungenveränderung. Urin normal. Am Hals vergrösserte Lymph- 
drüsen. Das rechte Ellbogengelenk im Winkel von $110^{\circ}$ flectirt. Bewegungen sehr beschränkt. Auf der Aussenseite des Olekranon, wie auf der Innenseite des Gelenkes mehrere tuberculöse Fisteln und Geschwüre. - Behandlung und path.-anat. Befund. 9. September 1886. Resectio cubiti nach Langenbeck. Das Gelenk ist mit Granulation erfullt. Ein grosser tuberculöser Herd im Condylus externus. Ebenso an der Innenseite der Ulna. Von tuberculöser Synovialis zu sehen. Verlauf aseptisch. Auf Wunsch mit noch fistulösem Gelenk, aber nicht geschwollenem Ellbogen in die Stadt entlassen.

71. Carl Corne1, 9 Jahre alt. Eintritt am 28. October 1886, Austritt am 4. December 1886. Alter bei Beginn der Krankheit 81/2 Jahr. Dauer bis zum Eintritt 9 Monate. - A n a m nese. Aus gesunder Familie. Seit dem Frühjahr Schmerzen und Steifigkeit des linken Ellbogengelenkes, Beides allmählich eintretend. Gypsverband ohne Erfolg. Schwellung und Abscessbildung. - Status praesens beim Eintritt. Linkes Ellbogengelenk in toto geschwollen und fluctuirend. Sehr empfindlich. Bewegungen sehr beschränkt. Lungen anscheinend gesund. - Behandlung und path. - a nat. Befund. 30. October 1886. Resectio cubiti. Eitriger Inhalt im Gelenk. Diffuse Synovialtuberculose mit Knochenschwund am lateralen Condylus und am Radiusköpfchen. Ausgangspunkt ist ein grosser Keilsequester des Condylus externus humeri. Verlauf fieberlos und aseptisch. Wunde mit ziemlich guter Beweglichkeit ohne Schlottergelenk entlassen. - Schlussresultat. Das Ellbogengelenk ist mit folgender Beweglichkeit geheilt: Extension bis zu einem Winkel von $135^{0}$; Flexion bis zum rechten Winkel; Pro- und Supination wie normal. Der Arm ist kräftig, und Patient kann mit demselben 8 Pfund wagerecht halten. Sonst ist Patient gesund.

72. Louise Bartels, 21 Jahre alt. Eintritt am 9. Februar 1887, Austritt am 28. März 1887. Alter bei Beginn der Krankheit 15 Jahre. Dauer bis zum Eintritt 6 Jahre. - A nam nese. Angeblich seit 6 Jahren Steifigkeit des rechten Ellbogengelenkes. Nachdem es einige Jahre besser gewesen war, traten wieder Schmerzen ein, infolge deren der Arm arbeitsunfähig wurde. Status praesens beim Eintritt. Rechtes Ellbogengelenk stark geschwollen. Bewegungen wenig möglich. Arm steht in Streckstellung. Gelenk sehr empfindlich. Lungen und Urin normal. Behandlung und path. - anat. Bef und. 10. Februar 1887. Resectio cubiti. Knorpel fast ganz erhalten. Dagegen besteht ein diffuser Synovialfungus. Eine grosse Knochencaverne lässt anf einen grossen Herd daselbst schliessen. - Verlauf aseptisch. Wunde geheilt. Gelenk ziemlich fest. Mit Verband entlassen. - Schlussresultat. Der Arm ist seit 1887 völlig heil und durchaus gebrauchsfähig. Bewegungen im Gelenk in beschränkter Weise möglich. Der operirte Arm ist etwas kürzer und dünner als der gesunde.

73. Elisabeth $\mathrm{Duhhans}, 19$ Jahre alt. Eintritt am 21. Februar 1887, Austritt am 26. März 1887. Alter bei Beginn der Krankheit 171/2 Jahr. Dauer bis zum Eintritt $1 \frac{1}{2}$ Jahr. - A namnese. Seit $1 \frac{1}{2}$ Jahren zunehmende Schmerzen, Schwellung und Steifigkeit im linken Ellbogengelenk. Trotz mancherlei Mittel keine Besserung. - Status 
praesens beim Eintritt. Der linke Arm steht im Ellbogengelenk steif und gestreckt. Das Gelenk ist geschwollen und schmerzhaft. Lungen und Urin normal. - Behandlung und pathol.-anatom. Befund. 23. Februar 1887. Resectio cubiti. Olekranon ist quer gebrochen und erweicht. Das ganze Gelenk ist stark zerstört. Knorpel wenig erhalten. Ueberall käsige Fungusmassen. Primäraffection. Es ist eine ausgedehnte käsige Infiltration des Humerusgelenkendes. - Verlauf fieberlos. Wunde bis anf kleine granulirende Stelle geheilt. Mit Verband entlassen. - Schlussresultat. Es besteht eine kleine Fistel seit $1 / 2$ Jahre nach der Operation. Der Arm ist gebrauchsfähig. Flexion und Extension im Gelenk möglich. Keine Abmagerung zu finden. Patientin ist sonst gesund.

74. Friederike Schöning, 68 Jahre alt. Eintritt am 9. März 1887, Austritt am 16. April 1887. Alter bei Beginn der Krankheit $66^{1 / 2} \mathrm{Jahr}$. Dauer bis zum Eintritt 1/2 Jahr. - Aetiologie. Bronchialkatarrh. - An a mnese. Sie leidet seit längerer Zeit an Husten. Seit $1 \frac{1}{2}$ Jahren Steifigkeit im linken, seit $3 / 4$ Jahren auch im rechten Ellbogengelenk. Beide Gelenke ohne Veranlassung geschwollen. Besonders das linke sehr empfindlich. - Status praesens beim Eintritt. Elend aussehende Frau, mit diffusem Bronchialkatarrh und Oedem beider unteren Extremitäten. Urin eiweissfrei. Linkes Ellbogengelenk in toto geschwollen. Abscess auf der Rückseite und Beugeseite. Bei Bewegung deutliches Krachen. Rechtes Ellbogengelenk geschwollen, aber gut beweglich. - B e handlung und path.-anatom. Befund. 14. März 1887. Resectio cubiti. Weiche fungöse Masse im Gelenk. Im Condylus externus humeri uud im Radius sind käsige Herde mit zum Theil gelöster Nekrose. Verlauf aseptisch. In letzter Zeit ohne nachweisbaren Grund hohes Fieber. Husten und Oedem des Fusses. Geheilt mit Verband entlassen. - S chl us sresultat. Pat. ist an Schwindsucht gestorben. Es fehlt nähere Angabe.

75. Heinrich X., 34 Jahre alt. Eintritt am 10. März 1887, Austritt am 12. April 1887. Alter bei Beginn der Krankheit 27 Jahre. Dauer bis zum Eintritt 7 Jahre. - An a mese. Aus gesunder Familie stammend. Seit 7 Jahren Schwellung, Schmerzen im rechten Ellbogen. Incision auswärts mit viel Eiterentleerung. - Status praesens beim Eintritt. Rechtes Ellbogengelenk rechtwinklig flectirt und spindelförmig geschwollen. Einige Fisteln an der lateralen Seite uber der Ulna. Lungen und Urin normal. - B e hand lung und path. - anat. Befund. 12. April 1887. Resectio cubiti. Auf der Gelenkfläche des Humerus an einigen Stellen der Knorpel abgehoben. Käsiger Eiter im Gelenk. An der Spitze des Olekranons ein erbsengrosser käsiger Sequester. Auf der Rïckseite des Olekranons ein vom oberen Ende bis zur Basis desselben fuhrender $1 \mathrm{Cm}$. breiter Defect. Knorpel vom Olekranon fast ganz abgehoben. Diffuse Synovitis. - Verlauf aseptisch. Mit Gypsverband entlassen. 11. Mai vorgestellt mit geheilter Wunde und ankylotischem Gelenk. Mit Bolint verbunden und entlassen.

76. Heinrich Stönelgundt, 22 Jahre alt. Eintritt am 17. März 1887, Austritt am 15. April 1887. Alter bei Beginn der Krankheit $21^{1 / 2}$ Jahr. Dauer bis zum Eintritt $1 / 2$ Jahr. - Anamnese. Seit $1 / 2$ Jahr bemerkte Patient mässige Schwellung und langsam zunehmende Schmerz- 
haftigkeit des linken Ellbogengelenkes. Es trat Bewegungsbeschränkung und schliesslich Contractionsstellung ein. - Status praesens beim Eintritt. Kräftiger Mann. Auf der Aussenseite zwischen Olekranon und Condylus externus eine starke Schwellung. Ausserdem an der Innenseite eine infiltrirte Partie. Der Arm steht im Ellbogen rechtwinklig gebeugt und fast unbeweglich. - Behandlung und path.-anat. Befund. 23. März 1887. Resectio. Ausserordentlich ausgedehnter Synovialfungus. Am Condylus internus humeri ein kleiner Granulationsherd. Ulna und Radius gesund. Incision des Abscesses. - Wunde vollkommen aseptisch. Mit Verband entlassen. - Schlussresultat. Der Arm ist seit August 1887 ohne Fistel im stumpfen Winkel ankylotisch geheilt und durchaus gebrauchsfähig. Patient ist sonst gesund.

77. Doris Rieken, 8 Jahre alt. Eintritt am 3. Juni 1887, Austritt am 7. Juli 1887. Alter bei Beginn der Krankheit 4 Jahre. Dauer bis zum Eintritt 4 Jahre. - Anamnese. Seit 4 Jahren eine allmäh. lich entstandene Schwellung und Steifigkeit des rechten Ellbogengelenkes. Trotz mannigfacher Mittel keine Besserung. Seit Monaten Fistelbildung. Ausserdem Geschwiirsbildung im anderen Ellbogen und im kleinen Finger. - Status praesens beim Eintritt. Rechtes Ellbogengelenk etwas geschwollen. Das Gelenk wenig beweglich. Es steht in Flexionscontractur. An der medialen Seite eine Fistel. Am Dorsum des Gelenkes ein tuberculöses Geschwür. - Behandlung und path.-anatom. Befund. 13. Juni. Resectio. Das Gelenk ist mit käsiger Masse gefüllt. Knorpel zum Theil verschwunden. Ausgangspunkt ist ein grosser Herd in der Ulna. Ein zweiter liegt im Humerus. - Fieberloser Verlauf. Mit geheilter Wunde und Verband entlassen. - Schlussresultat. Das Ellbogengelenk ist seit 4 Jahren völlig geheilt. Der Arm ist gebrauchsfähig. Das Gelenk ist beweglich. Rotation der Hand möglich. Der operirte Arm ist etwas magerer als der gesunde. Patientin ist angeblich ganz gesund.

78. Johanna Schmidt, 62 Jahre alt. Eintritt am 10. Januar 1857, Austritt am 6. Februar 1887. Alter bei Beginn der Krankheit $61^{1 / 2}$ Jahr. Dauer bis zum Eintritt $1 / 2$ Jahr. - An a mnese. Seit Juli 1886 Steifigkeit und allmähliche Schwellung des linken Ellbogengelenkes ohne bekanute Veranlassung. Erst seit einigen Wochen Verschlimmerung. Patientin ist sonst angeblich gesund. - Status praesens beim Eintritt. Das linke Gelenk theils fluctuirend, theils bedeutend geschwollen. An der vorderen Seite ein der Perforation nahestehender Abscess. Bewegungen im Gelenk möglich, aber empfindlich. Lungen und Urin normal. - Behandlung und path.-anat. Befund. 12. Januar 1887. Resectio cubiti. Das Gelenk mit weicher Granulationsmasse gefullt. Ausgangspunkt ist eine ausgedehnte Infiltration des Condylus internus humeri. - Fieberloser Verlauf. Mit Verband entlassen. - Schlussresultat. Der Ellbogen ist seit 3 Monaten völlig heil. Der Arm ist durchaus gebrauchsfähig. Bewegungen im Gelenk fast normal möglich. Verkürzung nicht bedeutend. Patientin ist nicht lungenleidend, hat aber ein chronisches Halsgeschwïr.

79. Heinrich Weber, 65 Jahre alt. Eintritt am 13. Juli 1887, Austritt am 2. Angust 1887. Alter bei Beginn der Krankheit 551/2 Jahr. 
Dauer bis zum Eintritt 1/2 Jahr. - A etiologie. Hereditäre Belastung. - Anamnese. Mutter und Geschwister des Kranken sollen an Schwindsucht gestorben sein. Im vorigen Winter bekam er Schwellung und Schmerzen im rechten Ellbogen. Vor 6 Wochen Incision vom Arzt und Eiterauslassen. Seitdem eine Fistel. - Status praesens beim Eintritt. Rechter Ellbogen geschwollen. Oedematös. An der Aussenseite eine Fistel. Das Gelenk steht im rechten Winkel flectirt und ist schmerzhaft. Lungen hinten oben verschwachtes Athmen. - Behandlung und path.-anat. Befund. 14. Juli 1887. Amputatio humeri wegen weit ausgedehnter Infiltration des Humerus und der Ulna. Ausserdem findet sich ausgedehnte Synovialtuberculose mit eitrigem Gelenkinhalt. - Verlauf aseptisch. Stumpfwinklig geheilt entlassen.

80. Ernst Grimme, 66 Jahre alt. Eintritt am 19. Juli 1887, Austritt am 7. September 1887. Alter bei Beginn der Krankheit 58 Jahre. Dauer bis zum Eintritt 8 Jahre. - A namnese. Seit 8 Jahren Schmerzen im rechten Ellbogen. Vor 6 Wochen Incision tiber dem Condylus externus, wobei sich Eiter entleerte. - Status praesens beim Eintritt. Der rechte Ellbogen erheblich geschwollen. Der Unterarm steht in Fle. xionsstellung. Bei Bewegung deutliches Krachen. Ueber dem Condylus externus eine Fistel, uber dem Condylus internus eine fluctuirende Stelle. - Behandlung und path.-anat. Befund. - 26. Jali 1887. Operation. Incision. Darauf Resectio cubiti. Das Gelenk mit alter tuberculöser Granulation und käsigem Eiter besetzt. Die Gelenkfläche von Granulation zerfressen und selr rauh. Im Olekranon zeigen sich an der ulnalen und radialen Seite bohnengrosse Defecte. - Aseptischer Verlauf. Wunde fast geheilt. Mit Verband entlassen. $-\mathrm{Schlussresultat}$. Patient ist 1890 an Bruchleiden nach 4 tägigem Krankenbett gestorben. Der Arm war nicht ganz heil. Er ist wiederholt operirt, jedoch eiterte er bis zum Tode. Patient hat sonst Lungenleiden gehabt.

81. Carolina D r o e ge, 48 Jahre alt. Eintritt am 30. Juli 1887, Austritt am 9. September 1887. Alter bei Beginn der Krankheit 43 Jahre. Dauer bis zum Eintritt 5 Jahre. - Anamnese. Seit 5 Jahren Verdickung des linken Ellbogens, die langsam zunahm und schmerzhaft wurde. An mehreren Stellen brach verdünnte Haut auf; seitdem Fistelbildung. Vor mehreren Jahren hatte ein Abscess bestanden, der nach dem Aufbruch heilte. - Status praesens beim Eintritt. Keine nachweisbare Lungenerkrankung. Urin normal. Der linke Ellbogen stark geschwollen. Mehrere Fisteln, die in das Gelenk führen. Der Arm ist sehr schlottrig. Bewegungen schmerzhaft und behindert. - Behandlung und path.an at. B efund. 1. August 1887. Resectio cubiti. Weiche Synovialtuberculose. Ein kirschgrosser Herd in der Ulna, da, wo sie in den Processus coronoidalis ausgeht; die tibrigen Knochen sind intact. - Fieberloser aseptischer Verlauf. In stumpfem Winkel verbunden entlassen. - S chlussresultat. Ellbogengelenk steht im rechten Winkel ankylotisch geheilt. Die Hand in pronirter Stellung. Der Arm ist kräftig und gut arbeitsfähig. Rotation der Hand wenig möglich. Patientin befindet sich viel besser als früher.

82. Carl M u tze, 41 Jahre alt. Eintritt am 9. September 1887, Austritt am 26. October 1887. Alter bei Beginn der Krankheit 401/4 Jahr. 
Dauer bis zum Eintritt $3 / 4$ Jahr. - Anamnese. Seit $3 / 4$ Jahren klagt er tiber Schmerzen im linken Ellbogen, der allmählich anschwoll. Status praesens beim Eintritt. Mittelkräftiger Mann mit geschwollenem, in Flexion stehendem Gelenk. Alle Bewegungen beschränkt. Fisteln über dem Condylus externus und internus des Humerus. - Behandlung und path. -anat. B efund. 9. September 1887. Resectio cubiti. Ausgedehnte käsige Synovialtuberculose, sowie Weichtheiltuberculose. Oberfläche des Olekranons höckrig. Knorpel vom Radiusköpfchen grossentheils abgehoben. Im Condylus internus humeri ein nussgrosses, hartinfiltrirtes Knochenstïck. - Verlauf mit Abendfieber. Es bildete sich ein Abscess an der Ellbogenbeuge. Incision. Eiterung der Wunde. Mit gut aussehender $W$ unde entlassen.

83. Hermann Hartman n, 35 Jahre alt. Eintritt am 29. September 1887, Austritt am 30. October 1887. Alter bei Beginn der Krankheit 35 Jahre. Dauer bis zum Eintritt 5 Monate. - Anamnese. Seit 5 Monaten eine allmählich zunehmende Schwellung des rechten Ellbogengelenkes. Die Beweglichkeit wurde immer schmerzhafter und beschränkter. Im Juni eine Incision vom Arzt vorgenommen. Trotzdem keine Besserung. - Status praesens beim Eintritt. Spindelförmige Schwellung des Gelenkes von ziemlich harter Consistenz. Entsprechend dem Condylus externus eine Narbe und eine Fistel. Bewegungen fast aufgehoben. Anf der Stirn eine Narbe, von früherer Knocheneiterung herrührend. Lungen normal. - Behandlung und path. - anat. Befund. 30. October 1887. Resectio cubiti. Erkrankte Knorpel entfernt. Es findet sich ein abgesprengtes Stïck im Gelenk. - Verlauf fieberlos. Mit gebeugt verbundenem Gelenk entlassen. - Schlussresultat. Patient ist gestorben. Es fehlt nähere Angabe.

84. Wilhelmine Otte, 57 Jahre alt. Eintritt am 3. October 1887, Austritt am 28. October 1887. Alter bei Beginn der Krankheit 56 Jahre. Dauer bis zum Eintritt 1 Jahr. - Anamnese. Seit 1 Jahre angeblich nach einem Fall eine Schwellung des linken Ellbogens, die allmählich zunahm und zugleich schmerzhaft wurde. Am Unterarm entstanden mehrere Abscesse, die aufgebrochen zu Fisteln wurden. - Status praesens beim Eintritt. Ziemlich elend aussehende Frau ohne nachweisbare Erkrankung der inneren Organe. Das linke Ellbogengelenk stark geschwollen, flectirt erhalten. An dem Oberarm mehrere Fisteln mit wenig Secret, die ins Gelenk führen. Bewegungen beschränkt und schmerzhaft. - Behandlung und path. -anat. Befund. 5. October 1887. Resectio cubiti. Am Knochen finden sich keine Herde. Ausgedehnte Synovialtuberculose. - Fieberloser Verlauf. Krumm verbunden. So entlassen. - Schlussresultat. Der Arm ist völlig heil und gut gebrauchsfähig. Patientin kann ihn bis zum Winkel von $150^{\circ}$ strecken und bis zu $70^{\circ}$ beugen. Pro- und Supination ziemlich gut möglich. Der Arm ist etwas schlottrig, aber kräftig. Keine Atrophie und Verkürzung zu bemerken. Patientin ist sonst gesund.

85. Carl Schoppe, 18 Jahre alt. Eintritt am 26. October 1887, Austritt am 27. November 1887. Alter bei Beginn der Krankheit 171/4 Jahre, Dauer bis zum Eintritt 1/4 Jahr. - Aetiologie. Lungenleiden. - 
A namnese. In letzter Zeit melirmals Blnthnsten, sonst immer gesund. Seit etwa 8 Monaten klagt er über Schmerzen im rechten Ellbogen. Status praesens beim Eintritt. Bleich aussebender Junge. Das rechte Ellbogengelenk geschwollen, besonders an der Aussenseite. Die Haut daselbst geröthet. Ablösungen von grossen Epidermisblättern. Kapsel fühlt sich verdickt an. Fluctuation am Oberarm uber dem Gelenk. Bewegungen beschränkt. - Behandlung und path.-anat. Befund. 28. October 1887. Resectio cubiti. Es handelt sich um einen trockenen Process. Die Synovialis zeigte ausgedehnte Fibrinauflagerungen, die im Radiohumeralgelenk auf den lateralen Rand des Radiusköpfchens tibergriffen und hier Knorpel und Knochen zerfressen hatten. Ein zehnpfennigstückgrosser Granulationsherd im Condylus lat. humeri. Ein zweiter kirschgrosser Herd in der Basis Olecrani. - Fieberloser Verlauf. Gebeugt verbunden entlassen. - Schlussresultat. Patient ist im Mai 1888 an Blutsturz gestorben. Der Arm war heil und ziemlich gut brauchbar.

86. Christian S tölzing. Eintritt am 7. Januar 1888, Austritt am 11. Februar 1888. Alter bei Beginn der Krankheit 16 Jahre. - A etio logie. Fall auf den Arm. - Anamnese. Vor 10 Jahren soll Patient auf den Arm gefallen sein, wonach leichte Schwellung eintrat. Vor 2 Wochen ist er wieder auf den Arm gefallen, und seitdem soll der Arm steifer geworden sein. - Status praesens beim Eintritt. Arm im Ellbogen stumpfwinklig flectirt und geschwollen. Bewegungen fehlen fast ganz und sind sehr schmerzhaft. Lungen und andere Organe normal. Behandlung und path. - anat. Befund. 11. Januar 1888. Resectio cubiti nach König. Kapsel zeigt an einigen Stellen sulzige Auflagerung. Der tuberculöse Process zum grossen Theil ausgeheilt. Knorpel vom Radius aufgehoben. Schwund des Knorpels am Humerus. Ein Herd in der Cavitas sigmoidea major und minor. - Fieberloser Verlauf. Flectirt verbunden entlassen. - Schlussresultat. Der Ellbogen ist ankylotisch geheilt und gebrauchsfähig. Patient ist gesund.

87. Minna $\mathrm{Oberchachsick,} 30$ Jahre alt. Eintritt am 30. Januar 1888, Austritt am 8. März 1888. Alter bei Beginn der Krankheit 23 Jahre. Dauer bis zum Eintritt 7 Jahre. - Anamnese. Vor 3 Jahren bekam Patientin ohne besondere Veranlassung langsam zunehmende Schwellung. Vor 1 Jahre eine schmerzhafte Stelle, die vom Arzt incidirt wurde. Danach Heilung. Vor 8 Monaten nahm das Leiden zu. - Status praesens beim Eintritt. Das linke Ellbogengelenk spindelförmig geschwollen. Die Kapsel ist verdickt und durch Flüssigkeit vorgewölbt. Bewegungen beschränkt und schmerzhaft. - Behandlung und path. a nat. B efund. 2. Februar 1888. Resectio cubiti. Eiter im Gelenk und sehr weiche Synovialtuberculose. In den Gelenkenden ist kein Knochenherd zu finden. - Verlauf aseptisch. Mit bis auf kleine Stelle geheilter Wunde entlassen. - Schlussresultat. Der Ellbogen ist völlig heil. Der Arm ist ziemlich gebrauchsfähig. Gelenk ist steif. Pro- und Supination unmöglich. Verkürzung, aber keine Abmagerung. Patientin ist vollständig gesund.

88. Friederike K r eik l er, 32 Jahre alt. Eintritt am 30. Januar 1888, Austritt am 25. Februar 1888. Alter bei Beginn der Krankheit 31 Jahre. 
Dauer bis zum Eintritt 1 Jahr. - An amnese. Ohne besonderen Grund bekam Patientin vor 1 Jahre Anschwellung und Schmerzhaftigkeit des linken Ellbogengelenkes. Sonst ist Patientin gesund. - Status praesens beim Eintritt. Lungen und Nieren normal. Der linke Ellbogen stark geschwollen. Die Kapsel verdickt. Sowohl auf der lateralen, wie medialen Seite neben dem Olekranon findet sich ein grosser Abscess. Alle Bewegungen sind beschränkt und schmerzhaft. - Behandlung und path.-anat. Befund. 1. Februar 1888. Resectio cubiti. Es findet sich eine sehr weiche Synovialtuberculose. An den Knochen kein Herd. Eiter im Gelenk. - Verlauf aseptisch. Mit krumm verbundenem Arm entlassen. - Schlussresultat. Die Kranke starb an Gehirnentzündung. Der Arm war aber vor dem Tode steif.

89. Heinrich Werder, 57 Jahre alt. Eintritt am 2. Februar 1888, Austritt am 1. März 1888. Alter bei Beginn der Krankheit $561 / 2$ Jahre. Dauer bis zum Eintritt 1/2 Jahr. - A etiologie. Stoss gegen den Ellbogen. Hereditäre Belastung. - An amnese. Mutter starb angeblich an Schwindsucht. Vor einigen Jahren Stoss von einer Kuh gegen den linken Ellbogen. Seit Herbst Schmerzen und allmähliche Schwellung desselben. - Stat us praesens beim Eintritt. Mittelkräftiger Mann mit Alterskyphose. Linker Arm steht in Flexion und Pronation. Ellbogen. gegend geschwollen, die Kapsel verdickt. Alle Bewegungen behindert und sehr schmerzhaft. - Behandlung und path.-anat. Befund. 2. Februar 1888. Resectio cubiti, wie gewöhnlich. Kapsel erheblich verdickt. Sie zeigt sulzige Auflagerung von Granulation. Am Condylus externus ein etwa haselnussgrosser Granulationsherd. - Aseptischer Verlauf. Flectirte Stellung. Mit Verbañd entlassen. - Schlussresultat. Der Ellbogen steht im Winkel von $145^{\circ}$ ganz ankylotisch geheilt. Der Arm ist wenig arbeitsfähig. Pro- und Supination unmöglich. Leichte Abmagerung und Verktirzung. Patient ist sonst gesund.

90. Henriette Nikolai, 63 Jahre alt. Eintritt am 9. Februar 1888, Austritt am 8. März 1888. Alter bei Beginn der Krankheit $62 \frac{1}{2}$ Jahre. Dauer bis zum Eintritt $1 / 2$ Jahr. - A n a m nese. Angeblich seit 10 Wochen eine Anschwellung auf der Aussenseite des linken Ellbogengelenkes. $\mathrm{Zu}$ gleich Beschränkung der Beweglichkeit des Armes. Die Schwellung brach auf, entleerte Eiter. Seitdem besteht an dieser Stelle ein Geschwür. Status praesens beim Eintritt. Innere Organe gesund. Das linke Ellbogengelenk steht im Winkel von $110^{\circ}$ flectirt. Bewegungen im Gelenk activ wenig, passiv nur mit Schmerzen ausfuhhrbar. Das Gelenk in toto geschwollen, die Kapsel verdickt. Auf der Aussenseite des Gelenkes ein thalergrosses Geschwür mit Unterminirung der Haut und weicher Granulation. - Behandlnng und path.- anat. Befund. 10. Februar 1888. Resectio cubiti. Am Knochen kein Herd. Secundüre Zerstörung durch Granulation. Weiche schmierige Synovialtuberculose. - Verlauf fieberlos. Mit bis auf kleine Stelle geheilter Wunde und Verband entlassen.

91. Eduard Zickler, 22 Jahre alt. Eintritt am 10. März 1888, Austritt am 28. April 1888. Alter bei Beginn der Krankheit 211/2 Jahre. Dauer bis zum Eintritt $1 / 2$ Jahr. - Anamnese. Seit letztem Herbst allmählich zunehmende Schwellung und Schmerzhaftigkeit des rechten 
Ellbogengelenkes. Oefter trockener Husten. - Status praesens beim Eintritt. Rechtes Ellbogengelenk stark geschwollen, elastisch und fluctuirend. Bewegungen beschränkt und empfindlich. - B e handlung und path. - an at. Befund. 14. März. Resectio cubiti. Hydrops tuberculosa mit Fibrinflöckchen. Am Knochen kein Herd zu finden. Starke Synovialtuberculose. - Verlauf mit geringer Temperatursteigerung. Wunde bis auf kleine Stelle gelieilt. Flectirt verbunden entlassen.

92. Elise Henning, 13 Jahre alt. Eintritt am 28. April 1888, Austritt am 25. Mai 1888. Alter bei Beginn der Krankheit 12 Jahre. Daner bis zum Eintritt 1 Jahr. - A e tiologie. Multiple Knochentuberculose. - An amnese. Das Kind ist hier wiederholt operirt. Im Jahre 1887 wurde an ihm eine partielle Operation am linken Ellbogengelenk vorgenommen, wobei ein Herd im Condylus internus humeri entfernt wurde. Ausserdem wurde ihm später wegen Tuberculose eine Zehe und ein Finger abgenommen. - Status praesens beim Eintritt. Blasses Mädchen ohne nachweisbare Lungenerkrankung. Urin normal. Das linke Ellbogengelenk im Winkel von $140^{\circ}$ flectirt, geschwollen, besonders in der Gegend des Radioulnalgelenkes. Alle Bewegungen behindert. - B e hand lung und path. - an at. B e fund. 28. April 1888. Resectio cubiti. Am Condylus internus humeri fehlt ein Stück, doch ist er ganz gesund. Ueberhaupt findet sich kein Knochenherd, ausser in der Fossa sigmoidea der Ulna ein secundärer Defect. Synovialis diffus erkrankt. - Fieber und Eiterung. Die Wunde in der Tiefe geheilt. Krumm verbunden entlassen. - Schlussresultat. Der Arm ist seit Sommer 1888 geheilt und gebrauchsfähig. Streckung fast ganz, Beugung theilweise möglich. Kraft des Armes mässig. Pro- und Supination möglich. Minimale Abmagerung. Patientin ist sonst gesund.

93. Minna Teuteburg, 21 Jahre alt. Eintritt am 30. April 1888, Austritt am 2. Juni 1888. Alter bei Beginn der Krankheit 20 Jahre. Dauer bis zum Eintritt I Jahr. - Anamnese. Vor 1 Jahre wurde Patientin hier wegen Tuberculose der Ulna operirt. Dabei wurde ein Herd in der Ulna geräumt. Seitdem bestehen noch Fisteln. Das Gelenk ist in letzter Zeit wieder dicker geworden. - Status praesens beim Eintritt. Die ganze Ellbogengegend ist geschwollen, besonders zwischen Ulna und Radius. Kapsel verdickt zu fühlen. Auf der Dorsalseite finden sich mehrere Fisteln, die ins Gelenk führen. Alle Bewegungen sind behindert. - Behandlung und path. - anat. Befund. 21. Mai 1888. Resectio cubiti. Um das Radiusköpfchen herum ist eine Synovialtuberculose sehr entwickelt. An der medialen Seite der Ulna ist ein secundärer Defect. Im Condylus externus humeri ein Knochenherd. - Verlauf mit minimaler Eiterung. Die Wunde fast ganz geheilt. In Flexion. Mit Verband entlassen. - Schlussresultat. Patientin ist in der Klinik gestorben. Nähere Angaben fehlen.

94. Regine Hinterthür, 36 Jahre alt. Eintritt am 21. Juni 1888, Austritt am 13. Juli 1888. Alter bei Beginn der Krankheit 351/2 Jahre. Dauer bis zum Eintritt 1/2 Jahr. - Aetiologie. Lungenspitzenkatarrh und multiple Knochentuberculose am Fusse. - A n a m nese. Vor 2 Jahren wurde Patientin hier wegen Tuberculose des Fersenbeins operirt, ausserdem wegen Tuberculose der Fusswurzelknochen. Seit Winter Schmerzen 
und allmähliche Schwellung des rechten Ellbogens. Seit 3 Wochen Aufbruch derselben. - Status praesens beim Eintritt. Ziemlich gesund aussehende Frau. Katarrh in der linken Lungenspitze. Rechtes Ellbogengelenk stark geschwollen. Die Kapsel verdickt. Bewegungen im Gelenk möglich, aber schmerzhaft. Abnorme seitliche Beweglichkeit zu constatiren. - Behandlung und path.-anat. Befund. 22. Juni 1888. Resectio cubiti. Sehr ausgedehnte Synovialtuberculose. Im Radiusköpfchen ein Keilherd. Kapsel auf demselben abgehoben. Ulna und Humerus gesund. - Verlauf aseptisch. Zur poliklinischen Behandlung entlassen. Schlussresultat. Patientin ist im October 1890 an Lungenleiden gestorben. Der Ellbogen war ganz steif und der Arm sehr mager und nicht gebrauchsfähig.

95. Dorothea Runge, 38 Jahre alt. Eintritt am 18. Juli 1888, Austritt am 9. August 1888. Alter bei Beginn der Krankheit 35 Jahre. Dauer bis zum Eintritt 3 Jahre. - A etiologie. Stoss gegen den Ellbogen und linker Lungenspitzenkatarrh. - A n a mnese. Patientin bekam vor 3 Jahren einen Stoss gegen den linken Ellbogen. Seitdem Schmerzen und allmählich zunehmende Schwellung und Behinderung der Gebrauchsfähigkeit. - S ta tu s praesens beim Eintritt. Magere Frau mit Dämpfung über der linken Lungenspitze. Urin normal. Das linke Ellbogengelenk stark geschwollen, Kapsel verdickt. Der Arm steht in gestreckter Stellung. In der Gegend des Condylus medialis eine Fistel. Bewegungen beschränkt. - Behandlung und path.-anat. Befund. 19. Juli 1888. Resectio cubiti. Ausgedehnte Synovialtuberculose. Nach dem Absägen findet sich im Condylus lateralis humeri ein erbsengrosser Käseherd. Sonst sind die Knochen gesund. - Verlauf aseptisch. Wunde geheilt und krumm verbunden. Damit entlassen. - Schlussresultat. Das Ellbogengelenk ist schlottrig geheilt. Es bleibt eine kleine Fistel. Patientin wurde nach der Entlassung vom Arzt an Spina ventosa und Lymphdrüsentuberculose operirt. Sie ist sonst gesund.

96. Wilhelm Maget, 50 Jahre alt. Eintritt am 23. Juli 1888, Austritt am 11. August 1888. Alter bei Beginn der Krankheit 45 Jahre. Dauer bis zum Eintritt 5 Jahre. - A e tio 10 gie. Lungenspitzenkatarrh. - Anamnese. Aus gesunder Familie stammend. Bereits seit 5 Jahren Schmerzen und langsam zunehmende Steifigkeit. - Status praesens beim Eintritt. Der linke Unterarm stelt in Flexion und Pronation. Sämmtliche Bewegungen beschränkt. Die Kapsel verdickt. Lungenspitzenkatarrh. Urin normal. - Behandlung und path.-anat. Befund. Resectio cubiti. Eingeschrumpfte Kapsel mit fibrinöser Auflagerung. Starke Zerstörung der Knochen. An der Basis des Olekranon ein etwa kirschgrosser Herd mit käsigem, fibrinösem Inhalt. Vom Radiuskopf nicht mehr viel erhalten. - Verlauf mit hohem Fieber und Eiterung. Die Naht durchschnitten. Tricepssehne zum Theil nekrotisch. Auf Wunsch entlassen. - Schlussresultat. Ellbogen ist seit Januar 1890 völlig heil und gebrauchsfähig. Streckung beinahe vollständig möglich. Beugung bis zum rechten Winkel. Pro- und Supination der Hand, wenn auch nicht normal, so doch ausfiihrbar. Verkürzung des operirten Armes beträgt $6 \mathrm{Cm}$. Erhebliche Abmagerung. Patient ist sonst gesund. 
97. Albertine Se i p pel, 8 Jahre alt. Eintritt am 5. November 1888, Austritt am 24. Januar 1889. Alter bei Beginn der Krankheit 4 Jahre. Dauer bis zum Eintritt 4 Jahre. - Anamnese. Seit 4 Jahren hat das Kind Ellbogenleiden. In den letzten 4 Wochen traten 2 malige Entzïndungen im Gelenk ein, welche Incision nöthig machten. Gesunde Familie. - Status praesens beim Eintritt. Das Ellbogengelenk ist stark geschwollen. Der Arm steht fleetirt. Das Gelenk ist schlottrig. Verdünnte Hand an mehreren Stellen. Aussen vorn ein grosses tuberculöses Geschwir, das ins Gelenk führt. Ausserdem 2 Fisteln. Bewegungen sehr schmerzhaft. - Behand lung und path. - anat. Befund. 7. November. Resectio cubiti. Schmierige Synovitis tuberculosa. Ein erbsengrosser Herd im lateralen Condylus. - Verlauf mit Temperatursteigerung und Abscessbildung. Auskratzung der Fistel. Incision des Abscesses. Mit oberflächlicher Granulation entlassen.

98. Heinrich Struckmann, 10 Jahre alt. Eintritt am 9. November 1888, Austritt am 10. December 1888. Alter bei Beginn der Krankheit 10 Jahre. Dauer bis zum Eintritt $1 / 4$ Jahr. - A e ti o logi e. Stoss gegen den linken Ellbogen. - An a mnese. Er wurde am 25. September 1888 in der Poliklinik vorgestellt. Seit 3 Wochen nach einem Stoss Schmerzen im linken Ellbogen. Auf dem Olekranon eine fluctuirende Stelle, welche bei Druck schmerzhaft ist. Zum 2. Male wurde Patient im October in der Poliklinik vorgestellt mit tuberculösem Abscess auf dem Olekranon. Incision. - Status praesens beim Eintritt. Ziemlich gleichmässige Schwellung im linken Ellbogengelenk, die auf Druck schmerzhaft ist und fluctuirt. Der Arm steht in leichter Flexionscontractur. Rotation schmerzhaft und beschränkt. Innere Organe frei. - Behandlung und p ath. - an at. B efund. 14. November 1888. Resectio cubiti. Tuberculöser Eiter im Gelenk. Ein laselnussgrosser Herd im Olekranon, selbst auf der Hinterfläche. Ausserdem allgemeine ausgedehnte Synovialtuberculose mit zerfallenen Faserstoffmassen. Auf dem Olekranon ein haselnussgrosser Weichtheilabscess. - Verlauf aseptisch. Die Wunde geheilt und in flectirter Stellung. Mit kleinem Verband entlassen. - Schlussresultat. Der Arm ist im Ellbogengelenk pronirt und total ankylotisch heil. Pro- und Supination etwas möglich, aber passiv. Der operirte Arm ist etwas kürzer, atrophisch und wenig gebrauchsfähig. Patient fühlt sich schwach, ist aber sonst gesund.

99. Sophie Weinreich, 10 Jahre alt. Eintritt am 15. Januar 1889. Austritt am 2. Februar 1889. Alter bei Beginn der Krankheit 93/4 Jahre. Dauer bis zum Eintritt $1 / 3 \mathrm{Jahr}$. - A etiologi e. Tuberculose der Tibia. - An amnese. Vor 8 Monaten bekam Patientin eine Schwellung der Tibia; vor 4 Monaten eine Schwellung des rechten Ellbogengelenkes, die allmählich zunahm. Sonst ist Patientin gesund. - Status praesens beim Eintritt. Rechtes Ellbogengelenk verdickt. Oberarm erscheint dicker, Ulna etwas medialwärts gerückt. Die Kapsel etwas verdickt. Arm steht mässig flectirt und ist nicht streckbar. In der Mitte der Tibia eine $10 \mathrm{Cm}$. lange Auftreibung. - Behandlung und path.-anat. Befund. 22. Januar 1889. Resectio cubiti. Ein Herd im Olekranon, dessen Innenfäche stark zerstört ist. Ausserdem ein secundärer Herd im Humerus, 
oberhalb der Trochlea. Zugleich eine Operation der Tibia, in welcher sich ein tuberculöser Herd findet. -- Verlauf aseptisch. Wunde geheilt und krumm verbunden. So entlassen. - Schlussresultat. Ellbogengelenk ist im Winkel von $145^{\circ}$ vollständig ankylotisch geheilt und gebrauchsfähig. Patientin ist sonst gesund.

100. Friederike Peter, 62 Jahre alt. Eintritt am 6. Februar 1889, Austritt am 7. März 1889. Alter bei Beginn der Krankheit 60 Jahre. Dauer bis zum Eintritt 2 Jahre. - Anamnese. Vor 2 Jahren lag sie im Bette wegen Schmerzen an einem Bruch. Dabei bekam sie allmähliche Schwellung und Schmerzen im linken Ellbogengelenk. Seit der Zeit ist.der Arm arbeitsunfähig. - Sta tu s pra es en s beim Eintritt. Patientin ist ziemlich gut ernährt. Innere Organe sind gesund. Das linke Ellbogengelenk ist geschwollen und schlottrig. An der Innenseite ein grosser Abscess. Arm druckempfindlich. - Behandlung und path,-anat. Befund. 9. Februar 1889. Resectio cubiti. Knochen gesund, kein Herd zu finden. Weiche ausgedehnte Synovialtuberculose. Abscess mit Communication im Gelenk. - Wunde ganz aseptisch. Arm krumm verbunden. Zur poliklinischen Behandlung entlassen. - Schlussresultat. Ellbogen ist seit $1 / 2$ Jahre völlig heil. Der Arm ist zu leichter Arbeit brauchbar. Bewegungen im Gelenk beschränkt. Patientin hat einen Schlaganfall gehabt.

101. Fritz Habke, 17 Jahre alt. Eintritt am 13. Februar 1889, Austritt am 22. März 1889. Alter bei Beginn der Krankheit 13 Jahre. Dauer bis zum Eintritt 4 Jahre. - A etiologie. Lungenspitzenkatarrh. - Anamnese. Er hat wiederholt an Lungenkatarrh gelitten. Seit 4 Jahren Schmerzen im rechten Ellbogen, welchen er von der Zeit an zu schonen pllegte. - Status praesens beim Eintritt. Der rechte Arm ist atrophisch in Flexion. Ellbogengegend geschwollen. Bewegungen sehr beschränkt. Grosse Schmerzhaftigkeit zu beiden Seiten vom Olekranon. Rechte Lungenspitze infiltrirt. Urin eiweissfrei. - Behandlung und path.- an at. Befund. 14. Februar 1889. Resectio cubiti. Kapsel durch Bindegewebsverwachsung verdickt und zeigt wenig sulzige Anflagerung. Die Gelenkfläche des Olekranon ulcerirt, an einer Stelle der Cavitas minor ein flacher Herd. - Fieberloser Verlauf. Zur poliklinischen Behandlung mit Verband entlassen.

102. Irene M eta, 6 Jahre alt. Eintritt am 25. März 1889, Austritt am 23. April 1889. Alter bei Beginn der Krankheit 51/2 Jahre. Dauer bis zum Eintritt $1 / 2$ Jahr. - Anamnese. Seit $1 / 2$ Jahre sich langsam entwickelnde Schmerzen und Schwellung im rechten Ellbogen. - Stat us praesens beim Eintritt. Gesund aussehendes Kind ohne andere nachweisbare Erkrankung. Der rechte Arm im Ellbogen flectirt gehalten. Bewegungen im Gelenk sehr schmerzhaft. - B e handlung und path. - anat. $\mathrm{B}$ e fun d. 29. März 1889. Resectio cubiti. Weiche ausgedehnte Synovialtubercnlose. Ein grosser tuberculöser Herd mit einem kirschgrossen Sequester am Humerusende, der in der Mitte des Humerus quer perforirt ist, derart, dass das äusserste Gelenkende intact geblieben ist. Auf der Vorderfläche ein Abscess mit Communication im Gelenk. - Verlauf fieberlos. Mit geheilter Wunde entlassen. 
103. Karoline Meier, 52 Jahre alt. Eintritt am 10. April 1889, Austritt am 27. Mai 1889. Alter bei Beginn der Krankheit 521/2 Jahr. Dauer bis zum Eintritt 1/2 Jahr. - A etiologie. Lungentuberculose. Trauma. - Anamnese. Patientin hat als Kind an Drtiseneiterung gelitten, ausserdem hatte sie eine eiternde Stelle am linken Ellbogen, die ganz ausheilte. Letzten Herbst bekam sie einen Stoss gegen den linken Ellbogen. Seitdem allmähliche Schwellung. Vor 1 Monate Aufbruch und Fistelbildung. - Status praesens beim Eintritt. Sehr elende, magere Frau mit einer Narbe am Hals. Dämpfung an der linken Lungenspitze. Das linke Ellbogengelenk spindelförmig geschwollen; die Kapsel verdickt; eine Fistel zwischen Olekranon und Condylus medialis. Vorn und hinten deutliche Fluctuation. Gelenk sehr schmerzhaft. - B ehandlung und path. -anat. Befund. 11. April 1889. Amputatio humeri wegen des schlechten Zustandes der Patientin. Etwa in der Mitte des Humerusgelenkendes findet sich ein kirschgrosser tuberculöser Herd. Sonstige Knochen sind intact. Weiche Synovialtuberculosc. - Verlauf aseptisch. Geheilt entlassen.

104. Friedrich Eisfelder. Eintritt am 13. Mai 1889, Austritt am 4. Juni 1889. Dauer bis zum Eintritt $1 / 2$ Jahr. - A etiol o gie. Fall auf den Ellbogen. - Anamnese. Patient fiel vor 2 Jahren auf den rechten Ellbogen. Seitdem konnte er ihn nicht mehr vollkommen strecken. Im September 1888 eine Anschwellung des Ellbogens, die incidirt wurde. Seit den letzten Wochen trat ausgedehnte Schwellung des Gelenkes ein. - Status praesens beim Eintritt. Rechter Arm sehr atrophisch. Ellbogengegend stark und spindelförmig, an der Innenseite stärker als aussen geschwollen. An der Riickseite mehrfache Fisteln. Der Arm steht flectirt. Alle Bewegungen beschränkt. Ueber beiden Lungenspitzen etwas Dämpfung und schwaches Athmen. - Behandlung und path. - anat. B efund. 5. Mai 1889. Resectio cubiti. Gelenk stark zerstört. Kapsel dicht mit tuberculöser Granulation besetzt. Radiuskopf vom Knorpel entblösst. Ein keilförmiger Infaret am äusseren Condylus des Humerus, dessen Basis nach unten gerichtet ist. - Verlauf aseptisch. Wunde bis auf kleine Stelle geheilt. In flectirter Stellung verbunden entlassen. Schlussresultat. Der Arm ist mit der Beweglichkeit von $15^{0}$ geheilt und gebrauchsfähig. Vorderarm steht zum Unterarm im stumpfen Winkel. Rotationsbewegung der Hand nicht ausführbar. Patient ist sonst gesund.

105. Dorothea 0 b erbeck, 30 Jahre alt. Eintritt am 15. Mai 1889, Austritt am 7. Juni 1889. Alter bei Beginn der Krankheit 291/2 Jahre. Dauer bis zum Eintritt $1 / 2$ Jahr. - Anamnese. Das rechte Ellbogengeleuk ist angeblich seit vorigem Herbst krank. Seit 2 Monaten bestehen Fisteln. Früher will Patientin nie krank gewesen sein. Keine hereditäre Belastung. - Status praesens beim Eintritt. Der rechte Arm in Flexionsstellung; ganzes Ellbogengelenk stark geschwollen. Teigige Consistenz. Beiderseits über dem Condylus internus und externus je eine Fistel mit eitrigem Secret. Bewegungen fast ganz aufgehoben und sehr schmerzhaft. Innere Organe anscheinend gesund. - Behandlung und path. anat. Befund. 16. Mai 1889. Resectio cubiti. Ausgedehnte Synovialtuberculose. Ein kirschgrosser Herd im lateralen Condylus des Humerus. 
- Reactionsloser Verlauf. Wunde aseptisch und in Flexionsstellung. Damit entlassen.

106. Dietrich Crasse, 52 Jahre alt. Eintritt am 31. Juli 1889. Alter bei Beginn der Krankheit 50 Jahre. Dauer bis zum Eintritt 2 Jahre. - Aetiologie. Ausgedehnte Lungenphthise. - Anamnese. Seit 2 Jahren hat sich eine Schwellung des rechten Ellbogens ausgebildet. Status praesens beim Eintritt. Sehr schwacher, magerer Mann mit schmalem flachen Thorax. Extreme Atrophie am Arm. Eine spindelförmige Schwellung am Ellbogen. Der Unterarm steht flectirt und kann activ gar nicht bewegt werden. Crepitation im Gelenk. Eine Fistel auf der Rückseite mit serös-blutigem Secret. - Behandlung und path.anat. Befund. Resectio cubiti. Die Gelenkknorpel sind ganz verschwunden. Knochen rauh und weich. Kapsel mit tuberculöser Granulation bedeckt. Am Condylus externus humeri ein alter keilförmiger Infarct. - Gleich nach der Operation traten Athmungsbeschwerden und Athmungspausen ein. Sah sehr eyanotisch aus. Bei diesem Zustande erfolgte Tod. Section ergiebt ausgedehnte alte Phthise mit Cavernenbildung. Pleuritis adhaesiva. - Schlussresultat. Patient starb gleich nach der Operation in der Klinik.

107. Conrad Beisner, 62 Jahre alt. Eintritt am 27. Juli 1889, Austritt am 2. October 1889. Alter bei Beginn der Krankheit 611/4 Jahre. Dauer bis zum Eintritt $1 / 4$ Jahr. - A etiologie. Fall auf den Ellbogen. - Anamnese. Patient ist im October 1888 auf den linken Ellbogen gefallen. Seit Anfang Sommer stellte sich allmähliche Schwellung und Schmerzhaftigkeit ein. Incision vom Arzt, wobei sich Eiter entleerte. Seitdem besteht eine Fistel. - Status praesens beim Eintritt. Gut ernährter Mann mit im Ellbogen flectirtem, wenig beweglichem Arm. Ueber dem Condylus externus eine Fistel. Ebenso eine Fistel auf der Radialseite der hinteren Fläche des Unterarmes. - Behandlung und path. - a nat. B ef und. 23. August 1889. Resectio cubiti. Am lateralen Condylus ein kirschgrosser Herd. Alle Knorpelflächen intact, nur auf der Ulnagelenkfläche theilweise zerstört. Die Kapsel von tuberculöser Granulation dicht durchwachsen. - Verlauf mit leichtem Fieber und etwas Eiterung. Mit Verband in rechtwinkliger Stellung entlassen. - Schlu s sresultat. Patient ist im Juni 1890 an Schwindsucht gestorben. Der Arm war steif und wurde immer im Tuch getragen.

108. Dorette Nose, 60 Jahre alt. Eintritt am 11. September 1889 , Austritt am 5. October 1889. Alter bei Beginn der Krankheit 591/2 Jahre. Dauer bis zum Eintritt $1 / 2$ Jahr. - Anamnese. Patientin hat viel an Husten zu leiden. Im März 1889 bekam sie Schmerzen und allmähliche Schwellung des linken Ellbogens. Im Sommer brach die Schwellung auf, und seitdem besteht eine Fistel, die mässig eitert. - Status praesens beim Eintritt. Elende Frau mit Lungenphthise und Bronchialkatarrh. Urin normal. Das linke Ellbogengelenk geschwollen. Gegentiber dem Rand des Olekranon eine Fistel, die mit dem Gelenk communicirt. Beugung und Streckung beschränkt. - Behandlung und path.-anat. Befund. 12. September 1889. Resectio cubiti. Weiche, schmierige Synovialtuberculose, die sich in die Olekranonschalen erstreckt hat. An der 
Innenseite des Olekranon ein grosser, tuberculös harter Knochenherd. Sonst sind die Knochen intact. - Aseptischer Verlauf. Mit flectirt verbundenem Arm entlassen. - Schlussresultat. Patientin ist im Juni 1890 an Entkräftung gestorben. Der operirte Arm eiterte bis zum Tode fort.

109. Heinrich B ïsch, 58 Jahre alt. Eintritt am 24. October 1889, Austritt am 22. November 1889. Alter bei Beginn der Krankheit 55 Jahre. Dauer bis zum Eintritt 3 Jahre. - A nam nese. Vor 3 Jahren zuerst Schmerzen im linken Ellbogen. Im Juni 1889 eine Schwellung, die vom Arzt incidirt wurde. Seitdem besteht Fistel mit mässigem Eiterfluss. S t a t u s p ra e s e n s beim Eintritt. Kräftiger Mann. Linkes Ellbogengelenk rechtwinklig flectirt. Bewegungen beschränkt und nur mit Schmerzen möglich. Gelenk spindelförmig geschwellt. Fistel auf der Rückseite zwischen Radiuskopf und Olekranon, die ins Gelenk führt. - Behandlung und path.-anat. Befund. 25. October 1889. Resectio cubiti. Die ganze Gelenkkapsel mit dicker Lage von tuberculöser Granulation und Fibringerinnsel erfüllt. Knorpel stellenweise abgehoben. Im Knochen kein Herd zu finden. - Das Gelenk fast geheilt und in Flexion verbunden. Damit entlassen.

110. Friedrich $\mathrm{Holstein,79}$ Jahre alt. Eintritt am j. November 1889. Alter bei Beginn der Krankheit 77 Jahre. Dauer bis zum Eintritt 2 Jahre. - Anamnese. Vor 2 Jahren soll linkes Ellbogengelenk spontan geschwollen und schmerzhaft geworden sein. Vor 2 Monaten Incision. Sonstige Angabe sehr undeutlich. - S ta t u s pra es en s beim Eintritt. Gut genährter Mann. Lungen und Urin normal. Linker Ellbogen diffus geschwollen. Beweglichkeit beschränkt. Unterhalb des Radiusköpfchens auf der Beugeseite eine Fistel und ein Abscess, die von Incision herrühren. - Behandlung und path.-anat. Befund. 8. November 1889. Amputatio humeri. Die Kapsel ist uberall mit tuberculöser Granulation besetzt. Die Knorpel theilweise zerstört. Am Radiusköpfchen befindet sich ein oberflächlicher Knochenherd ohne Sequester. - Patient war immer unruhig. Nach der Operation erfolgte Tod an Lungenödem. Section ergiebt Bronchopneumonie im rechten Unterlappen mit diffusem Lungenödem. - Schlussresultat. Nach der Operation an Lungenödem und Bronchopneumonie gestorben.

11. Minna Gese, 19 Jahre alt. Eintritt am 27. Februar 1890, Austritt am 5. April 1890. Alter bei Beginn der Krankheit 17 Jahre. Dauer bis zum Eintritt 2 Jahre. - Anamnese. Patientin wurde vor 2 Jahren hier an der rechten Schulter und dem Ellbogengelenk wegen Tuberculose resecirt. Schon damals war das linke Ellbogengelenk erkrankt. Status praesen s beim Eintritt. Gesundes Aussehen. Lungen und Urin normal. Linkes Ellbogengelenk diffus geschwollen, aber beweglich. Bei Bewegungen Crepitation. Eine Fistel am Condylus externus. Die resecirte Schulter ziemlich gut beweglich. - Behandlung und path. an at. B efund. 5. März 1890. Resectio cubiti. Lateral zwischen Radiusköpfchen und dem stark zerstörten Condylus externus humeri ein bohnengrosses Knochenstück. Diffuse tuberculöse Granulation im Gelenk. Fieberloser Verlauf. In flectirtem Verbande entlassen. - Schluss- 
resultat. Der Ellbogen war 4 Wochen nach der Operation heil, bis er vor Kurzem wieder eiterte. Der Arm ist theils wegen der steifen Schulter, theils wegen des Ellbogens nicht gebrauchsfähig. Gelenk kann gebeugt und gestreckt werden bis zu $160^{\circ}$. Pro- und Supination wenig möglich. $4 \mathrm{Cm}$. Verkurzung und erhebliche Abmagerung. Geschwür am Sternum und fortwährender Husten.

112. Minna Muddelkamp, 12 Jahre alt. Eintritt am 2. Mai 1890, Austritt am 13. Juni 1890. Alter bei Beginn der Krankheit 9 Jahre. Dauer bis zum Eintritt 3 Jahre. - Aetiologie. Lungenleiden. Anamnese. Patientin hatte früher Lungenentzundung. Seit 3 Jahren allmähliche Schwellung des rechten Ellbogens. Seit einiger Zeit ist die rechte Wange dick. - Status praesens beim Eintritt. Rechtes Ellbogengelenk stark geschwollen, besonders zu beiden Seiten der Ulna. Dort Fluctuation. Vorderarm steht in Flexion. Bewegungen beschränkt und schmerzhaft. Lungen zweifelhaft. Urin normal. - Behandlung und path.-anat. Befund. Resectio cubiti. Ein kirschgrosser Granulationsherd an der Ulna; dicht unter dem Tricepsansatz noch ein grosser Herd an der Vorderseite der Ulna, am Processus coronoidalis beginnend, der sich etwa $1 \frac{1}{1} 2 \mathrm{Cm}$. nach oben erstreckt und einen Defect bewirkt hat. Im Uebrigen besteht eine schmierige Synovialtuberculose mit halborganisirten Fibrinmassen. - Vollkommen aseptischer Verlauf. Wunde fast heil. Arm krumm verbunden. Damit entlassen. - S chlussresultat. Ellbogengelenk eitert noch. Es wurde eine 2. Operation auswärts vorgenommen. Arm ist schwach und beschränkt gebrauchsfähig. Gelenk fast steif. Rotationsbewegung der Hand wenig ausfiuhrbar. Verkürzung $10 \mathrm{Cm}$. Abmagerung wenig. Patientin hat Drüsenschwellung am Hals. Vom Unterkiefer wurde ein Knochenstulck entfernt.

113. Lisbeth Hubner, 39 Jahre alt. Eintritt am 3. October 189u, Austritt am 6. December 1890. Alter bei Beginn der Krankheit 37 Jahre. Dauer bis zum Eintritt 2 Jahre. - Anamnese. Seit 2 Jahren fortwährender Husten. Angeblich vor 2 Jahren plötzlich Schmerzen im rechten Ellbogengelenk. Dann allmähliche Anschwellung desselben. Seit Ostern 1890 bestehen Fisteln. - Status praesens beim Eintritt. Gesund aussehendes Mädchen. Lungen und Nieren gesund. Das rechte Ellbogengelenk geschwollen und in Flexion stehend. Die Bewegungen beschränkt. Fluctuation auf dem Radiusköpfchen. Eine mit Schorf verklebte Fistel auf dem medialen Condylus. - Behandlung und path. - anat. Be fund. 4. November 1890. Resectio cubiti. Alle Gelenkflächen oberflächlich stark zerstört. Ein käsiger Herd in der Mitte des Humerusgelenkendes. - Fieberloser Verlauf. Mit Verband in flectirter Stellung entlassen.

114. Katharina Hartmann, 65 Jahre alt. Eintritt am 4. Juli 1882, Austritt am 11. August 1882. Alter bei Beginn der Krankheit 643/4 Jahre. Dauer bis zum Eintritt $1 / 4$ Jahr. - Anamnese. Aus gesunder Familie stammend. Angeblich seit Pfingsten 1890 eine ohne besondere Veranlassung langsam zunehmende Schwellung des rechten Ellbogens. Im Laufe der Zeit Aufbruch. Seitdem besteht Fistel. - Status praesens beim Eintritt. Starke Schwellung des rechten Ellbogens, die spindel- 
förmig nach oben und unten abnimmt. Eine Eiter secernirende Fistel, eine grosse auf der Rickenseite neben dem Olekranon und auf der Beugeseite. - Behandlung und path.-anat. Befund. 4. Juli 1892. Resectio cubiti. Ausgedehnte Synovialtuberculose mit Eiter im Gelenk. Ein Knochenherd mit 8 vollständig gelösten Sequestern im Gelenktheile des Humerus. Daranf folgende secundäre Amputatio humeri. - Verlauf ohne Fieber. Es trat wenig Eiterung ein. Patientin ist immer unruhig. Urin mit Jodoform. Beschleunigter Puls. Wegen fortwährender Eiterung Amputatio humeri vorgenommen. Verlauf günstig. Mit Verband entlassen.

115. Carolina Drage, 59 Jahre alt. Eintritt am 12. Februar 1894, Austritt am 9. März 1854. Alter bei Beginn der Krankheit 58 Jahre. Dauer bis zum Eintritt 1 Jahr. - An amnese. Seit 1 Jahre eine langsam zunehmende Erkrankung des rechten Ellbogengelenkes. Patientin ist sonst angeblich gesund. - Status praesens beim Eintritt. Das rechte Ellbogengelenk steht in Flexion; ausgiebige Beugung ohne Schmerzen. Pro- und Supination sehr schmerzhaft. Starke Schwellung. Vom Gelenk aus perforirende Abscesse am Vorder- und Oberarm, auch dem Radioulnalgelenke entsprechend. - Behandlung und path.-anat. Befund. 14. Februar 1884. Resectio cubiti. Zuerst Incision und Auskratzung von allen verschiedenen Abscessen. Diffuse Synovialtuberculose. Kleiner Herd an der Basis des Olekranon, der ins Gelenk perforirt. Sonst Knochen intact. - Verlauf aseptisch. Flectirt verbunden zur poliklinischen Behandlung entlassen.

\section{Allgemeiner Theil.}

Die Gesammtzahl derjenigen Kranken, welche innerhalb einer fünfzehnjährigen Zeitperiode (vom April 1875 bis December 1890) in die chirurgische Klinik zu Göttingen aufgenommen und dort kurze oder lange Zeit behandelt worden sind, bei denen die Diagnose auf eine tuberculöse Erkrankung des Ellbogengelenkes gestellt wurde, beträgt 137. Die Zabl der ỉberhaupt wegen Fungus cubiti zur Behandlung gekommenen Patienten würde sich noch höher stellen, wenn es möglich gewesen wäre, auch die Kranken, welche in der Poliklinik behandelt worden sind, mit in die Rechnung hineinzuziehen; das habe ich absichtlich nicht gethan, weil die Zahl der mir bei meiner Arbeit zur Verfügung stehenden Patienten gross genug ist, so dass ich eine endguiltige statistische Angabe erzielen kann. Die Erkrankung betraf $74 \mathrm{mal}=54$ Proc. die rechte Seite, und $61 \mathrm{mal}$ $=44,5$ Proc. die linke Seite, während nur $3 \mathrm{mal}=1,5$ Proc. eine gleichzeitige Erkrankung beider Ellbogengelenke desselben Individuums beobachtet worden ist.

Von den 137 Kranken waren männlichen Geschlechtes $63=$ 46 Proc., weiblichen Geschlechtes $74=54$ Proc. 
Es ist ein solches Ueberwiegen der Patienten des weiblichen Geschlechtes nichts Gewöhnliches, indem in der Regel bei sonstigen tuberculösen Gelenkaffectionen die männlichen Kranken ziemlich weit za uberwiegen pflegen. Ob bei meinen Fällen zufällige Ereignisse, oder ob andere Griunde vorgelegen haben, wonach ich solches beurtheilen sollte, vermag ich nicht $\mathrm{zu}$ entscheiden.

Man hat bekanntlich meist erhebliches Ueberwiegen der männlichen Kranken bei anderen Erkrankungen des Gelenkes auf häufiges Zustandekommen des Traumas zurickzuführen versucht. Das ist wohl anzunehmen, dass die männlichen Personen wegen der Verschiedenheit ihrer Lebensweise in anstrengenden Arbeiten von der des weiblichen Geschlechtes leichter einer Verletzung ausgesetzt sind. Infolgedessen kann ein günstiger Boden für die Localisation der Krankheit, mit anderen Worten "locus minoris resistentiae" am Knochen und Gelenke herbeigefiihrt werden. Das ist bei den 16 Kranken auch der Fall gewesen, bei denen angeblich das Trauma, sei es dass es sich um einen Fall, Schlag oder Stoss auf den Ellbogen handelte, der Erkrankung vorausgegangen ist, wie man in der folgenden Zusammenstellung sehen kann.

Das Trauma hat $13 \mathrm{mal}=81$ Proc. das männliche Geschlecht, $3 \mathrm{mal}=19$ Proc. das weibliche Geschlecht betroffen.

Indessen braucht man sich nicht darüber zu wundern, dass die Zahl der männlichen Patienten, trotz der oben angedeuteten Thatsache, so viel weniger beträgt, als die Zahl der weiblichen, da die Zahl der Kranken, deren Krankheit ein Trauma zu Grunde lag, zu klein ist, um auf die Gesammtzahl Einfluss haben zu können. Ob es, abgesehen vom Trauma, noch irgendwie eine mir unbekannte Veranlassung für das Ueberwiegen des weiblichen Geschlechtes bei der Ellbogengelenktuberculose giebt, lasse ich dahingestellt sein.

Aetiologie.

Was die Aetiologie anbelangt, so ist sie am häufigsten eine Theilerscheinung der tuberculösen Erkrankung der anderen Organe, sei es dass es sich um die Tubereulose der inneren Organe, besonders der Lunge, oder um die Tuberculose der Haut, Knochen und Gelenke u. s. w. handelt. Aber bei einer kleinen Anzahl der Fälle, welche mir bei meinem Material zu Gebot standen, war die Ellbogengelenktuberculose zweifellos bei anscheinend gesunden Menschen infolge eines Traumas, welches das Ellbogengelenk betroffen hat, zum Ausbruch gelangt. Es ist aber nicht unmöglich, dass es sich bei solchen anscheinend gesunden Menschen an irgend einer Stelle des Körpers 
um eine verkäste Lymphdrüse handelt, wie z. B. bei Bronchiallymphdrüsen oder bei Mesenteriallymphdrüsen, welche wir mit unseren Augen oder durch sonstige Untersuchungsmethoden nicht leicht entdecken können. Von da aus können sich die Tuberkelbacillen metastatisch an der Stelle, wo das Trauma für ihre Ansiedelung glinstigen Boden geschaffen hat, niederlassen.

Jedoch ist damit nicht gesagt, dass die Tuberculose der Knochen und des Gelenkes immer metastatisch sein muss. Es ist schon ron verschiedenen Seiten aus dem Sectionsbefund festgestellt worden, dass die Tuberculose der Knochen und des Gelenkes zweifellos primär, nicht nur bei schwachen Individuen, sondern bei ganz kräftigen, blühenden Leuten sich entwickeln kann.

Was die hereditäre Belastung betrifft, so möchte ich nicht schweres Gewicht darauf legen, weil den Angaben der Kranken in dieser Beziehung nicht viel Vertrauen geschenkt werden kann. Aber es ist nicht zu leugnen, dass diejenigen Individuen, deren Mutter oder Vater an Lungen- oder sonstiger Tuberculose zu Grunde gegangen sind, irgendwie eine Constitutionsanomalie vererben können, denn solche Leute sind gegen die Tuberkelbacillen weniger widerstandsfähig, als die Menschen, welche aus ganz gesunder Familie stammen. Obwohl, wie erwähnt, auf diese Fälle kein schweres Gewicht zu legen ist, möchte ich doch diese hereditäre Belastung durch eine Zahlenangabe kurz erläutern. Ich scheide die ätiologischen Momente in 4 Gruppen:

1. Die Tuberculose der Lunge, Haut, Lymphdrusen, Knochen und Gelenke, welche der Ellbogengelenktuberculose vorausgingen. $57 \mathrm{mal}=41,5$ Proc.

2. Trauma: $16 \mathrm{mal}=12$ Proc.

3. Hereditäre Belastung: $8 \mathrm{mal}=6$ Proc.

4. Unbekannte Ursache bei anscheinend gesunden Menschen: $56 \mathrm{mal}=40,5$ Proc.

Indessen wissen wir nichts Genaues uber die Kranken, welche in diese letzte Gruppe eingerechnet sind, ob es sich bei ihnen nicht etwa um eine Tuberculose an irgend einer Stelle des Körpers bandelt, welche bei unserer Untersuchung ubersehen worden ist.

\section{Alter der Kranken.}

Unter den 137 wegen Ellbogengelenktuberculose behandelten Kranken begann die Erkrankung:

vor dem 10. Lebensjahre: $\quad 34 \mathrm{mal}=25$ Proc.

Zwischen dem 10.-20. Lebensjahre: $27 \mathrm{mal}=20=$

Deuteche Zeltschrift f. Chirurgle. XXXV. Bd., 
Zwischen dem 20.-30. Lebensjahre: $16 \mathrm{mal}=12$ Proc.

$\begin{array}{lllll}= & =30 .-40 . & = & 21 \mathrm{mal}=15= \\ = & =40 .-50 . & = & 11 \mathrm{mal}=8= \\ = & =50 .-60 . & = & 19 \mathrm{mal}=14= \\ = & =60 .-70 . & = & 9 \mathrm{mal}=6 \text { Proc. }\end{array}$

Diese Zahlen sprechen so deutlich ftir sich, dass es keiner Auseinandersetzung bedarf. Aber es ist doch zu beachten, dass die Tuberculose des Ellbogengelenkes keinesweges mit der Alterszunahme abnimmt, sondern im Gegentheil bei ziemlich hohem Alter vorkommt, wie die Zahlangabe zwisehen dem 50.-60. Jahre daftur den Beweis liefert. Bei ihrem Eintritt in die klinische Bebandlung befanden sich im Alter:

$\begin{array}{lll}\text { Unter } 10 \text { Jahren: } & 29=21,5 \text { Proc. } \\ \text { Zwischen } 10-20 \text { Jahren: } & 20=18,5= \\ =20-30= & 17=12,5= \\ =30-40= & 21=15,5= \\ =40-50= & 14=10= \\ =50-60= & 18=13= \\ =60-70= & 12=9 \text { Proc. }\end{array}$

Symptome und Verlauf.

Die Ellbogengelenktuberculose verläuft für gewöhnlich sehr langsam mit mehr oder weniger ähnlichen Erscheinungen. Das Gelenk schwillt oft nach einer ganz geringen Verletzung des Ellbogens allmählich an. Der Fall, dass tuberculöse Erkrankung nach einer schweren Verletzung eintritt, ist im Grossen und Ganzen selten. Die Schwellung beschränkt sich unter Umständen auf eine Stelle, oder sie nimmt die ganze Ausdehnung der Gelenkgegend ein und verbreitet sich anf die hintere Fläche oberhalb des Olekranon, unten und $z \mathfrak{u}$ beiden Seiten der Tricepssehne. Wenn die Synovialis erkrankt, wie das in den meisten Fällen geschieht, so pflegt man am deutlichsten die elastische Schwellung zwischen dem Radiuskopf und dem lateralen Rand des Olekranon und auch in der Gegend des Sulcus fur den Ulnarnervus zu fuhlen. Die Form der Schwellung ist in manchen Fällen deutlich spindelförmig, da die Muskeln am Oberund Vorderarm infolge des Nichtgebrauchs abmagern. Es kann die Schwellung auf eine Stelle, so öfter auf den Condylus beschränkt bleiben. Sie kann sehr minimal sein, ja sogar ganz fehlen. Man kann unter Umständen an beiden Seiten der Tricepssehne die verdickte Kapsel deutlich fiuhlen.

Die Functionen des erkrankten Armes werden mehr oder weniger beeinträchtigt. Der Arm wird im Ellbogengelenke meistens recht- 
winklig oder stumpfwinklig flectirt gehalten. Die Bewegungen der Hand im Sinne der Pro- und Supination können anch mehr oder weniger beschränkt werden, also befindet sich das Ellbogengelenk im Zustande der Contractur, ja sogar der Ankylose. Das Gelenk ist bei Druck und Bewegungsversuchen fast immer schmerzhaft, besonders wenn es sich um einen ostalen Process handelt. Spontanluxation kommt zuweilen am Radiuskopfe vor. Die Fistelbildung, welche sehr häufig aus der Gelenktuberealose entspringt, kommt hier auch in den meisten Fällen zur Geltung. Unter den 137 Fällen, die ich zusammengestellt babe, befanden sich 72 Fälle $=53$ Proc., uber die Hälfte der sämmtlichen Fälle, welche frther oder später zur Fistelbildung kamen. Die Fisteln kamen von selbst nach dem Aufbruche eines Abscessus zu Stande oder rührten von der Incision her, welche meistens auswärts vom Arzte gemacht worden war. Die Stelle, wo die Fisteln meistens zur Entstehung kommen, ist hinten zwischen Radius und Ulna, sodann hinter dem Condylus internus, öfter auch, wenn ein tuberculöser Abscess aufbricht, welcher vom localen, ostalen Process ausgeht, auf den Condylen, ja sogar unter Umständen auf dem Olekranon. Der Abscess, der bei der Ellbogengelenktuberculose zu Stande kommt, kann pararticulär oder Senkungsprocess sein. Er kann sich den Radius entlang nach unten erstrecken und am Vorderarm auf der lateralen Seite eine Schwellung zeigen, oder es kann sich der Abscess auf der Hinterfläche der Gelenke zeigen. Die Zahl derjenigen Krankheitsprocesse der Ellbogengelenktuberculose, welche mit Abscessbildung am Gelenk oder in dessen Umgebung verliefen, betrug unter den 137 Fällen $48=35$ Proc. Es giebt unter Umständen sebr rasch verlaufende Fälle von tuberculöser Entzündung am Ellbogengelenk mit früherer Destruction der Knochen und Weichtheile. In anderen Fällen bleibt die Schwellung und Functionsstö. rung sehr gering, und es dauert lange Zeit, ehe sich Fisteln bilden. Nun bleibt es mir noch uibrig, Hydrops tuberculosus mit Fibrinausscheidung zu erwähnen. Hydrops tuberculosus kommt im Ellbogengelenk gelegentlich vor, wie das bei anderen Gelenken, z. B. am Kniegelenke, häufiger ist. Das ist aber im Grossen und Ganzen selten. Die Diagnose ist in solchen Fällen nicht leicht, da die Synovialis in der Regel enorm anschwillt und es schwer werden kann, diese Schwellung von einer Knochenschwellung zu unterscheiden. Der Verlauf der Ellbogengelenktuberculose ist im Allgemeinen ein sehr langsamer. Dabei kann es sehr lange andauern, ehe die ärztliche Hülfe in Betracht kommt. In meiner Zusammenstellung habe ich als durchschnittliche Dauer vom Anfang der Erkrankung bis zum Eintritt in 
die Klinik 2 Jahre und 1 Monat gerechnet. Bei dieser Rechnung betrug das Maximum 16 Jahre, das Minimum 1 Monat. Es ist selbstverständlich die Richtigkeit dieser Zahlangabe nur eine relative, weil es für den Laien nicht leicht ist, solche allmählich entstehende Erkrankung von Anfang an sicher bemerken zu können. Es würde sich diese Zahl in Wirklichkeit noch höher stellen, wenn man von den Kranken genau den Anfang ihrer Erkrankung erfahren könnte.

\section{Pathologisch-anatomischer Befund.}

Die Ellbogengelenktuberculose kann, wie es bei den anderen Gelenken der Fall ist, in „2 Formen eintreten. Eine Form ist die, in welcher der tuberculöse Process sich nur auf die Synovialis beschränkt und hier hauptsächlich Veränderung erzeugt, während der Knorpel und zum Theil der Knochen auch erst secundär in Mitleidenschaft gezogen zu werden pflegen. Die zweite Form ist die, welche primär den Knochen angreift und hier eine localisirte Veränderung verursachen kann. Erst dann, wenn dieser Process weiter vorschreitet und in die Gelenkhöhle durchbricht, entsteht eine Communication zwischen dem Process und der Gelenkhöhle. Infolge deren entsteht eine Inficirung der Synovialis. Es können diese beiden Formen gleichzeitig auftreten, und man würde auf Schwierigkeiten stossen, wenn man ermitteln wollte, welcher Process primär und welcher secundär ist. Es kann der ostale Process in demselben Gelenke nur bei einem Knochen sich localisiren, oder zugleich in verschiedenen Knochen, oder bei einem Knochen zuerst, bei dem zweiten später. Ausserdem kommt die Tuberculose in der Form von Hydrops tuberculosus vor, welcher im Gelenk durch mehr oder weniger Flussigkeit, Faserstoffe, Reiskörper, zottenartige Wucherung u. s. w. charakterisirt wird. Es kann sich diese Form zu ostalem Process oder zu synovialem Process gesellen, aber sie ist im Grossen und Ganzen seltener, als z. B. im Kniegelenk. Unter den 131 Fällen ist die Form von Hydrops tuberculosus 6 mal bei ostalem Processe, 4 mal bei synovialem Processe gefunden. Also im Ganzen $10 \mathrm{mal}=7$ Proc. Nachdem ich die Form der tuberculösen Erkrankung kurz auseinandergesetzt babe, kann ich nun auf die statistische Zahlangabe mit Bezug auf die synovialen Erkrankungen, resp. auf ostalen Process und endlich auf die Verschiedenheit der Localisation, je nachdem die Knochen verschieden sind, zu sprechen kommen. Die 131 operirten Fälle vertheilen sich in folgende Zahlen:

1. Knochenherde $91=71$ Proc.

2. Synovialer Fungus $37=29$ Proc. 
In den 6 Fällen, welche nicht operirt worden sind, lässt sich nichts Sicheres ther die ursprungliche Form der Erkrankung sagen. Ausserdem handelt es sich um 3 Fälle, bei denen das Gelenk sicher zerstört war, die ich infolgedessen nicht in die Rechnung hineinziehen konnte. Jedenfalls lag in diesen Fällen eine ausgedehnte Zerstörung der Gelenkenden vor, und es ist nicht ausgeschlossen, dass ein solcher Process ursprünglich ein ostaler gewesen ist. Wenn ich diese 3 Fälle in die Rechnung des ostalen Processes mit aufnehmen wurde, so wtirde sich naturlich der Procentsatz etwas höher stellen. Es ist bisweilen sehr schwer zu unterscheiden, ob man es mit Synovialprocessen oder Ostalprocessen zu thun hat. Die Präparate, welche meiner Statistik zur Verftgung standen, sind grösstentheils von Herrn Prof. König sehr sorgfältig untersucht worden. Zum Theil bin ich durch die Krankengeschichte unterrichtet worden, welche meistens genau und eingehend aufgezeichnet war. Nachdem ich jetzt das Verhältniss der Procentsätze beim ostalen und synovialen Processe summarisch angegeben habe, werde ich nun auf die Verschiedenheit der Localisation in jedem Knochen eingeben:

Von $91=71$ Proc. befanden sich $43=47$ Proc. am Humerus, $36=40$ Proc. am Olekranon resp. Ulna und $2=2$ Proc. am Radius.

Dagegen $9=10$ Proc. gleichzeitig an Humerus und Ulna und $1 \mathrm{mal}=1$ Proc. an Radius und Humerus. Also kommt die ostale Tuberculose im Ellbogengelenk am bäufigsten am Humerus und am Olekranon und Ulna, am seltensten am Radius vor. Die am bäufigsten befallene Stelle am Humerus ist nach meiner Statistik der Condylus externus humeri. Unter $43 \mathrm{mal}$ kamen 21 am Condylus externus, 12 am Condylus internus vor, während 10 in der Mitte des Humerus vorkamen. Am Humerus kommt der tuberculöse Herd, wie ich eben erwähnt habe, an verschiedenen Stellen des Gelenkes vor. Wenn der Herd in der Mitte des Humerus seinen Sitz hat, so perforirt er öfter entweder in die Fossa intercondyloidea, oder in die Fossa olecrani, weil diese Stelle viel dunner als andere Theile ist. In diesem Falle bildet sich eine Communication des Granulationsherdes mit der Gelenkhöble, und dadurch kann sehr leicht die Synovialis tuberculosa zu Stande kommen. Es kann der Process im Condylus externus humeri entstehen und von da aus ins Gelenk perforiren, oder, wenn er sehr weit oben sitzt, in das pararticuläre Gewebe durchbrechen, wodurch ein pararticulärer Abscess zur Entwicklung kommt. Es kann der ganze Condylus durch den Granulationsherd zerstört werden. Die Stelle an der Ulna, wo tuberculöse Herde am häufigsten beobachtet worden sind, ist die innere Fläche des Olekranon, die Cavitas sig- 
moidea major, in welcher bohnengrosse, wallnussgrosse oder noch grössere Herde sitzen können mit mehr oder weniger gelöstem Sequester. Diese Granulationsherde perforiren in der Regel in die Gelenkhöhle. Der Process kann sich auch an dem inneren oder äusseren Rande der Cavitas sigmoidea major localisiren und schliesslich einen Defect von verschiedener Grösse erzeugen. Ausser an oben angegebenen typischen Stellen können noch in wenigen Stellen tuberculöse Herde weiter unten nach der Ulna zu oder ganz auf der Hinter. fläche des Olekranon zu Stande kommen, wobei öfter der Abscess pararticulär verlaufen kann. Am und im Radius kommt die Herderkrankung äusserst selten vor. Ich habe an meinen 131 nur $3=$ 2 Proc. gefunden.

Die Formen der tuberculösen Herde sind sehr verschieden, bald unregelmässig, bald rundlich oder oval. Der interessanteste Fall ist der, wenn der tuberculöse Herd keilförmig ist. Herr Prof. König hat zuerst auf diese Form aufmerksam gemacht. Dieselbe kommt daher, dass die tuberculösen Pfröpfchen, kleine käsige Masse mit Tuberkelbacillen, welche irgendwo im Körper vorhanden gewesen sind, auf dem Wege der arteriellen Blutbahn in den Knochen hineingeschleppt und hier in einem kleinen Gefässe stecken geblieben sind. Es wäre noch eine andere Möglichkeit, nämlich, dass sich die Tuberkelbacillen zuerst in der Wand der Gefässe localisiren, dann durch weitere Wucherung das Lumen derselben verengern, ja sogar ganz verschliessen, wie es gelegentlich bei der Niere beobachtet worden ist, wodurch die Circulation in hohem Grade gehindert und eine weitere Zerstörung des Knochengewebes herbeigefübrt werden mussste. Bei fast allen Fällen der ostalen Processe war die Synovialis in grösserem oder geringerem Grade erkrankt, da der ostale Process im Laufe der Krankheit endlich in das Gelenk durchbricht, oder irgendwo Communication der Knochenherde mit der Gelenkhöhle zu Stande kommt. Ein anderer Fall ist, dass der Process zuerst ins pararticuläre Gewebe durchbricht und von da aus die Synovialis inficirt.

\section{Behandlung.}

Die Behandlung möchte ich in 2 grosse Gruppen theilen, je nachdem von einer eingreifenderen oder einer wenig eingreifenden Methode Gebrauch gemacht worden ist. Zu der letzteren Gruppe rechne ich die Behandlung mit Gypsverband, ferner die Injection von Jodoformglycerin, sowie Incision des Abscesses und die Auskratzung der tuberculösen Granulation und endlich noch eine partielle Resection.

Als eingreifende Behandlungsmethode betrachte ich die Amputa- 
tion und die typische Resection. Unter dem Ausdrucke partielle Resection verstehe ich diejenige Operation, bei welcher das Gelenk zur Auffindung und Beseitigung eines Krankheitsherdes ausgiebig geöffnet wurde, um die Entfernung solcher Herde aus dem Knochen oder dem erkrankten Theile der Synovialis vorzunehmen, ohne dabei Knochen abzutragen, wie es bei der typischen Resection geschieht, sondern nur eins der 3 Gelenkenden oder einen Theil desselben Knochenendes. Jodoforminjection ins Gelenk, welche in der letzten Zeit vielfach fur Gelenktuberculose angewandt wurde, und auf die infolge einiger gthstiger Resultate grosser Werth gelegt wurde, haben wir bei unseren Eällen wenig angewendet. Es wurde Jodoformglycerin nur für 2 Kranke gebraucht. Einer Kranken wurde Jodoformglycerin wegen des schlechten Allgemeinbefindens wiederholt injicirt, aber es trat keine Besserung ein, und sie starb nach einem Jahre an Lungenphthise. Dem zweiten Kranken mit Lungenveränderung wurde wiederholt Jodoform injicirt, doch auch in diesem Falle ohne Erfolg. Der jetzige Befund fehlt. Es sind in neuer Zeit 3 Fälle, bei denen in der hiesigen Klinik Jodoformglycerin injicirt worden ist, mitgetheilt worden. Bei 2 Kranken wurde die Besserung erzielt. Es ist schon lange bekannt, dass Jodoform die Fähigkeit hat, local verstanden, Tuberkelbacillen zu vernichten. Deswegen hat man vielfach Versuche damit gemacht und gunstige Resultate erzielt. Aber ich denke mir, dass Jodoformglycerin nicht in allen Gelenken wegen der grossen Verschiedenheit des Baues derselben ein und dieselbe Wirkung hervorbringen kann. Denn eben bei complicirter Lage der Gelenke, wie z. B. der Ellbogengelenke, dürte es wohl nicht überallhin zugänglich sein.

Gypsverband oder sonstige feste Verbände sind in sehr wenigen Fällen versucht worden. Ich kann kein sicheres Urtheil in Bezug auf ibre Wirksamkeit bei der Ellbogengelenktuberculose fällen. Es ist nur zweimal ein Gypsverband angelegt worden. Eine Kranke ist ohne Besserung entlassen und bald an Lungentuberculose gestorben. Der andere wurde zuerst incidirt und dann in einen Gypsverband gelegt und dadurch etwas gebessert entlassen, starb jedoch 1 Jahr nachher an einem Lungenleiden. Ausserdem weiss ich von 11 Fällen, welche zum Theil in der Poliklinik, zum Theil auswärts mit Gypsverband behandelt sind, bei denen aber keine Besserung eingetreten ist, so dass schliesslich bei allen zum operativen Eingriff geschritten werden musste. In 8 Fällen ist Amputatio humeri vorgenommen worden, nicht wegen des hohen Alter's der Patienten, sondern hauptsächlich wegen der ausgedehnten Zerstörung des Gelenkes und der 
vorgeschrittenen Tuberculose der inneren Organe. Darunter ist in 7 Fällen primär und in 1 Fall secundär nach der Resection, welche nicht zum gewunschten Ziele fuhrte, amputirt worden. Ein Ueberblick uber die gemachten Behandlungsmethoden wird sich folgendermaassen gestalten:

A. Fälle, welche mit der wenig eingreifenden Methode behandelt wurden, sind $21=15$ Proc.

1. mit Gypsverband . . . . 2,

2. Incision u. s. $\mathbf{w}$. . . . . 17,

3. Jodoformglycerin . . . . 2.

B. Die Fälle, welche mit eingreifender Methode behandelt wurden, sind $116=85$ Proc.
1. Resectio . . . . . . 108,
a) Nach Langenbeck. . 94,
b) Nach König . . . . 14.
2. Amputatio humeri . . . 8.

Also kamen 15 Proc. wenig eingreifende Methode, 85 Proc. eingreifende Methode zur Anwendung.

Im Folgenden beabsichtige ich kurz die Methode der Resection, welche bei unseren Fällen in Betracht kommt, zu erwähnen, obwohl sie schon bekannt ist. Ich unterscheide hier zwei Methoden der Resection, eine von Langenbeck und die andere von Prof. König.

Die Methode von Langenbeck, welche in der chirurgischen Klinik in 94 von unseren Fällen gebraucht worden ist, ist folgende. Der Schnitt, welcher das Gelenk eröffnet, von dem aus man die Losschälung der Weichtheile vom Knochen vornehmen soll, verläuft auf der Rickseite des Ellbogens, ungefähr in der Mitte der Hinterfläche des Olekranon und etwas nach innen von dessen Mitte. Er dringt sofort durch den Triceps bis auf den Knochen und ebenso auf dem Olekranon bis zu demselben ein. Die Länge dieses Schnittes ist verschieden, 8-10 $\mathrm{Cm}$., je nachdem die Schwellung mehr oder weniger stark vorhanden ist. Nun beginnt man sämmtliche Weichtheile zwischen dem Olekranon und dem Condylus internus scharf vom Knochen abzutrennen. Dazu gebraucht man. gewöhnlich die Pincette und das Knochenmesser, oder auch man spannt die Theile durch den Fingernagel an und schneidet direct vor dem Knochen, mit fast senkrecht auf denselben gerichteten kurzen Schnitten Alles, was sich spannt, ab. Nur hier und da kann man, besonders auf der Ulna, das Elevatorium benutzen. Auf diese Weise gelingt es, den Ulnalnerven mit allen Weichtheilen auf dem Knochen uiber den Condylus internus humeri hinwegzuschieben, ohne dass man ihn zu sehen 
bekommt. Ist man bis an den Epicondylus internus gekommen, so sollen die Muskelinsertionen in Verbindung mit dem Periost und dem Ligamentum internum in der gleichen Weise hart vom Knochen abgetrennt werden.

Hat man so den inneren Abschnitt des Gelenkes blossgelegt, so verrichtet man das Gleiche auf der lateralen Seite. Man lässt die Weichtheile vorläufig wieder auf ihr Knocbenlager zurïckgleiten und beginnt nun die Tricepssehne von ibrer Verbindung mit dem Olekranon und der Ulna, im Zusammenhang mit dem Periost und dem sich an der Aussenseite der Ulna inserirenden Muskel (Anconeus quartus), immer streng am Knochen operirend, mit Pincette und Messer, nur abwcchselnd mit dem Elevatorium, abzulösen. Schliesslich kommt man am Condylus externus und den sich bier inserirenden Muskeln an. Auch diese werden in Zusammenhang mit Periost und Ligamentum externum abgelöst. Die Weichtheile werden mit kurzen krummen, nicht zu scharfen Doppelhaken zurickgehalten. Ist keine erhebliche Schwellung da, so lässt man den Humerus bei starker Flexion zu Tage treten und sägt ihn mit der Blattsäge ab. Dann folgt die Abtragung der Vorderarmknochen. Darauf zunächst die Säuberung des Gelenkes von der fungösen Granulation. Man schabt dieselbe mit dem scharfen Löffel ab und schneidet das Kranke mit der Scheere aus. In die operirten Gelenke wird vor der Naht und Anlegung der Drainage Jodoformpulver gestreut und eingerieben, da die Heilung ohne Wiederbildung tuberculöser Granulation dadurch entschieden besser garantirt wird. Der Verband ist zum Theil nach Lister, zum grossen Theil aber mit einfachen Mooskuchen angelegt worden, welcher letztere wegen seiner Bequemlichkeit vor dem ersteren grossen Vorzug hat. Der Arm wird unbedingt wenigstens $3-4$ Wochen lang in gestreckter Stellung und in supinirter Stellung der Hand verbunden gehalten, damit das Aneinandervorbeigleiten der resecirten Theile sicher vermieden wird. Erst dann, wenn die resecirten Knochen durch Knochenbildung und durch Verwachsung der Weichtheile festen, sicheren Halt gefunden haben, muss man in flectirter Stellung bei supinirter Hand verbinden.

Die zweite Methode, welche von Herrn Prof. Kö ni g vorgeschlagen wurde, weicht von der ersten dadurch ab, dass man hier einen grossen Theil des Olekranon und die Epicondylen erhalten kann. Die Operation lässt sich ziemlich rasch so ausführen, dass man von einem auf der Innenseite des Gelenkes, ähnlich dem Langen beck'schen, geftihrten Schnitte aus nicht das Periost und sonstige Theile von der Ulna und dem Olekranon, sondern mit demselben durch einen breiten 
Meissel die Aussenschale des Knochens abschält und sie in Verbindung mit der Tricepssehne lässt. In gleicher Weise wird nach Lösung des Ulnalnerven der Epicondylus internus mit dem Meissel abgeschlagen und mit den an ihm bängenden Weichtheilen in Verbindung gelassen, und ebenso der Epicondylus externus abgestemmt. Man spart auf diese Weise die ja immer schwierige Abstemmung der Weichtheile von den betreffenden Knochen.

Schlussresultate.

Um die Endresultate der eingreifend oder wenig eingreifend operativ behandelten Kranken zu ubersehen, ist es am besten, folgende Kategorien zu unterscheiden.

Vollkommene Heilung mit mehr oder weniger Beweglichkeit . 48

Unvollkommene Heilung mit zurlickgebliebener kleiner Fistel und beschränkter Gebrauchsfähigkeit . . . . . . . 8

Heilung durch Amputatio . . . . . . . . . . . 6

Todesfälle . . . . . . . . . . . . . . 38

Unbekannte Fälle ...................... . . . . .

Zur ersten Gruppe rechne ich diejenigen Fälle, bei denen die Krankheitsprocesse ganz ausgeheilt sind, obwohl sie mannigfache Verschiedenheit in Bezug auf die Function des operirten Armes darbieten. Auf die Einzelheiten der Functionsverhältnisse werde ich erst später noch einmal zurückkommen.

Unter der zweiten Gruppe der unvollkommenen Heilung fasse ich diejenigen Fälle zusammen, bei denen die Krankheitsprocesse entweder seit der Entlassung gar nicht zur Heilung gekommen sind, oder, wenn sie auch eine Zeit lang, etwa 2-5 Jahre, ganz ausgeheilt waren und gebrauchsfähig wurden, wieder von Neuem zur Schwellung, zur Eiterung und zur Fistelbildung führten.

Unter die dritte Gruppe sind die Kranken gerechnet, welche primär, das heisst ohne vorausgegangene Operation amputirt und geheilt entlassen wurden.

Unter die Gruppe der Todesfälle habe ich die Kranken zusammengefasst, bei welchen der Tod entweder gleich nach der Operation eintrat, oder im Laufe der Jahre nach der Entlassung, infolge einer anderen Krankheit, oder infolge der bei der Behandlung schon vorhandenen Krankheit der inneren Organe, besonders der Lunge, der Niere u. s. w.

An Unbekannten sind, trotz meiner mannigfachen Ermittlungsversuche, noch 34 Fälle zu verzeichnen.

Die Zahlenangaben, die ich oben gemacht babe, sollen nur einen aligemeinen Ueberblick bieten. Sie geben die Resultate aus den zwei 
verschiedenen Behandlungsmethoden, nämlich der wenig eingreifenden und der eingreifenden (Resectio und Amputatio). Wenn ich nun die Endresultate der mit der ersten Methode, Incision, locale Resection u. s. w., behandelten Kranken von den mit der zweiten Methode behandelten trenne, so verhalten sich dieselben folgendermaassen:

Vollkommene Heilung, abgesehen von Bewegungsbeschränkung und Contraction ........ $8=31$ Proc.

Unvollkommene Heilung mit beschränkter Gebrauchsfähigkeit ............... $1=7=7,5=$

Todesfälle .............. $8=61,5=$

Unbekannte . . . . . . . . . . . 8

Diesen Procentsatz muss man natürlich mit Ausschluss der unbekannten Fälle darstellen. Also: 31 Proc. vollkommene Heilung, 7,5 Proc. unvollkommene Heilung, 61,5 Proc. Todesfälle.

Die Resultate der eingreifenden Methode sind:

Vollkommene Heilung mit Beweglichkeit und Gebrauchsfahigkeit ........... 45 $=54$ Proc.

Unvollkommene Heilung mit Functionsstörung. . . $7=8=$

Heilung durch Amputation . . . . . . . . . 6

Todesfälle ............... $30=38=$

Unbekannt . . . . . . . . . . . . 28

Wenn man diese Zahlen mit Ausschluss der Unbekannten und amputirten Fälle im Procentsatz berechnet und die Resultate dieser Methode mit denen der wenig eingreifenden vergleicht, so erbält man Folgendes:

Vollkommene Heilung .. 45=54 Proc.
Unvollkommene Heilung. $7=8=$
Todesfälle . . . . $30=38=$

Stellt man noch einmal beide Resultate zum Vergleich neben einander, so ergiebt sich:

$\begin{array}{lc}\text { Resec. Fälle. } & \text { Nicht reseo. Fälle. } \\ \text { Vollkommene Heilung. . 54 Proc. } & 31,5 \text { Proc. } \\ \text { Unvollkommene Heilung. } 8= & 7,5= \\ \text { Todesfälle . . . . } 38= & 61,5=\end{array}$

Wollte man die Zahl der mit Amputatio behandelten Fälle in die Rechnung der unvollkommen geheilten Kranken hineinziehen, so stejgt nattirlich die Zahl der mit eingreifender Methode behandelten und unvollkommen geheilten Kranken.

Aber ich möchte diese Rechnung nicht aufstellen, da die Fälle mit Amputatio ganz anders beschaffen sind, als die mit Resectio.

Wenn man oben angegebene Zahlenverhältnisse im Grossen und Ganzen betrachtet, so muss man obne Weiteres sagen, wie der Procentsatz uns lehrt, dass die Resectionsresultate für die in Betracht 
kommenden Kranken entschieden bessere sind, als die Resultate für die mit weniger eingreifender Methode behandelten Kranken. Allerdings ist die Zahl der mit letzterer Methode behandelten Patienten nicht so genügend, dass man ganz endgültige, einwandfreie, sichere Schlussresultate erzielen kann. Indessen scheint es mir nicht unrichtig zu sein, wenn man die Resectionsresultate mebr begtinstigt, als die des localen Eingriffes.'

Es handelt sich nun um die Frage, wie die operirten Arme sich in Bezug auf die Function und Gebrauchsfähigkeit verhalten. Ich möchte hier auch beide Functionsresultate neben einander getrennt betrachten, je nachdem die Behandlungsmethode verschieden ist. Ich will hier zunächst die Functionsverhältnisse der durch Resectio geheilten Kranken in 3 Gruppen unterbringen, abgesehen von den gestorbenen Kranken, unter denen auch der Fall einmal vorkam, dass der Arm vor dem Tode ganz gut geheilt war. Die 3 Arten vertheilen sich folgendermaassen:

1. Heilung mit mehr oder weniger Beweglichkeit und guter Gebrauchsfähigkeit.

2. Heilung mit Ankylose und befriedigender Gebrauchsfähigkeit.

3. Heilung mit Schlottergelenk.

Bei den 45 Kranken, welche durch die Resectio geheilt sind, war der Zustand des Armes folgender:

1. Heilung mit mehr oder weniger Beweglichkeit und guter Brauchbarkeit $27=60$ Proe.

2. Heilung mit Ankylose und befriedigender Gebrauchsfähigkeit $15=33$ Proc.

3. Heilung mit Schlottergelenk $3=7$ Proc.

4 Fälle der mit wenig eingreifender Methode behandelten Kranken vertheilen sich in folgenden Zahlen:

Heilung mit mehr oder weniger Beweglichkeit $3=75$ Proc. Heilung mit Ankylose $1=25$ Proc.

Diese Zahlen sind jedoch zu klein, um mit Sicherheit Functionsresultate zu erzielen. Wie ich bei der Behandlungsmethode 2 Resectionsmethoden erwähnt habe, so möchte ich hier 2 Gruppen der Resectionsresultate zur Vergleichung bringen und zeigen, ob es irgendwo einen Unterschied zwischen den beiden Schlussresultaten der Methoden giebt. Die Zahlen der mit der Langenbeck'schen Methode resecirten Fälle beträgt im Ganzen 94, davon sind 27 unbekannt, während die Zahl der mit Prof. König's Methode resecirten Fälle 14 beträgt, wovon 1 unbekannt ist. 
Verlauf und Ausgang der tuberculösen Erkrankung des Ellbogengelenkes. 125

Resect. nach Langenbeok

Vollkommene Heilung . . $40=60$ Proc.

Unvollkommene Heilung . . $60=9=$

Todesfälle ........ $30=31=$

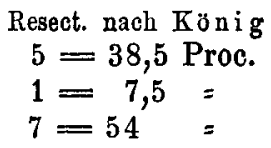

Wenn ich diese Zahlen, abgesehen von den Resultaten der gestorbenen und unvollkommen geheilten Kranken in Bezug auf die Heilungszustände analysiren will, so ergiebt sich Folgendes:

Heilung mit mehr oder weniger Beweglichkeit:

$$
\begin{array}{cc}
\text { Langenbeck } & \text { König } \\
25=62,5 \text { Proc. } & 2=40 \text { Proc. }
\end{array}
$$

Heilung mit Ankylose und Gebrauchsfähigkeit:

$$
\begin{array}{cc}
\text { Langenbeck } & \text { König } \\
12=30 \text { Proc. } & 3=60 \text { Proc. }
\end{array}
$$

Heilung mit Schlottergelenk:

$$
\begin{array}{ll}
\text { Langenbeck } & \text { König } \\
3=7,5 \text { Proc. } & 0=0 \text { Proc. }
\end{array}
$$

Es scheint mir nach meiner Zusammenstellung durch die Methode nach König viel mehr Ankylose zu Stande gekommen zu sein, als es nach der Methode nach Langen beck der Fall ist, aber die Zahl der mit Abmeisselungsmethode operirten Kranken ist ja zu klein, um die wichtige Entscheidung dieser Frage zu ermöglichen. Das Ueberwiegen der Todesfälle der nach der Methode von König operirten Kranken, gegenuber der Zahl der nach Langenbeck operirten Kranken, ist mir nicht leicht $\mathbf{z u}$ erklären. Indessen möchte ich bemerken, dass schon eine viel zu lange Zeit seit der Behandlung jener Kranken nach König's Methode verflossen ist, als dass recht viele der Patienten infolge hohen Alters oder irgend einer anderen tuberculösen Erkrankung gestorben sein müssten. Ob dieses der Fall gewesen ist, werde ich noch bei der Zusammenstellung der Todesfälle bemerken. $\mathrm{Ob}$ die Operation selbst an ihrem Tode schuld war, kann ich nicht sagen, weil die Krankheit während der Behandlung einen ebenso gthstigen Verlauf genommen hat, wie bei der Operation mit der Langenbeck'schen Methode.

Verlauf nach der Operation.

Was den Wundverlauf nach der Operation, nach der mit eingreifender oder wenig eingreifender Methode anbelangt, so ist er in folgender Kategorie unterzubringen:

Aseptischer, fieberloser Verlauf . . . . . . . . 101 $=74$ Proe.

Verlauf mit Fieber, Eiterung und Abscessbildung . $32=23=$

Todesfälle nach der Operation ......... 4=3 = 
Also $101=74$ Proc. verliefen ohne besondere Reaction aseptisch, und einer nur wurde mit wenig geheilter Wunde entlassen, während alle anderen Kranken mit geheilter Wunde entlassen wurden. $32=$ 23 Proc. verliefen mit Eiterung der Wunde, Abscessbildung in der Umgebung derselben und daza mit höherer oder geringerer Temperaturerhöhung, infolgedessen wiederholte Incision, Auskratzung u.s. w. nöthig gewesen ist. Darunter befanden sich 2 Fälle von Erysipel, welches sich an die Operationswunde anschloss, aber unschädlichen Verlauf nahm. Die Todesfälle nach der Operation verhalten sich folgendermaassen: Ein Kranker ist an Jodoformintoxication, der zweite an Bronchiopneumonie, der dritte an Diphtherie im Laufe der Be. handlung, der vierte an weit vorgeschrittener Lungentuberculose direct nach der Operation zu Grunde gegangen. Also lässt es sich, wie die oben angegebene Thatsache angiebt, sicherstellen, dass die Operation selbst keine Gefahr darbietet. Wenn ich den oben angegebenen Procentsatz in 2 Gruppen, je nachdem die Behandlungweise verschieden ist, getrennt betrachte, so stellt sich folgendes Zahlenverhältniss dar :

Resecirtc Fälle

1. Aseptisch . . . $85=73$ Proc.

2. Eiterung . . $28=24=$

3. Todesfälle .. $3=3=$
Incidirte Fulle

$16=76$ Proc.

$4=19=$

$1=5=$

Wenn man die Todesfälle, bei denen der Tod gar nicht von den Wundkrankheiten selbst abhängt, weglässt, so stellt sich folgendes Resultat heraus:

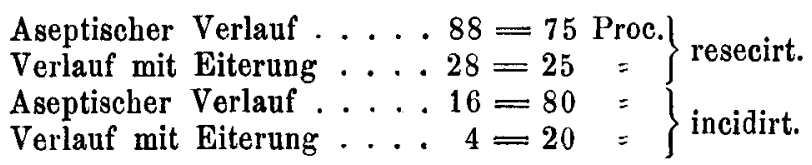

Man kann also leicht heraussehen, dass der Verlauf der Wundenheilung bei den Fällen, welche mit der wenig eingreifenden Methode operirt wurden, etwas günstiger ist, als der bei den Fällen mit eingreifender Methode.

Was nun endlich die Dauer rom Eintritt in die Klinik bis zum Austritt anbelangt, so ist sie eine verschiedene, je nachdem die vorgenommene Behandlung verschieden ist. Die durchschnittliche Dauer ist nach meiner Zusammenstellung 41 Tage, wobei das Maximum 6 Monate, das Minimum 11 Tage beträgt für die Resection. Die Durchschnittszeit der Amputation 19 Tage, wobei das Maximum 29 und das Minimum 9 Tage beträgt. Für die nicht resecirten Fälle lässt sich die Durchschnittsdauer auf 33 Tage für die wenig eingreifende Methode berechnen, wobei 10 Tage das Minimum und 99 Tage das Maximum ist. 


\section{Todesfälle und Todesursache.}

Zum Schlusse meines allgemeinen Theiles der Zusammenstellung habe ich jetzt noch eine Besprechung der Todesfälle und besonders der Todesursache hinzuzufügen, da sich ja aus dem Letzten ersehen lässt, ob und wie weit man hoffen kann, für die Zukunft bessere Behandlungsresultate der Ellbogengelenktuberculose zu erzielen, als bei den vorliegenden Fällen. Leider habe ich nicht iberall zuverlässige und genaue Angaben über die nach der Entlassung gestorbenen Kranken erhalten, aber es ist mir doch in 34 Fällen gelungen, eine mehr oder weniger sichere Auskunft ther die Todesursache und den Zustand der operirten Extremitäten nach der Entlassung oder beim Tode zu bekommen.

Es sind 30 von 83 resecirten Kranken, also 36 Proc., 3 Fälle unter 13 weniger eingreifend operirten Fällen, nach der Operation sofort oder lange Zeit nach der Operation zu Grunde gegangen. Weit wichtiger aber, als diese numerische Darstellung, ist die, bei welcher die Todesursache in jedem Falle zur Grundlage gemacht wird. Deswegen werde ich hier im Wesentlichen 3 Gruppen unterscheiden:

1. Fälle, bei denen der Tod als unmittelbare oder mittelbare Ursache der Operation nachfolgte.

2. Fälle, in welchen der Tod infolge der Tuberculose, welche während der Behandlung schon in den inneren Organen, besonders der Lunge war, oder nach der Entlassung zur Entwicklung gekommen ist.

3. Fälle, welche auf eine weder mit der Operation, noch mit der Tuberculose im Zusammenhang stehende Veranlassung hin zum tödtlichen Ausgange gefuhrt haben.

Leider muss ich nothwendiger Weise wegen des Mangels an genauen Angaben der Todesursache noch eine 4. Gruppe für unbekannte Fälle hinzuftugen. 4 Kranke gehören der ersten Kategorie an, wie ich schon bei der Darstellung des Wundverlaufes kurz erwähnt habe.

Der Tod erfolgte an:

$$
\begin{aligned}
& \text { Jodoformintoxication . . . } 1 \text { mal } \\
& \text { Lungentuberculose. . . . . } 1 \mathrm{mal} \\
& \text { Bronchopneumonie. . . . } 1 \text { mal } \\
& \text { Rachendipltherie ..... } 1 \text { mal }
\end{aligned}
$$

Von den Patienten waren im Alter von 17 Jahren, von 52 Jahren, von 79 Jahren und von 3 Jahren je einer. Man sieht also, dass von dieser Zahl von Todesfällen wesentlich alte Leute betroffen werden, von welchen theils wegen des hohen Alters, theils wegen der vor- 
handenen Lungenerkrankung Chloroform, Jodoform u. s. w. wenig ertragen werden konnte. Was den letzten Fall betrifft, so ist das ein ganz zufälliges Ereigniss gewesen.

Zur zweiten Gruppe gehören 25 Fälle, bei welchen die Tuberculose der Lungen, Nieren u. s. w., welche sich beim Eintritt in die Klinik schon nachweisen liess, unbehinderten Fortgang bis zum Tode der Kranken genommen hat, oder bei denen nach der Entlassung aus der Klinik bei anscheinend gesunden Zuständen die Tuberculose der Lunge, des Gelenkes, Darmes u. s. w. zur Entwicklung gekommen und infolgedessen der Tod eingetreten war. Ausserdem sind 9 Fälle uibrig, in denen theils infolge einer anderen, acuten Krankheit, theils aus gewisser Anzahl von unbekannten Gründen der Tod eingetreten ist. Es ist höchst wahrscheinlich, dass eine gewisse Anzahl von Kranken, bei denen diese unbekannten Fälle eintraten, an irgend einer tuberculösen Erkrankung gestorben sein würden. Von den 25 Patienten waren im Alter von 1-10 Jahren 2; von 10-20 Jahren 7 ; von 20-30 Jahren 3; von 30-40 Jahren 7; von 40-50 Jahren 1 ; von 50-60 Jahren 1; and endlich von 60-70 Jahren 4. Man sieht also, dass in dieser Zahl die grösste Sterblichkeit in den Jahren von 10-20 und 30-40 und schliesslich zwischen $60-70$ herrscht. Wenn ich diese 25 Fälle nach der Localisation der Tuberculose auseinandertheile, so kommt bei 20 Fällen $=80$ Proc. die Lungentuberculose, bei 5 Fällen $=20$ Proc. die Tuberculose des Darmes, der Wirbelsäule, des Gehirns u. s. w. in Betracht.

Von den 9 ubrigen Kranken sind 3 an einer anderen Krankheit, an Magenleiden, an Gehirnentzündung oder an Bruchleiden gestorben. Die übrigen 6 Fälle sind mir unbekannt. Unter den 8 mir bekannten Fällen, welche mit Abmeisselung von Condylen resecirt worden sind, starb 1 Kranker an Jodoformintoxication, 1 an Darmtuberculose, 3 an der schon vor der Operation vorhandenen Lungentuberculose. Von 3 anderen Kranken fehlen mir nähere Angaben.

Wir kommen nun zu der Frage, ob bei den Krankeu der Arm geheilt war oder nicht, wie er geheilt und wie weit er gebrauchsfähig war. Ich kann leider diese Frage nur in wenigen Fällen beantworten, doch möchte ich diese wenigstens im Folgenden erwähnen. Von den 8 Fällen, welche wenig eingreifend operirt wurden, waren 3 Fälle $=60$ Proc. nicht geheilt, 2 Fälle $=40$ Proc. geheilt, während 3 Fälle mir nicht bekannt sind. Von den 25 Todesfällen, welche resecirt worden sind, waren $10=67$ Proc. geheilt mit mehr oder weniger Gebrauchsfähigkeit, 5 Fälle $=33$ Proc. waren nicht geheilt, sondern eiterten von der Entlassung bis zum Tode, während 10 Fälle 
mir unbekannt blieben. Unter den 7 mir bekannten Fällen, welche nach der Methode mit Abmeisselung von Condylen operirt worden sind, zeigte sich Folgendes: 1 Fall $=25$ Proc. geheilt, 3 Fälle $=$ 75 Proc. nicht geheilt, 3 Fälle unbekannt, während 9 Fälle von $17=$ 82 Proc., welche nach Lange $\mathrm{nbeck}$ operirt worden sind, abgesehen von 6 , in denen der Zustand des operirten Armes mir unbekannt ist, geheilt worden sind, 2 Fälle $=18$ Proc. nicht geheilt.

\section{Specieller Thell.}

I. Gruppe: Eintritt der Kranken in die klinische Behandlung vor dem 10. Lebensjahre.

Unter den 137 Fällen der tuberculösen Erkrankung des Ellbogengelenkes, welche innerhalb des Zeitraumes vom April 1876 bis zum December 1890 in der chirurgischen Klinik zu Göttingen behandelt worden sind, befanden sich 29, das heisst 21,5 Proc. der Fälle vor dem 10. Lebensjahre. Von den 29 Kranken waren männlichen Geschlechts $16=55$ Proc., weiblichen Geschlechts $13=45$ Proc.

Aetiologische Momente.

Wie ich schon im allgemeinen Theile die ätiologischen Momente in 4 Gruppen getheilt habe, so möchte ich auch hier in folgender Weise gruppiren:

1. Tuberculose der anderen Organe $13 \mathrm{mal}=45$ Proc.

2. Trauma $5 \mathrm{mal}=17$ Proc.

3. Hereditäre Belastung $1 \mathrm{mal}=3,5$ Proc.

4. Unbekannte Ursache $10 \mathrm{mal}=34,5$ Proc.

Unter die erste Gruppe gehören 3 mal Lupus am Gesicht und Arm, 5 mal Tuberculose der Hand und des Fingers, 1 mal die Tuberculose der Tibia, 2 mal Tuberculose der Lymphdrulsen, 1 mal Lungentuberculose und 1 mal Coxitis tuberculosa.

Unter die zweite Gruppe rechne ich 3 mal Fall auf den Ellbogen, 2 mal Stoss gegen das Ellbogengelenk.

Die Kranken, welche vor dem 10. Lebensjahre in die Behandlung eintraten, befanden sich in folgendem Alter:

Im 2. Lebensjahre . . . $1 \mathrm{mal}$

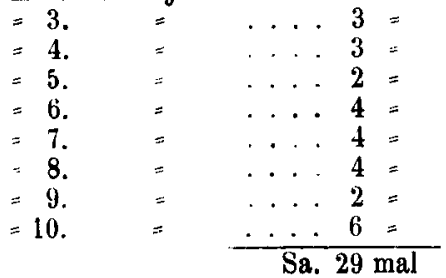




\section{Verlauf.}

Die Dauer der Krankheit bis zum Eintritt in die chirurgische Behandlung beträgt durchschnittlich 1 Jahr 4 Monate und 24 Tage, wobei das Maximum 7 Jahre, das Minimum 3 Monate gerechnet wurde. Die Erkrankung verlief $24 \mathrm{mal}=76$ Proc. mit Fisteln und Abscess und 5 mal ohne solche. Unter die ersten gehören 20 mal Fisteln und 4 mal Abscesse. Aber es ist selbstverständlich diese Unterabtheilung nicht ganz einwandfrei, weil die Fisteln und Abscesse öfter zugleich beobachtet werden können.

Bebandlung.

Von 29 Patienten wurden behandelt:

a) mit Ineision und Gypsverband $1 \mathrm{mal}=3,5$ Proe.

b) mit localer Resection $2 \mathrm{mal}=6,5$ Proc.

c) mit Incision und Auskratzung $9 \mathrm{mal}=31,5$ Proc.

d) mit typischer Resection $17 \mathrm{mal}=58,5$ Proc.

Stellt man die Gruppen von a-c als die wenig eingreifenden, und $d$ als die eingreifende Behandlungsmethode zusammen, so ergiebt sich, dass die Fälle, welche mit der ersteren Methode behandelt worden sind, gegentiber den mit der letzteren Methode behandelten $17=$ 58,5 Proc. Fällen, $12=41,5$ Proc. betragen.

Pathologische Anatomie.

Was nun die pathologisch-anatomische Frage nach der Häufigkeit der ostalen Formen der Ellbogengelenkstuberlose gegenüber den rein synovialen Formen betrifft, so ergeben die 29 Fälle folgendes Resultat: Knochenherde $19=70$ Proc.; rein synovialer Fungus $8=30$ Proc.

In 2 Fällen von resecirtem Fungus cubiti liess sich nichts über die ursprüngliche Form der Erkrankung sagen, weil die Gelenke sehr stark destruirt waren. Dieser Procentsatz entspricht demnach dem Verhältnisse der ostalen Processe gegentiber den rein synovialen Processen, welches ich schon im allgemeinen Theile uber die sämmtlichen Fälle gegeben habe, nämlich: ostaler Process für sämmtliche Fälle 71 Proc., für 10 Lebensjahre 70 Proc.; synovialer Process fur sämmtliche Fälle 29 Proc, für 10 Lebensjahre 30 Proe.

Ueber die Einzelheiten des ostalen Processes in Bezug auf verschiedene Knochen und die Stelle des Processes beziehe ich mich darauf, was ich schon im allgemeinen Theile genauer erörtert habe.

Behandlungsresultate.

Nun kommt die wichtige Frage uber den Ausgang der Erkrankung, welchen ich, wie im allgemeinen Theile, in folgender Weise 
Verlauf und Ausgang der tuberculösen Erkrankung des Ellbogengelenkes. 131

unterscheide. Leider enthält gerade auch sie eine verbältnissmässig grosse Anzahl von Kranken, iber deren jetzigen Zustand keine Auskunft zu erlangen war; bei 11 ron 29 war nichts genauer uber das Schlussresultat zu ermitteln.

1. Vollkommen ausgeheilt ist die Erkrankung (abgesehen von functionellen Verhältnissen) $11 \mathrm{mal}=61$ Proc.

2. Unvollständig ausgeheilt $1 \mathrm{mal}=5,5$ Proc.

3. Todesfälle $6 \mathrm{mal}=33,5$ Proc.

Die erste Gruppe theilt sich in Bezug auf die Functionen in folgender Weise:

Heilung mit mehr oder weniger Beweglichkeit und guter Brauchbarkeit $7=63,5$ Proc.

Heilung mit Ankylose $4=36,5$ Proc.

Unter den 7 Kranken in der ersten Gruppe waren 5 mit ziemlich guter Beweglichkeit geheilt, während 2 andere mit sehr beschränkter Beweglichkeit geheilt waren.

Von 4 Fällen von den mit Ankylose geheilten Kranken waren 3 vollständig, 1 wenig arbeitsfähig. Ein unvollständig geheilter Kranker befand sich in folgendem Zustande: Der Arm ist in rechtem Winkel im Ellbogengelenk fast ankylotisch, und es finden sich noch mebrere Fisteln an der lateralen Seite des Ellbogengelenkes.

Wollte man hier die Resultate von 11 resecirten Kranken mit denen der mit der wenig eingreifenden Methode behandelten vergleichen, so ergiebt sich Folgendes:

\begin{tabular}{|c|c|c|c|c|c|}
\hline \multirow{3}{*}{$\begin{array}{l}\text { Vollständige Heilung . } \\
\text { Unvollständige Heilung }\end{array}$} & \multicolumn{2}{|c|}{ Resecirt } & \multicolumn{3}{|c|}{ Nicht resecirt } \\
\hline & $8=73$ & Proc. & $3=$ & 42,5 & Proc. \\
\hline & $1=$ & $=$ & $0=$ & 0 & $=$ \\
\hline Todesfälle... & $2=18$ & $=$ & $4=$ & 57,5 & $=$ \\
\hline
\end{tabular}

Was nun schliesslich die Todesfälle betrifft, so sind die Patienten an folgenden Erkrankungen gestorben: 1 an Lungentuberculose 1/4 Jahr nach der Entlassung, bei dem der operirte Arm bis zum Tode eiterte; 3 an allgemeiner Tuberculose, bei denen in 2 Fällen der operirte Arm noch nicht geheilt war, während bei 1 Kranken der Zustand des Armes unbekannt war. Sonst starb 1 Kranker an unbekannter Ursache und 1 an Diphtherie in der Klinik, kurz nach der Operation.

$$
\text { Verlauf nach der Operation. }
$$

Was endlich den Verlauf nach der Operation anbelangt, so unterscheide ich einen aseptischen Verlauf und den Verlauf mit Eiterung der Wunde, und mehr oder weniger hohe Temperatursteigerung, infolgedessen wiederholt Incision, Auskratzung u. s. w. nöthig war. 
Unter den 27 resecirten Fällen verliefen $12=70$ Proc. vollständig aseptisch, unter denen bei 2 nach einigen Monaten wegen des Recidivs wieder Incision, Auskratzung vorgenommen werden musste, $11=30$ Proc. mit Eiterung und Fieber. Von den 12 Fällen, welche wenig eingreifend behandelt worden sind, verliefen $9=75$ Proc. aseptisch, 1 mit Fieber und Eiterung. Einmal trat der Tod wegen der Diphtherie ein, einmal ist der Kranke mit Gypsverband behandelt und gebessert entlassen worden.

Die durchschnittliche Dauer vom Eintritt bis zum Austritt beträgt 38,7 Tage, wobei die Dauer für die resecirten Fälle 44 Tage, für nicht resecirte Fälle 23,7 Tage gerechnet worden ist.

II. Gruppe: Eintritt der Kranken in die klinische Behandlung im Alter von 10-20 Jahren.

$\mathrm{Zu}$ dieser Gruppe gehören 25 Fälle $=48,5$ Proc. der tuberculösen Erkrankung des Ellbogengelenkes, bei denen $13=52$ Proc. weiblichen, $12=48$ Proc. männlichen Geschlechtes waren:

Aetiologische Momente.

Sie lassen sich in folgender Weise theilen:

I. Tuberculose der anderen Organe $12 \mathrm{mal}=48$ Proc.

II. Trauma ........... $3 \mathrm{mal}=12=$

III. Hereditäre Belastung ..... $3 \mathrm{mal}=12=$

IV. Unbekannte Ursache . . . . $7 \mathrm{mal}=28=$

Unter den 12 Fällen von Tuberculose der anderen Organe befanden sich $5 \mathrm{mal}$ Lungentuberculose, $3 \mathrm{mal}$ Tuberculose der Hand und des Fingers, 1 mal multiple Knochentuberculose, 1 mal Tuberculose der Wirbelsäule und Niere, 1 mal Tuberculose der Wange und 1 mal tuberculöse Erkrankung der Lymphdrusen.

Unter den 3 Fällen von Trauma befand sich einmal Erkrankung durch Fall auf den Ellbogen, einmal durch Schlag gegen den Ellbogen, einmal nach der Fractur am Ellbogengelenke.

Die Kranken, welche in die zweite Gruppe gerechnet werden befanden sich in folgendem Alter:

$$
\begin{aligned}
& \text { Im 11. Jahre . . . . = } 1 \mathrm{mal} \\
& =12 .=\ldots \ldots=1= \\
& =13 . \quad=\ldots \ldots=1= \\
& =14 . \quad=\ldots \ldots=3= \\
& =15 .=\ldots \ldots=2= \\
& =16 .=\ldots \ldots=3= \\
& =17 .=\ldots \ldots=3= \\
& =18 .=\ldots \ldots=4= \\
& =19 . \quad=\ldots \ldots=5= \\
& =20 . \quad=\ldots \ldots=2=
\end{aligned}
$$


Verlauf und Ausgang der tuberculösen Erkrankung des Ellbogengelenkes. 133

Die Dauer der Erkrankung bis zum Eintritt in die Behandlung beträgt durchschnittlich 1 Jahr 11 Monate und 6 Tage, wobei das Maximum 8 Jahre, das Minimum 1 Jahr 5 Monate gerechnet wurde. Wenn man diese durchschnittliche Dauer mit der für die Kranken in der .ersten Gruppe vergleicht, so ist die erste uiber 8 Monate länger als die letzte.

Die Erkrankung verlief $19 \mathrm{mal}=76$ Proc. der Fälle mit Fisteln und Abscessen, wobei die letzten $7 \mathrm{mal}$ gerechnet werden konnten. 6 Fälle $=24$ Proc. waren ohne solche Erscheinungen.

\section{Behandlung.}

Von den 25 hier in Frage kommenden Patienten wurden behandelt:

a) mit Gypsverband $1=4$ Proc.

b) mit Incision und Auskratzung $3=12$ Proc.

c) mit typischer Resection $21=84$ Proc.

Pathologische Anatomie.

Wenn man, abgesehen von 2 unbekannten Fällen, die Zahlen. angabe des ostalen Processes derjenigen des rein synovialen Processes gegenuberstellen will, so ergiebt sich Folgendes:

Knochenherde $18=77$ Proc.

Synovialfungus $5=23=$

Wie dieser Procentsatz lehrt, überwiegt die Zahl des ostalen Processes etwas über die von 70 Proc., welche sich in der ersten Gruppe ergiebt. Aber es ist im Allgemeinen kein grosser Unterschied zu bemerken.

Behandlungsresultate.

Es handelt sich hier um die Frage über die Schlussresultate, welche ich in folgender Weise, wie in der ersten Gruppe, auseinandersetzen will.

I. Vollst. Heilg. (abgesehen v. functioneller Beziehung) $10=50$ Proc.

II. Unvollständige Heilung . . . . . . . . . $3=15=$

III. Todesfälle ............... $7=35=$

Unbekannt sind 5 Fälle. Die 10 vollständig geheilten Fälle theilen sich in Bezug auf die Function der operirten Stelle in folgende Unterabtheilungen:

a) Heilung mit mehr oder weniger Beweglichkeit and befriedigender Gebrauchsfähigkeit $6=60$ Proc.

b) Heilung mit Ankylose und relativ guter Brauchbarkeit $4=$ 40 Proc.

Wenn man die 6 Fälle der ersten Kategorie, welche mit Beweglichkeit gebeilt sind, noch genauer betrachtet, so ergeben sich 
folgende Resultate: 2 sind mit fast normaler Beweglichkeit und guter Gebrauchsfähigkeit, 2 mit ziemlich guter Beweglichkeit, 2 mit weniger Beweglichkeit geheilt. Von den 4 Fällen der mit Ankylose geheilten Kranken waren 3 arbeitsfähig geheilt, während 1 Fall mit wenig brauchbarem Arm zur Heilung kam. Was nun die 3 unvollständig geheilten Fälle anbetrifft, so verhält es sich mit ihnen in folgender Weise: 2 mal waren die Gelenke mit Fisteln und Beweglichkeit, einmal mit Ankylose und noch secernirenden Fisteln geheilt.

Unter den 7 Todesfällen trat der Tod nach folgender Erkrankung ein: $3 \mathrm{mal}$ infolge von Lungentuberculose, einmal von unbekannter Ursache. Der operirte Arm war bei 3 Fällen unter 6 Fällen geheilt, uber die ubrigen Fälle ist mir nichts bekannt.

Nach der Operation verlief die operirte Wunde $16 \mathrm{mal}=66,5$ Proc. vollständig aseptisch und fieberlos, $7 \mathrm{mal}=23,5$ Proc. mit Eiterung und Fieber, infolgedessen wiederholt Incision und Auskratzung u. s. w. vorgenommen wurde, $1 \mathrm{mal}=4$ Proc. mit Erysipel, $1 \mathrm{mal}$ wurde ein Gypsverband angelegt und der Kranke gebessert entlassen.

Die Dauer der Behandlung in der Klinik vom Eintritt bis zum Austritt beträgt durchschnittlich für die resecirten Fälle 45,6 Tage, für die nicht resecirten Fälle 47,8 Tage, wobei für erstere das Maximum 150 Tage, das Minimum 10 Tage, für letztere das Maximum 75 Tage und das Minimum 25 Tage betrug.

III. Gruppe: Eintritt der Kranken in die klinische Behandlung im Alter zwischen dem 20. und 30. Lebensjahre.

$\mathrm{Zu}$ dieser Gruppe gehören 18 Fälle, d. h. 12,5 Proc. der sämmtlichen Kranken, bei denen $9=50$ Proc. männlichen und $9=50$ Proc. weiblichen Geschlechtes zur Beobachtung kamen. In Bezug auf die ätiologischen Momente rechne ich folgendermaassen:

1. $5 \mathrm{mal}=27,5$ Proc. lag Tuberculose der anderen Organe vor, wobei 3 mal Lungentuberculose, $1 \mathrm{mal}$ Tuberculose der Lymphdrtisen, und 1 mal Tuberculose des Handgelenkes.

2. $1 \mathrm{mal}=6$ Proc. Trauma.

3. $2 \mathrm{mal}=11$ Proc. hereditäre Belastung.

4. $10 \mathrm{mal}=55,5$ Proc. an unbekannter Ursache. Die 18 Kranken befanden sich in folgendem Alter:

$$
\begin{aligned}
\text { Im } & 21 . \text { Jahre } \ldots \ldots=3 \mathrm{mal} \\
& =22 . \quad=\ldots \ldots=3= \\
& =23 . \quad=\ldots \ldots=2= \\
& =24 . \quad=\ldots \ldots=2= \\
& =25 . \quad=\ldots \ldots=0 \\
& =26 . \quad=\ldots \ldots=1=
\end{aligned}
$$




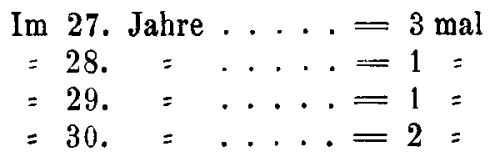

Verlanf.

Die Dauer der Krankheit bis zum Eintritt in die klinische Behandlung beträgt durchschnittlich 3 Jahre 8 Monate und 13 Tage, wobei das Maximum 10 Jahre, das Minimum 1/2 Jahr gerechnet worden ist. Diese durchschnittliche Dauer der Krankheit liefert gegenuber der Dauer, welche ich in der 1. und 2. Gruppe angenommen habe, eine bedeutende Steigerung, nämlich fur die erste Gruppe $1 \mathrm{Jahr}$ 4 Monate und 24 Tage; für die 2. Gruppe 1 Jahr 11 Monate und 6 Tage; flur die 3. Gruppe 3 Jahre 8 Monate und 13 Tage. Die Erkrankung verlief $7 \mathrm{mal}$ mit Fisteln, $8 \mathrm{mal}$ mit Abscess, beide zusammen $13 \mathrm{mal}=72$ Proc.; $5 \mathrm{mal}=28$ Proc. verlief die Krankheit ohne solche.

\section{Behandlung.}

Alle Fälle der III. Gruppe sind mit typischer Resection behandelt worden.

Pathologisch-anatomische Befunde: Was die Häufigkeit des ostalen Processes gegenuber der rein synovialen Form betrifft, so ist folgende Zablenangabe zu machen:

Knochenherd $.11 \mathrm{mal}=61$ Proc.

Synovialfungus $7==39=$

Ausserdem ist Hydrops tuberculosus mit Faserstoff, Reiskörper u. s. w. bei 4 Fällen beobachtet worden, unter denen 2 bei. ostalem, 2 bei Synovialprocess verliefen.

Schlussresultat.

Bei 2 Fällen liess sich über die Schlussresultate nichts ermitteln, die ubrigen 16 Fälle geben folgende Resultate:
I. Vollständige Heilung $\cdot 12=75$ Proc.
II. Unvollständige Heilung $1=6=$
III. Todesfalle ..... $3=19=$

Die erste dieser Gruppen theilt sich in Bezug auf Function folgendermaassen:

a) Heilung mit Beweglichkeit $8 \mathrm{mal}=66,5$ Proc.

b) Heilung mit Ankylose $3 \mathrm{mal}=25$ Proc.

c) Heilung mit Schlottergelenk $1 \mathrm{mal}=8,5$ Proc.

Unter den mit Beweglichkeit geheilten Kranken sind 4 mit ziemlich guter Beweglichkeit und befriedigender Gebranchsfähigkeit, 4 mit beschränkter Beweglichkeit und guter Arbeitsfähigkeit geheilt. Drei 
mit Ankylose geheilte Fälle sind arbeitsfähig, während ein Fall mit Schlottergelenk wenig arbeitsfähig ist. Bei 3 Fällen trat der Tod ein; einmal $1 \mathrm{Jahr}$ nach der Operation infolge eines Lungenleidens, einmal 1 Jahr nach der Entlassung wegen allgemeiner Tuberculose, und endlich einmal wegen einer unbekannten Ursache. Der operirte Arm war einmal nicht geheilt, einmal geheilt, beim 3. Falle ist mir der Zustand des Armes unbekannt. Bei einem unvollständig geheilten Falle war der operirte Arm nach der Entlassung 5 Jahre lang ganz gut geheilt und gebrauchsfähig, seit einem Jabre kam er wieder zur Schwellung und Schmerzhaftigkeit, und der Kranke wurde wieder aufgenommen. Die Operationswunde verlief $14 \mathrm{mal}=77,5$ Proc. aseptisch und fieberlos, 4 mal $=22,5$ Proc. mit Eiterung und Fieber. Die Dauer der Behandlung beträgt durchschnittlich 38,6 Tage.

Bemerken möchte ich, wie oben beschriebene Thatsache angiebt, dass die Resultate der Behandlung in dieser Gruppe in Bezug auf Function, Prognose und Verlauf nach der Operation gegenüber der der 1. und 2. Gruppe bedeutend besser sich gestaltet haben. Um die Resultate für die 3 Gruppen mit einander vergleichen zu können, gebe ich noch einmal folgende Zahlenangabe:

\begin{tabular}{|c|c|c|c|c|}
\hline \multirow[b]{2}{*}{ Dauer der Behandlung fur Resection } & \multicolumn{4}{|c|}{ Gruppe } \\
\hline & $\stackrel{\text { I }}{44 \text { Tage }}$ & $\begin{array}{c}\text { II } \\
45,6 \text { Tage }\end{array}$ & $\begin{array}{r}1 \\
38,6\end{array}$ & I Tage \\
\hline$\underset{\text { der }}{\text { Verlauf }}\}$ aseptisch $\ldots \ldots$ & 75,5 Proc. & 66,5 Proc. & 77,5 & Proc. \\
\hline Wunde mit Eiterung. & 24,5 & 33,5 & 22,5 & $=$ \\
\hline Vollständige Heilung & 61 & $50^{\circ}$ & 75 & $=$ \\
\hline Unvollkommene Heilung & 5,5 & 15 & 6 & $=$ \\
\hline Todesfäle $\ldots \ldots \ldots$ & $33,5=$ & 35 & 19 & $=$ \\
\hline Heilung mit Beweglichkeit & $63,5=$ & 60 & 66,5 & $=$ \\
\hline Heilung mit Ankylose... & $36,5=$ & 40 & 25 & $=$ \\
\hline Heilung mit Schlottergelenk .... & - & - & 8,5 & $=$ \\
\hline
\end{tabular}

IV. Gruppe: Eintritt der Kranken in die Klinik im Alter $z$ wischen dem 30. und 40. Lebensjahre.

In diese Gruppe gehören 22 Kranke $=15,5$ Proc. aller 137 Patienten.

Die Erkrankung betrifft $18 \mathrm{mal}=82$ Proc. das weibliche Geschlecht und $4 \mathrm{mal}=18$ Proc. das männliche Geschlecht. Es ist dieses Ueberwiegen des weiblichen Gesehlechtes in dieser Gruppe gegenüber dem männlichen so auffallend, dass es für sich allein einen nicht unerheblichen Einfluss auf die gesammten Zahlenverhältnisse, welche aus der Vergleichung der weiblichen und männlichen Individuen hervorgehen, ausgetibt zu haben scheint. 


$$
\text { Aetiologie. }
$$

Unter den 22 Patienten der IV. Gruppe lässt sich die Tuberculose der anderen Organe in 12 Fällen $=54,5$ Proc. nachweisen. Es befanden sich darunter 8 Kranke mit Lungentuberculose, 2 Kranke mit Tuberculose der Hand und des Fingers, 1 Kranker mit Tuberculose des Fusses und einer mit Coxitis tuberculosa. Unter das Trauma rechne ich 2 Fälle $=9$ Proc., einmal Fall auf den Ellbogen und einmal Stoss gegen denselben. Ueber die anderen 7 Fälle $=36,5$ Proc. lässt sich nichts Genaueres sagen. Die hier in Frage kommenden 22 Kranken traten in folgendem Alter in die Behandlung ein:

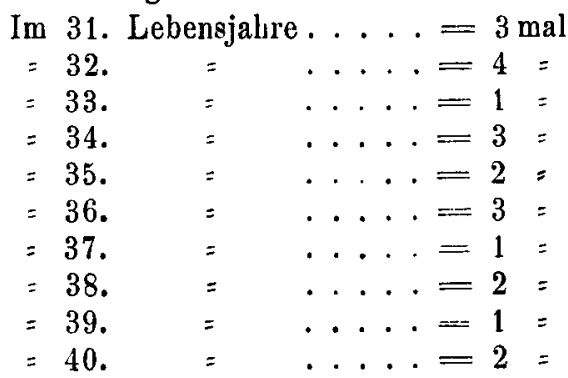

\section{Verlauf.}

Die Dauer der Erkrankung bis zum Eintritt in die Klinik beträgt durchschnittlich 1 Jahr 10 Monate 28 Tage. Dabei war das Maximum 7 Jahre, das Minimum 2 Monate. Die Erkrankung verlief $8 \mathrm{mal} \mathrm{mit} \mathrm{Fistel,} 7 \mathrm{mal}$ mit Abscess, im Ganzen $15 \mathrm{mal}=$ mit Abscess und Fistel 18 Proc. 7 Fälle $=32$ Proc. verliefen ohne solche.

\section{Behandlung.}

Die 22 Kranken wurden behandelt:

a) mit typischer Resection $18=82$ Proc.

b) mit partieller Resection $1=18$ Proc.

c) mit Injection von Jodoformglycerin $1=18$ Proc.

d) mit Incision und Auskratzung $1=18$ Proc.

e) mit Amputation $1=18$ Proc.

Pathologisch-anatomische Befunde.

Die bei den typischen Resectionen und bei den Amputationen erlangten pathologisch-anatomischen Befunde an den erkrankten Gelenken lassen sich in folgender Weise zusammenstellen:

Kuochenherde . . $14 \mathrm{mal}=66,5$ Proc.

Synovialer Fungus $7==33,5=$

Einmal blieb die Frage unentschieden. Ausserdem konnte man bei 2 ostalen Processen Reiskörpel und Faserstoffauflagerung im Ge. lenke nachweisen. 
Schlussresultate.

Was nun die Schlussresultate betrifft, so ist Folgendes zu sagen:
I. Vollkommene Heilung $4=25$ Proc.
II. Unvollkommene Heilung $2=12,5=$
III. Todesfälle . . . 10 $10=62,5=$

In den ubrigen 6 Fällen ist mir nichts von ihrem jetzigen $\mathrm{Zu}$ stande bekannt.

a) Heilung mit Beweglichkeit $4=10$ Proc. 3 Kranke davon sind mit ziemlich guter Beweglichkeit, 1 Kranker mit sehr wenig Beweglichkeit und trotzdem guter Brauchbarkeit geheilt.

b) Von unvollständiger Heilung kamen 2 Fälle $=12,5$ Proc. vor, bei denen die operirten Gelenke schlottrig und wenig gebrauchsfähig geheilt sind. Zum Schluss der Behandlungsresultate möchte ich bemerken, dass von wenig eingreifend behandelten Fällen 3, und zwar 1 Fall mit Incision, 1 Fall mit Jodoforminjection und 1 Fall mit partieller Resection zum Tode der Patienten gefubrt haben; ebenso 1 Fall mit Amputation.

c) $\mathrm{Zu}$ den Todesfällen rechne ich 10 Fälle $=62,5$ Proc., bei denen der Tod infolge von folgenden Krankheiten eingetreten ist:

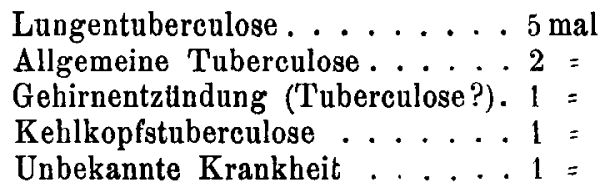

Bei den eben genannten Kranken folgte der Tod durchschnittlich 1 Jahr 4 Monate nach der Entlassung. Unter den gestorbenen 10 Kranken konnte man 7 mal schon in der Behandlungszeit vorhandene Tuberculose der Lunge nachweisen. Der Zustand des operirten Armes beim Tode konnte nur 4 mal ermittelt werden, und zwar war der Arm 2 mal ankylotisch, 1 mal schlottrig und 1 mal nicht geheilt. Es ist wohl zu bemerken, dass die Resultate der zur IV. Gruppe gerechneten Kranken sich sehr traurig gestaltet haben. Doch das ist ganz einfach zu erklären, weil die Kranken, welche im Alter von 30-40 Jahren in die Behandlung kamen, in vielen Fällen mit Lungentubereulose behaftet waren. Die Erkrankung verlief nach der Operation $17 \mathrm{mal}=77$ Proc. aseptisch und fieberlos, $1 \mathrm{mal}$ mit Erysipel, $4 \mathrm{mal}$ mit Eiterung und Fieber; im Ganzen $5 \mathrm{mal}=23$. Proc. Die durchschnittliche Dauer der Behandlung in der Klinik betrug 39,2 Tage, wobei das Maximum 120 Tage, das Minimum 16 Tage war. Für die Resection allein beträgt die durchschnittliche Daver 33,6 Tage. 
Verlauf und Ausgang der tuberculösen Erkrankung des Ellbogengelenkes. 139

V. Gruppe: Eintritt der Kranken in die klinische Behandlung im Alter $z$ wischendem 40. und 50. Lebensjahre.

Unter diese Gruppe gehören 13 Patienten, bei denen $9=69$ Proc. männlich, $4=31$ Proc. weiblich waren. Die ätiologischen Momente lassen sich in folgender Weise zusammenstellen:

Trauma ..........4 mal $=31$ Proc.

Tuberculose der anderen Organe. $4==31=$

Unbekannte Ursache........5 = $=38=$

Als tuberculöse Erkrankung der anderen Organe kamen 3 Fälle mit Lungenschwindsucht und 1 Fall mit Rippentuberculose in Betrachtung.

Als Trauma sind Auffallen eines Steines auf den Ellbogen, leichter Stoss und Fall u. s. w. beobachtet worden.

Die Kranken befanden sich in folgendem Alter:

$$
\begin{aligned}
& \text { Im 41. Lebensjahre. . . . = } 4 \text { mal } \\
& =42 . \quad=\ldots \ldots=2= \\
& =45 . \quad=\ldots \ldots=1= \\
& =46 . \quad=\ldots \ldots=1= \\
& =47 . \quad=\ldots \ldots=1= \\
& =48 . \quad=\ldots \ldots=1= \\
& =50 . \quad=\ldots \ldots=2=
\end{aligned}
$$

Als die durchschnittliche Dauer der Krankheit bis zum Eintritt in die Klinik rechne ich 2 Jahr 10 Monate und 27 Tage.

Die Erkrankung verlief $8 \mathrm{mal}=61$ Proc. mit Fisteln und Abscess, $5 \mathrm{mal}=39$ Proc. ohne nennenswerthe Abscesse und Fisteln.

Behandlung.

13 Fälle der V. Gruppe wurden in folgender Weise behandelt:

a) mit typischer Resection $11=81,5$ Proc.

b) mit Jodoforminjection $1=15,5$ Proc.

c) mit Incision und Auskratzung $1=15,5$ Proc.

$\mathrm{Zu}$ den pathologisch-anatomischen Befunden lassen sich folgende Bemerkungen machen:

Knochenherd ..... $8=66,5$ Proc.

Rein synovialer Fungus . . $4=33,5=$

Nicht operirt. . . . . . 1 .

Es liess sich Hydrops tuberculosus mit Fibrinauflagerung und Zottenbildung einmal bei ostalem und einmal bei synovialem Processe nachweisen.

Behandlungsresultate.
I. Vollständige Heilung
$5=55$ Proc.
II. Unvollkommene Heilung $2=22,5=$
III. Todesfälle.....2 $2=22,5=$ 
Ueber die Resultate bei 4 Patienten ist nichts zu ermitteln. Die vollständig geheilten Fälle theilen sich in Bezug auf Function in folgende Zahlen:

a) Heilung mit Beweglichkeit $3=60$ Proc.

b) Heilung mit Ankylose $1=20$ Proc.

c) Heilung mit Schlottergelenk $1=20$ Proc.

2 unvollkommen geheilte Fälle kamen mit beweglichem Gelenk zur Beobachtung. Bei 2 Fällen trat der Tod einmal wegen Darmtuberculose und einmal wegen unbekannter Ursache ein.

Die Erkrankung verlief nach der Operation $7 \mathrm{mal}=58,5$ Proc. aseptisch, $6 \mathrm{mal}=41,5$ Proc. mit Eiterung und Fieber. Die Dauer vom Eintritt bis zum Austritt aus der Klinik beträgt durchschnittlich 38,6 Tage, für resecirte Fälle 36,5 Tage.

VI. Gruppe: Eintritt der Kranken in die klinische Bebandlung zwischen dem 50. und 60. Lebensjabre.

Es wurden unter die VI. Gruppe 17 Fälle gerechnet, von denen $7=40$ Proc. Männer, $10=60$ Proc. Weiber waren.

Sie lassen sich nach dem Alter in folgende Tabelle vertheilen:

Im 52. Lebensjahre. . . . = $4 \mathrm{mal}$

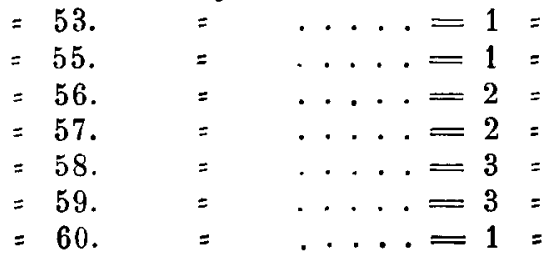

Ueber die ätiologischen Momente konnte man Folgendes nachweisen:

Tuberculose der anderen Organe $8=47$ Proc.

Trauma .......... $2=11,5=$

Hereditäre Belastung . . . 2 $=11,5=$

Ohne nachweisbare Ursache $\ldots 5=30=$

In den 8 Fällen der Tuberculose der anderen Organe lag immer Tuberculose der Lunge zu Grunde. Als Trauma konnte man einmal Fall und einmal Stoss gegen den Ellbogen nachweisen.

Die Erkrankung verlief 2 mal mit Abscess, 12 mal mit Fisteln; zusammen $14 \mathrm{mal}=82$ Proc. 3 Fälle waren ohne solche.

Die Dauer der Krankheit bis zum Eintritt in die Klinik beträgt durchschnittlich 1 Jahr 5 Monate und 15 Tage, wobei das Maximum 4 Jahre, das Minimum 6 Monate zu rechnen ist.

Behandlung.

Die 17 Patienten der VI. Gruppe wurden in folgender Weise behandelt : 
Verlauf und Ausgang der tuberculösen Erkrankung des Ellbogengelenkes. 141

a) mit Amputation $4=23,5$ Proc.

b) mit Resection $13=76,5$ Proc.

Die Amputationen sind hauptsächlich wegen Aussichtslosigkeit auf Heilung infolge der sehr ausgedehnten Zerstörung des Gelenkes und der Weichtheile vorgenommen worden.

Ueber die pathologisch-anatomischen Befunde lässt sich folgende Zahlenangabe machen:

Rein synovialer Fungus . . $4=26,5$ Proc.

Knochenherde ......11=73,5 =

Ueber 2 Fälle kann ich keine genaue Angabe machen, weil die Gelenke sehr stark zerstört waren. Ausserdem kam 1 Fall unter synovialem Process mit Faserstoffauflagerung vor.

Die Schlussresultate gestalten sich, abgesehen von 9 in ihrem jetzigem Bestande unbekannten Fällen, in folgender Weise:

I. Vollkommene Heilung . . $5=62,5$ Proc.

II. Todesfälle....... $3=37,5=$

Die Fälle von vollkommener Heilung geben folgende functionelle Resultate:

1 mal mit guter Beweglichkeit und guter Brauchbarkeit,

$1 \mathrm{mal}$ mit Ankylose und wenig Brauchbarkeit,

2 mal mit geringer Beweglichkeit und wenig Gebrauchsfähigkeit, 1 mal mit Ankylose und guter Brauchbarkeit.

Die 3 Todesfälle hatten folgende Ursache:

1 mal infolge eines Lungenleidens 5 Jahre nach der Operation (der operirte Arm war gut geheilt);

$1 \mathrm{mal}$ an Lungenleiden $1 \mathrm{Jahr}$ nach der Operation (der Arm war nicht geheilt);

$1 \mathrm{mal}$ direct nach der Operation.

Die Dauer der Bebandlung vom Eintritt in die Klinik bis zum Austritt rechne ich durchsehnittlich 34 Tage, wobei 39,4 Tage für resecirte Fälle und 21 Tage für amputirte Fälle gerechnet worden sind. Die Erkrankung verlief nach der Operation $15 \mathrm{mal}=88$ Proc. ohne Eiterung und Fieber, 1 mal mit Eiterung, und 1 mal trat der Tod ein.

VII. Gruppe: Eintritt der Kranken im Alter von $60-70$ Jahren.

Zur VII. Gruppe gehören 13 Patienten, 6 männliche $=46,5$ Proc. und 7 weibliche $=53,5$ Proc. Sie befanden sich in folgendem Alter:

Im 61 . Lebensjahre . . . 2 mal

$=62 . \quad=\ldots 3=$

$=63 . \quad=\ldots .3=$ 


$$
\begin{aligned}
& \text { Im } 65 . \text { Lebensjahre } \ldots 1 \mathrm{mal} \\
& =66 . \quad=\ldots 1= \\
& =67 . \quad=\quad \ldots 11= \\
& =68 . \quad=6.1= \\
& =69 . \quad=\quad \ldots 1=
\end{aligned}
$$

In Bezug auf die ätiologischen Momente konnte ich nur $3 \mathrm{mal}$ $=23$ Proc. die Tuberculose der Lunge, $1 \mathrm{mal}=8$ Proc. Trauma constatiren. Bei den anderen 9 Fällen liess sich nichts über die Aetiologie erfabren.

Die Erkrankung verlief 5 mal mit Abscess, 8 mal mit Fisteln, im Ganzen $13 \mathrm{mal}=100$ Proc.

Die Dauer der Krankheit bis zum Eintritt in die Klinik beträgt in dieser Gruppe 1 Jahr und 4 Monate, wobei das Maximum 7 Jahre, das Minimum 3 Monate war.

$$
\text { Behandlung. }
$$

Bei diesen 13 Fällen ist $3 \mathrm{mal}=23$ Proc. Amputation, $10 \mathrm{mal}$ $=77$ Proc. Resection vorgenommen worden. Bei 2 Kranken wurde primär, wegen ausgedehnter Tuberculose, bei 1 Kranken nach vorausgeschickter Resection, welche nicht zum gewünschten Ziele fubrte, amputirt.

Ueber die pathologisch-anatomischen Befunde ist folgende Zahl zu geben:

$$
\begin{aligned}
& \text { Knochenherde . . . . . 9 }=69 \text { Proc. } \\
& \text { Rein synovialer Fungus . } 4=31= \\
& \text { Verlauf nach der Operation. }
\end{aligned}
$$

Die Krankbeit bei den operirten Kranken nahm folgenden Verlauf:

$$
\left.\begin{array}{l}
8 \mathrm{mal}=61 \text { Proc. aseptisch und fieberlos, } \\
3 \mathrm{mal} \\
2 \mathrm{mal}
\end{array}\right\}=39=\begin{aligned}
& \text { mit Eiterung und Fieber, } \\
& \text { mit Tod. }
\end{aligned}
$$

Die Dauer der Behandlung in der Klinik vom Eintritt bis zum Austritt rechne ich durchschnittlich 37,7 Tage; fur Resection 38,5 Tage, für Amputation 34 Tage.

Ueber die Schlussresultate sind mir 4 Fälle unbekannt, uber die anderen 9 Fälle ist folgendes Resultat erzielt worden:

$$
\begin{aligned}
& \text { Vollkommene Heilung . } 2=20 \text { Proc. } \\
& \text { Todesfälle ..... } 7=80 \text { = }
\end{aligned}
$$

Unter den 2 geheilten Kranken war 1 Kranker mit fast normaler Beweglichkeit, 1 mit beschränkter Beweglichkeit und weniger Brauchbarkeit geheilt.

Bei den 8 Todesfällen erfolgte der Tod in folgender Weise:

1 mal direct nach der Operation an Lungenödem;

1 mal nach der Operation an Jodoformintoxication; 
Verlauf und Ausgang der tuberculösen Erkrankung des Ellbogengelenkes. 143

1 mal 2 Jahre nach der Operation an einem Magenleiden;

$1 \mathrm{mal} 19$ Monate nach der Operation an Meningitis tuberculosa;

2 mal an Lungentuberculose (bei 1 Kranken war der Arm steif geheilt);

1 mal 3 Jahre nach der Operation an acuter Krankheit (der Arm war nicht geheilt).

Es ist nichts Wunderbares, dass das Material in der VII. Gruppe ein erhebliches Ueberwiegen der Todesfälle gegenuber dem der anderen Gruppen liefert, da die Kranken im Alter zwischen 60 und 70 Jahren gegen mannigfache Krankheitseinflusse sehr wenig widerstandsfähig zu sein pflegen. -

Um die oben auseinandergesetzten Zahlangaben für jede Gruppe mit einander vergleichen zu können und damit einen allgemeinen Ueberblick über den Verlauf und Ausgang der tuberculösen Erkrankung des Ellbogengelenkes zu erhalten, möchte ich noch einmal eine tabellarische Zahlenangabe anschliessen, damit man sich einen Begriff machen kann, welche Resultate wir in Bezug auf die Prognose und Function des operirten Armes erwarten dutrfen (s. S. 144).

Zum Schluss meiner Arbeit sei es mir gestattet, meinem hochgeehrten Lehrer, Herrn Geh. Medicinalrath Prof. Dr. F. König, sowohl für die freundliche Unterstitzung und gutige Ueberlassung des Materials, als auch fur seine liebenswtirdige und eingehende Anleitung in meinem Specialstudium, der Chirurgie, meinen besten und innigsten Dank auszusprechen. Ebenso erfulle ich gern die angenehme Pflicht, meinem hochgeehrten Lehrer, Herrn Prof. Dr. J. Rosenbach, der mich bei der Untersuchung der Kranken tuber ihren jetzigen Zustand unterstitzte, sowie dem Privatdocenten Herrn Dr. O. Hildebrand, der mich durch freundlichen Rath anregte, meinen wärmsten Dank abzustatten. 
144 II. Kosma, Verlauf u. Ausgang d. tuberc. Erkrankung d. Ellhogengelenkes.

\begin{tabular}{|c|c|c|c|c|c|c|c|c|}
\hline 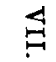 & 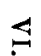 & .4 & 4 & $\Xi$ & $\exists$ & $H$ & \multicolumn{2}{|c|}{ Gruppe } \\
\hline$\theta$ & -1 & 0 & 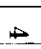 & $\bullet$ & $\bar{v}$ & $\vec{\sigma}$ & Männlieh & \multirow{3}{*}{ 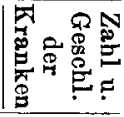 } \\
\hline-1 & $\Xi$ & $\triangle$ & $\vec{\infty}_{0}-1$ & 0 & $\vec{\omega}$ & $\vec{\omega}$ & Weiblich & \\
\hline$\vec{\omega}$ & $\Rightarrow$ & $\vec{\omega}$ & 密 & $\vec{\pi}$ & 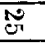 & 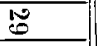 & sunıma & \\
\hline نِ & $\Rightarrow$ & $\stackrel{\omega}{\oplus}$ & 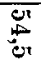 & $\begin{array}{c}-1 \\
-1\end{array}$ & 嵅 & 응 & $\begin{array}{l}\text { Tuberculose der } \\
\text { anderen Organe }\end{array}$ & \multirow{4}{*}{ 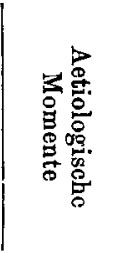 } \\
\hline$\infty$ & $\vec{\sigma}$ & 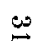 & 0 & $\sigma$ & $\overrightarrow{0}$ & $\Rightarrow \div$ & Trauma & \\
\hline 1 & $\vec{F}$ & $\ddot{\infty}$ & 1 & $\Xi$ & $\vec{N}$ & $\stackrel{0}{0}$ & $\begin{array}{r}\text { Hereditäre } \\
\text { Belastung }\end{array}$ & \\
\hline 8 & $\stackrel{\infty}{\circ}$ & $\infty$ & 常 & 皆 & $\mathbb{\infty}$ & 䓪 $\div$ & $\begin{array}{c}\text { Ohne nachweis- } \\
\text { bare Ursache }\end{array}$ & \\
\hline $\bar{\varepsilon}$ & \begin{tabular}{c}
$\infty$ \\
\hdashline \\
\end{tabular} & $\stackrel{\rho}{\longrightarrow}$ & $\infty$ & $\frac{1}{4}$ & $\vec{\sigma}$ & $\sigma \div$ & Mit Eiterung & \multirow{2}{*}{ 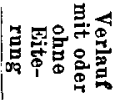 } \\
\hline I & $\infty$ & $\ddot{\theta}$ & 惉 & $\stackrel{\infty}{\infty}$ & $\stackrel{2}{*}$ & $\div \div$ & Obne Eiterung & \\
\hline \multicolumn{7}{|c|}{ 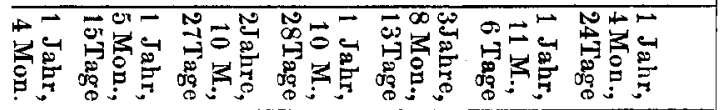 } & \multicolumn{2}{|c|}{ 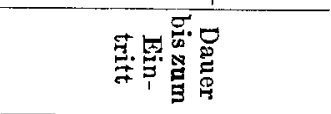 } \\
\hline$\stackrel{9}{-}$ & $\stackrel{\infty}{\infty}$ & 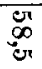 & $\Rightarrow$ & 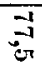 & 焉 & वे : & $\begin{array}{l}\text { Aseptisch } \\
\text { und fieberlos }\end{array}$ & \multirow{3}{*}{ 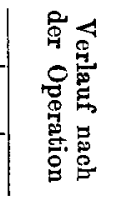 } \\
\hline 8 & $\vec{N}$ & $\underset{\text { ज़ }}{ \pm}$ & 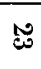 & 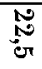 & 焉 & $\stackrel{\circ}{0} \div$ & $\begin{array}{l}\text { Mit Eiterung } \\
\text { und Fieber }\end{array}$ & \\
\hline 串 & $\overrightarrow{\mathrm{g}}$ & 1 & 1 & 1 & 1 & 烝 & Tod & \\
\hline 离 & 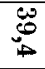 & 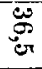 & 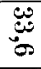 & $\begin{array}{l}\dot{\infty} \\
\dot{\infty} \\
\infty\end{array}$ & $\begin{array}{l}\frac{1}{\Delta \pi} \\
0 \\
0\end{array}$ & 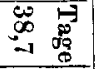 & Fur Resection & \multirow{3}{*}{ 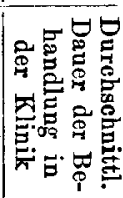 } \\
\hline 1 & 1 & $\stackrel{9}{=}$ & $-i$ & $!$ & $\begin{array}{c}0 \\
-1 \\
\infty \\
\infty\end{array}$ & 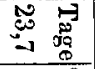 & $\begin{array}{c}\begin{array}{c}\text { ur nicht rese- } \\
\text { eirte Fülle }\end{array} \\
\end{array}$ & \\
\hline$\ddot{H}$ & $\cong$ & 1 & $\vec{\sigma}$ & 1 & 1 & $1 \stackrel{0}{100}$ & Fur Amputation & \\
\hline$\Rightarrow$ & 兽 & 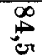 & 我 & $\overline{8}$ & $\infty$ & 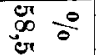 & Resecirt & \multirow{3}{*}{ 兽 } \\
\hline 1 & 1 & $\overrightarrow{v i n}$ & 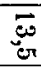 & 1 & $\sigma$ & $\stackrel{t}{\mathrm{E}} \div$ & Nicht reseoirt & \\
\hline ఉే & 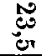 & 1 & $\stackrel{\Delta}{\sigma}$ & I & 1 & $1 \div$ & Amputirt & \\
\hline 8 & لj & 趸 & 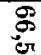 & 9 & $\vec{y}$ & $\ddot{\theta} \div$ & Ostaler Process & \multirow{3}{*}{ 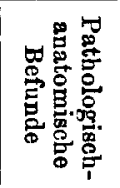 } \\
\hline$\stackrel{\omega}{-}$ & $\begin{array}{ll}10 \\
0 \\
0 \\
0\end{array}$ & 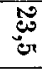 & لَّ & 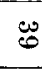 & ש & $\stackrel{0}{0} \div$ & $\begin{array}{l}\text { Synovialer } \\
\text { Process }\end{array}$ & \\
\hline 1 & $\bar{g}$ & 苋 & 萢 & 窇 & 跣 & $1 \div$ & $\begin{array}{l}\text { Hydrops tuber- } \\
\text { culosus }\end{array}$ & \\
\hline 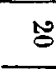 & 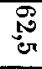 & 思 & i & जे & II & $\stackrel{\circ}{\circ} \div$ & $\begin{array}{l}\text { Vollkommene } \\
\text { Heilung }\end{array}$ & \multirow{6}{*}{ 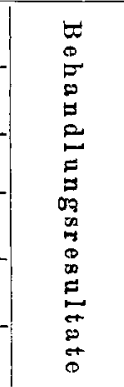 } \\
\hline 1 & 1 & 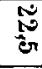 & No & $\theta$ & $\vec{v}$ & $\stackrel{0}{0} \div$ & $\begin{array}{c}\text { Unvoll kommene } \\
\text { Heilung }\end{array}$ & \\
\hline$\stackrel{\infty}{\infty}$ & 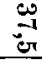 & $\begin{array}{l}1 \\
N \\
0 \\
0 \\
0\end{array}$ & 疍 & $\overrightarrow{0}$ & $\ddot{\leftrightarrow}$ & 崖。 & Todesfälle & \\
\hline$\overline{8}$ & \& & $\stackrel{\circ}{\circ}$ & 8 & $\stackrel{8}{\circ}$ & $\stackrel{8}{8}$ & 焉 & $\begin{array}{l}\text { Heilung mit } \\
\text { Bewergliehkeit }\end{array}$ & \\
\hline 1 & है & $\stackrel{10}{\circ}$ & 1 & 党 & है & $\stackrel{\infty}{\infty}: 0$ & $\begin{array}{l}\text { Heilung mit } \\
\text { Ankylose }\end{array}$ & \\
\hline 1 & 1 & $\mathbb{8}$ & 1 & $\pi$ & 1 & $1 \div$ & $\begin{array}{l}\text { Heilung mit } \\
\text { Schlottergelenk }\end{array}$ & \\
\hline
\end{tabular}

